Artículo especial

\title{
Guía ESC/EACTS 2017 sobre el tratamiento de las valvulopatías
}

\author{
Grupo de Trabajo de la Sociedad Europea de Cardiología (ESC) y la European Association \\ for Cardio-Thoracic Surgery (EACTS) sobre el tratamiento de las valvulopatías
}

\begin{abstract}
Autores/miembros del Grupo de Trabajo: Helmut Baumgartner* (coordinador de la ESC) (Alemania), Volkmar Falk*, (coordinador de la EACTS) (Alemania), Jeroen J. Bax (Países Bajos), Michele De Bonis ${ }^{\diamond}$ (Italia), Christian Hamm (Alemania), Per Johan Holm (Suecia), Bernard Iung (Francia), Patrizio Lancellotti (Bélgica), Emmanuel Lansac ${ }^{\diamond}$ (Francia), Daniel Rodríguez Muñoz (España), Raphael Rosenhek (Austria), Johan Sjögren ${ }^{\diamond}$ Suecia), Pilar Tornos Mas (España), Alec Vahanian (Francia), Thomas Walther ${ }^{\diamond}$ (Alemania), Olaf Wendler ${ }^{\diamond}$ (Reino Unido), Stephan Windecker (Suiza) y José Luis Zamorano (España)
\end{abstract}

Revisores del documento: Marco Roffi (coordinador de revisión de las GPC) (Suiza), Ottavio Alfieri` (coordinador de revisión de la EACTS) (Italia), Stefan Agewall (Noruega), Anders Ahlsson` (Suecia), Emanuele Barbato (Italia), Héctor Bueno (España), Jean-Philippe Collet (Francia), Ioan Mircea Coman (Rumanía), Martin Czerny (Alemania), Victoria Delgado (Países Bajos), Donna Fitzsimons (Reino Unido), Thierry Folliguet ${ }^{\diamond}$ (Francia), Oliver Gaemperli (Suiza), Gilbert Habib (Francia), Wolfgang Harringer ${ }^{\diamond}$ (Alemania), Michael Haude (Alemania), Gerhard Hindricks (Alemania), Hugo A. Katus (Alemania), Juhani Knuuti (Finlandia), Philippe Kolh (Bélgica), Christophe Leclercq (Francia), Theresa A. McDonagh (Reino Unido), Massimo Franciasco Piepoli (Italia), Luc A. Pierard (Bélgica), Piotr Ponikowski (Polonia), Giuseppe M.C. Rosano (Reino Unido/Italia), Frank Ruschitzka (Suiza), Evgeny Shlyakhto (Federación Rusa), Iain A. Simpson (Reino Unido), Miguel Sousa-Uva` (Portugal), Janina Stepinska (Polonia), Giuseppe Tarantini (Italia), Didier Tchétché (Francia), Victor Aboyans (supervisor de las GPC) (Francia)

'Representante de la European Association for Cardio-Thoracic Surgery (EACTS).

GEste VÉASE CONTENIDO RELACIONADO:

https://doi.org/10.1016/j.recesp.2017.11.034, Rev Esp Cardiol. 2018;71:67-73.

*Autores para correspondencia: Helmut Baumgartner, Division of Adult Congenital and Valvular Heart Disease, Department of Cardiovascular Medicine, University Hospital Muenster, Albert Schweitzer Campus 1, Building A1, 48149 Münster, Alemania, Tel: +49 251 834 6110, Fax: +49 2518346109. Correo electrónico: helmut.baumgartner@ukmuenster.de (H. Baumgartner).

Volkmar Falk, Department of Cardiothoracic and Vascular Surgery, German Heart Center, Augustenburger Platz 1, D-133353 Berlín, Alemania, y Department of Cardiovascular Surgery, Charite Berlin, Charite platz 1, D-10117 Berlín, Alemania. Tel: +49 304593 2000, Fax: +49 3045932100.

Correo electrónico: falk@dhzb.de (V. Falk).

La lista de miembros del Comité de la ESC para la Elaboración de Guías de Práctica Clínica y revisores del documento representantes de las sociedades nacionales de cardiología se recoge en el apéndice.

Entidades de la ESC que han participado en el desarrollo de este documento:

Asociaciones: Acute Cardiovascular Care Association (ACCA), European Association of Cardiovascular Imaging (EACVI), European Association of Percutaneous Cardiovascular Interventions (EAPCI), Heart Failure Association (HFA).

Grupos de Trabajo: Farmacoterapia Cardiovascular, Cirugía Cardiovascular, Enfermedades Cardiacas Congénitas del Adulto, Valvulopatías.

El contenido de esta Guía de Práctica Clínica de la Sociedad Europea de Cardiología (ESC) se ha publicado para uso personal y educativo solamente. No se autoriza su uso comercial. No se autoriza la traducción o reproducción de ningún fragmento de esta guía sin la autorización escrita de la ESC. La autorización se solicitará por escrito a Oxford University Press, editorial de European Heart Journal, o a los representantes autorizados de la ESC para tales permisos (journals.permissions@oxfordjournals.org).

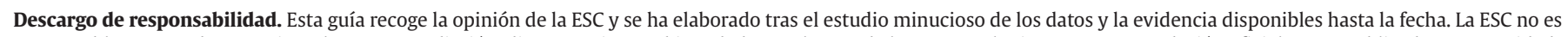

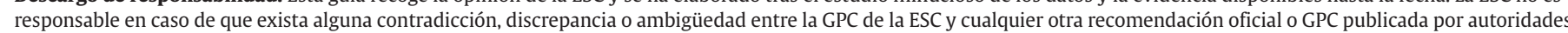

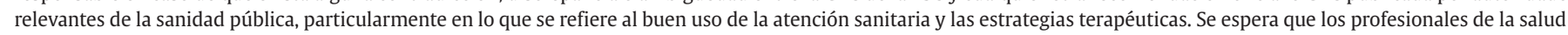
tengan en consideración esta GPC a la hora de tomar decisiones clínicas, así como al implementar estrategias médicas preventivas, diagnósticas o terapéuticas. No obstante, esta guía no anula la responsabilidad individual de cada profesional al tomar las decisiones oportunas relativas a cada paciente, de acuerdo con dicho paciente y, cuando fuera necesario, con su tutor o representante legal. Además, las GPC de la ESC no eximen al profesional médico de su obligación ética y profesional de consultar y considerar atentamente las recomendaciones y GPC actualizadas emitidas por autoridades sanitarias competentes. Es también responsabilidad del profesional verificar la normativa y la legislación sobre fármacos y dispositivos médicos a la hora de prescribirlos.

Este documento se ha publicado con permiso de European Heart Journal [10.1093/eurheartj/ehx391] en representación de la ESC y de European Journal of Cardio-Thoracic Surgery

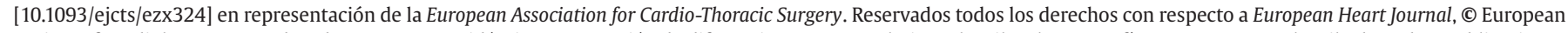

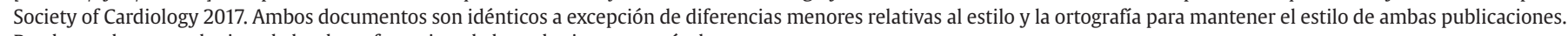
Puede emplearse cualquiera de las dos referencias a la hora de citar este artículo.

Para la solicitud de autorizaciones, contacte con: journals.permissions@oup.com. Las declaraciones de conflicto de intereses de los expertos participantes en el desarrollo de esta guía se encuentran disponibles en la página web de la ESC: www.escardio.org/ guidelines.

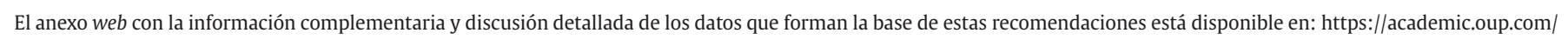
eurheartj/article-lookup/ doi/10.1093/eurheartj/ehx391\#supplementary-data.

Palabras clave:

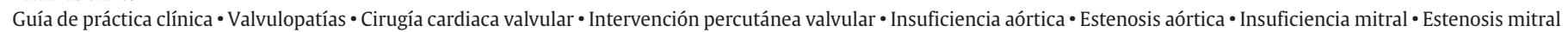
- Insuficiencia tricuspídea • Estenosis tricuspídea • Válvulas cardiacas protésicas 


\section{TABLA DE CONTENIDOS}

Abreviaturas ... 2

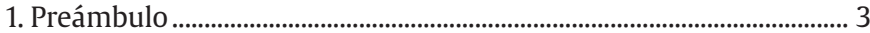

2. Introducción

2.1. ¿Por qué necesitamos una nueva guía sobre valvulopatías? .... 4

2.2. Contenido de esta nueva edición ........................................................... 4

2.3. Nuevo formato de la guía .................................................................. 4

2.4. Cómo usar esta guía .......................................................................... 4

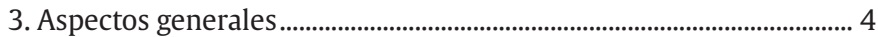

3.1. Evaluación del paciente ............................................................................ 4

3.1.1. Ecocardiografía ............................................................................... 5

3.1.2. Otras pruebas no invasivas ......................................................... 5

3.1.2.1. Prueba de estrés .......................................................... 5

3.1.2.2. Resonancia magnética cardiaca................................ 6

3.1.2.3. Tomografía computarizada ....................................... 6

3.1.2.4. Fluoroscopia............................................................... 6

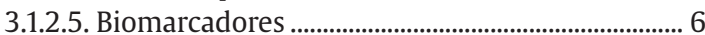

3.1.3. Pruebas invasivas............................................................................ 6

3.1.3.1. Coronariografía............................................................ 6

3.1.3.2. Cateterismo cardiaco ................................................... 6

3.1.4. Evaluación de comorbilidades .................................................. 6

3.2. Estratificación del riesgo .................................................................. 6

3.3. Consideraciones especiales con pacientes ancianos ................... 7

3.4. Profilaxis de la endocarditis .................................................................... 7

3.5. Profilaxis de la fiebre reumática ....................................................... 7

3.6. Concepto de equipo cardiológico multidisciplinario

(heart team) y centros especializados en valvulopatías ............ 7

3.7. Tratamiento de comorbilidades ............................................................. 8

3.7.1. Enfermedad arterial coronaria ............................................... 8

3.7.2. Fibrilación auricular .................................................................. 8

4. Insuficiencia aórtica....................................................................................... 8

4.1. Evaluación....................................................................................... 9

4.1.1. Ecocardiografía ....................................................................... 9

4.1.2. Tomografía computarizada y resonancia magnética cardiaca

4.2. Indicaciones para la intervención .................................................... 10

4.3. Tratamiento médico................................................................................... 11

4.4. Pruebas seriadas....................................................................................... 11

4.5. Grupos especiales de pacientes ........................................................ 11

5. Estenosis aórtica ................................................................................... 11

5.1. Evaluación.................................................................................................... 11

5.1.1. Ecocardiografía ........................................................................ 11

5.1.2. Aspectos adicionales sobre el diagnóstico, incluida la evaluación de parámetros pronósticos .......................... 13

5.1.3. Proceso diagnóstico antes del implante percutáneo de válvula aórtica ................................................................... 13

5.2. Indicaciones para la intervención..................................................... 13

5.2.1. Indicaciones para la intervención de la estenosis aórtica sintomática 14

5.2.2. Elección del tipo de intervención en la estenosis aórtica sintomática

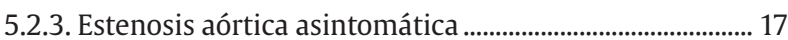

5.3. Tratamiento médico................................................................................. 17

5.4. Pruebas seriadas.................................................................................... 17

5.5. Grupos especiales de pacientes....................................................... 17

6. Insuficiencia mitral ....................................................................................... 18

6.1. Insuficiencia mitral primaria ............................................................... 18

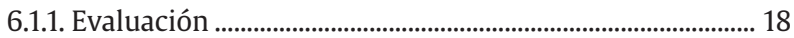

6.1.2. Indicaciones de la intervención .............................................. 18

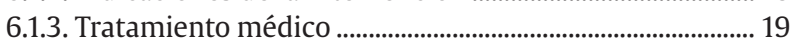

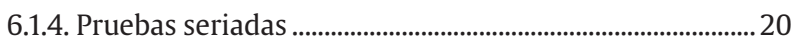

6.2. Insuficiencia mitral secundaria .......................................................... 20

6.2.1. Evaluación.................................................................................. 20

6.2.2. Indicaciones para la intervención........................................... 20

6.2.3. Tratamiento médico ............................................................ 21
7. Estenosis mitral

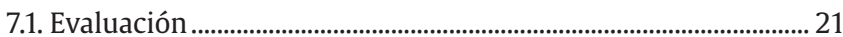

7.2. Indicaciones para la intervención ....................................................... 22

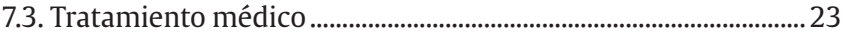

7.4. Pruebas seriadas .................................................................................. 23

7.5. Grupos especiales de pacientes ........................................................ 23

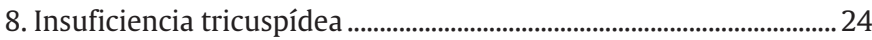

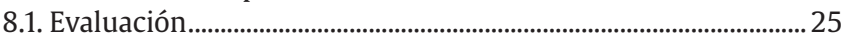

8.2. Indicaciones de la intervención......................................................... 25

9. Estenosis tricuspídea ..................................................................................... 26

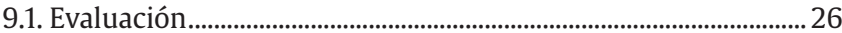

9.2. Indicaciones de la intervención.......................................................... 26

9.3. Tratamiento médico.......................................................................... 27

10. Valvulopatías combinadas y múltiples ...............................................2

11. Válvulas protésicas......................................................................................... 27

11.1. Elección de la válvula protésica...................................................... 27

11.2. Tratamiento después de la intervención valvular...................... 28

11.2.1. Evaluación basal y modalidades de seguimiento .........28

11.2.2. Tratamiento antitrombótico ................................................. 29

11.2.2.1. Tratamiento general ................................................. 29

11.2.2.2. Objetivo de cociente internacional normalizado (INR) .................................................22

11.2.2.3. Tratamiento para la sobredosis de antagonistas de la vitamina K y sangrado .....29

11.2.2.4. Combinación de fármacos anticoagulantes y antiagregantes

11.2.2.5. Interrupción del tratamiento anticoagulante para procedimientos invasivos planificados . 30

11.2.3. Tratamiento de la trombosis valvular................................ 31

11.2.4. Tratamiento de la tromboembolia..................................... 32

11.2.5. Tratamiento de la hemolisis y de la fuga paravalvular

11.2.6. Tratamiento de la disfunción de válvulas bioprotésicas ........................................................................... 32

11.2.7. Insuficiencia cardiaca ........................................................... 33

12. Tratamiento durante la cirugía no cardiaca ......................................... 35

12.1. Evaluación preoperatoria................................................................ 35

12.2. Lesiones valvulares específicas …………………………………... 36

12.2.1. Estenosis aórtica..................................................................... 36

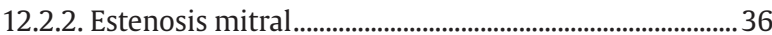

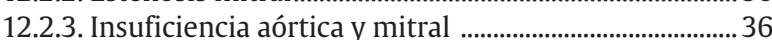

12.3. Monitorización perioperatoria........................................................... 36

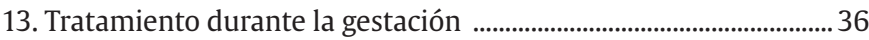

13.1. Valvulopatía nativa ................................................................................ 36

13.2. Prótesis valvulares........................................................................ 36

14. Mensajes clave de la guía sobre qué hacer y qué no ......................... 37

15. ¿Qué hay nuevo en la edición de 2017? ................................................39

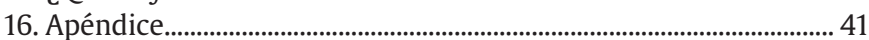

17. Bibliografía ................................................................................................. 41

\section{Abreviaturas}

AI: aurícula izquierda

ARA-II: antagonistas del receptor de la angiotensina II

ASC: área de superficie corporal

AVK: antagonistas de la vitamina $\mathrm{K}$

BNP: péptido natriurético cerebral

CABG: cirugía de revascularización coronaria

CMP: comisurotomía mitral percutánea

DTSVI: diámetro telesistólico del ventrículo izquierdo

EAC: enfermedad arterial coronaria

EACTS: European Association for Cardio-Thoracic Surgery 
ECG electrocardiograma

ESC: Sociedad Europea de Cardiología

ETE: ecocardiografía transesofágica

ETT: ecocardiografía transtorácica

FEVI: fracción de eyección del ventrículo izquierdo

GPC: guías de práctica clínica

HBPM: heparina de bajo peso molecular

HNF: heparina no fraccionada

i.v.: intravenoso

ICP: intervención coronaria percutánea

INR: cociente internacional normalizado

IVL: índice de volumen-latido

NACO: nuevos anticoagulantes orales no dependientes de la vitamina $\mathrm{K}$

NYHA: New York Heart Association

PAPs: presión arterial pulmonar sistólica

RMC: resonancia magnética cardiaca

RQVA: reemplazo quirúrgico de válvula aórtica

SCA: síndrome coronario agudo

STS: Society of Thoracic Surgeons

TAPD: tratamiento antiagregante plaquetario doble

TAVI: implante percutáneo de válvula aórtica

TC: tomografía computarizada

TCMC: tomografía computarizada multicorte

VD: ventrículo derecho

VI: ventrículo izquierdo

2D: bidimensional

3D: tridimensional

\section{PREÁMBULO}

Las guías de práctica clínica (GPC) tienen como objetivo reunir y evaluar toda la evidencia relevante disponible durante el proceso de elaboración sobre un tema particular para ayudar a los médicos a seleccionar la mejor estrategia posible de tratamiento para un paciente en particular que sufre una enfermedad determinada. Las GPC y las recomendaciones deben ayudar a los profesionales de la salud en la toma de decisiones clínicas en su ejercicio diario. No obstante, la decisión final sobre un paciente concreto la debe tomar el médico responsable de su salud, en consulta con el propio paciente 0 , cuando proceda, con la persona encargada de sus cuidados.

En los últimos años, la Sociedad Europea de Cardiología (ESC) y la European Association for Cardio-Thoracic Surgery (EACTS), además de otras sociedades y organizaciones científicas, han publicado un gran número de GPC. Debido al impacto de las GPC, se han establecido criterios de calidad para su elaboración de modo que todas las decisiones se presenten de manera clara y transparente al usuario. Las recomendaciones de la ESC para la elaboración y publicación de GPC están disponibles en la sección de guías de la página web de la ESC (https://www.escardio.org/Guidelines/Clinical-Practice-Guidelines/ Guidelines-development/Writing-ESC-Guidelines). Las GPC de la ESC representan la postura oficial de la ESC sobre un tema particular y se actualizan con regularidad.

Los miembros de este Grupo de Trabajo fueron seleccionados por la ESC y la EACTS en representación de los profesionales de la salud dedicados a los cuidados médicos de la patología tratada en el presente documento. Los expertos seleccionados realizaron una revisión exhaustiva de la evidencia publicada sobre la atención a esta entidad concreta (incluidos el diagnóstico, el tratamiento y la relación entre el riesgo y el beneficio) según las normas establecidas por el Comité de la ESC para la Elaboración de GPC y con la aprobación de la EACTS. Se valoraron el nivel de evidencia y la fuerza de la recomendación de una opción terapéutica particular según escalas predefinidas, tal como se indica en la tabla 1 y la tabla 2.

Los expertos responsables de la redacción y la revisión del documento han declarado por escrito cualquier relación que se pueda considerar conflicto de intereses real o potencial. Estas declaraciones escritas están archivadas y disponibles en la página web de la ESC (http://www.escardio.org/guidelines). Durante el periodo de redacción, las modificaciones en las relaciones que se pudieran considerar conflicto de intereses se notificaron a la ESC y se actualizaron. El informe del Grupo de Trabajo fue financiado en su totalidad por la ESC/EACTS y se desarrolló sin ninguna participación de la industria.

El Comité para la Elaboración de GPC de la ESC supervisa y coordina la preparación de nuevas GPC. El Comité es responsable también del proceso de aprobación de las GPC. El Comité de la ESC y expertos externos realizaron una revisión exhaustiva del documento, y en este caso también expertos seleccionados por la EACTS, tras lo cual fue aprobado por todos los miembros del Grupo de Trabajo. Por último, el documento final fue aprobado por el Comité de GPC de la ESC y la EACTS para su publicación en European Heart Journal y European

Tabla 2

Niveles de evidencia

\begin{tabular}{|ll}
\hline Nivel de evidencia A & $\begin{array}{l}\text { Datos procedentes de múltiples ensayos clínicos } \\
\text { aleatorizados o metanálisis }\end{array}$ \\
\hline Nivel de evidencia B & $\begin{array}{l}\text { Datos procedentes de un único ensayo clínico } \\
\text { aleatorizado o de grandes estudios no aleatorizados }\end{array}$ \\
\hline Nivel de evidencia C & $\begin{array}{l}\text { Consenso de opinión de expertos y/o pequeños } \\
\text { estudios, estudios retrospectivos, registros }\end{array}$ \\
\hline
\end{tabular}

Tabla 1

Clases de recomendación

\begin{tabular}{|c|c|c|}
\hline Grados de recomendación & Definición & Expresiones propuestas \\
\hline Clase I & $\begin{array}{l}\text { Evidencia y/o acuerdo general en que un determinado procedimiento diagnóstico/tratamiento } \\
\text { es beneficioso, útil y efectivo }\end{array}$ & Se recomienda/está indicado \\
\hline Clase II & Evidencia conflictiva y/o divergencia de opinión acerca de la utilidad/eficacia del tratamiento & \\
\hline Clase IIa & El peso de la evidencia/opinión está a favor de la utilidad/eficacia & Se debe considerar \\
\hline Clase IIb & La utilidad/eficacia está menos establecida por la evidencia/opinión & Se puede recomendar \\
\hline Clase III & $\begin{array}{l}\text { Evidencia o acuerdo general en que el tratamiento no es útil/efectivo y en algunos casos puede } \\
\text { ser perjudicial }\end{array}$ & No se recomienda \\
\hline
\end{tabular}


Journal of Cardio-Thoracic Surgery. La elaboración de la presente GPC se realizó tras la meticulosa evaluación del conocimiento científico y médico y la evidencia disponible hasta la fecha de su redacción.

La tarea de elaboración de GPC de la ESC/EACTS incluye no solo la integración de la investigación más reciente, sino también la creación de herramientas educativas y programas de implementación de las recomendaciones. Para su implementación, se desarrollan ediciones de bolsillo, diapositivas, resúmenes en tarjetas para no especialistas, folletos con mensajes clave y versiones electrónicas para aplicaciones digitales (smartphones, etc.). Estas versiones son resumidas y, por lo tanto, en caso de necesidad, debe consultarse la versión completa que se encuentra disponible gratuitamente en las páginas web de la ESC y Eur Heart J. Se recomienda a las sociedades nacionales que forman parte de la ESC suscribir, traducir e implementar las GPC de la ESC. Los programas de implementación son necesarios porque se ha demostrado que los resultados clínicos se ven favorablemente influidos por la aplicación de las recomendaciones clínicas.

Asimismo es necesario realizar encuestas y registros para verificar si la práctica clínica real se corresponde con las recomendaciones de las guías y así se completa el ciclo entre la investigación clínica, la elaboración de las guías y su implementación en la práctica clínica. Se recomienda a los profesionales de la salud que tengan en consideración la presente guía de la ESC/EACTS en la toma de decisiones clínicas en su ejercicio diario, así como en la determinación y la implementación de estrategias preventivas, diagnósticas y terapéuticas; no obstante, la decisión final sobre el cuidado de un paciente concreto, en consulta con dicho paciente y, si fuera necesario, con su representante legal, debe tomarla el médico responsable de su cuidado. Además, es responsabilidad del profesional de la salud comprobar la normativa aplicable a fármacos y dispositivos médicos antes de su prescripción.

\section{INTRODUCCIÓN}

\section{1. ¿Por qué necesitamos una nueva guía sobre valvulopatías?}

Desde la versión anterior de esta guía publicada en 2012, se dispone de nueva evidencia, especialmente en el campo de las intervenciones percutáneas y la estratificación del riesgo para establecer cuál es el mejor momento para la intervención, que hace necesaria una revisión de las recomendaciones sobre el diagnóstico y el tratamiento de las valvulopatías.

\subsection{Contenido de esta nueva edición}

La toma de decisiones en el tratamiento de las valvulopatías debe incluir un diagnóstico preciso, decidir el momento de intervenir, evaluar el riesgo y, basándose en ellos, seleccionar el tipo de intervención más adecuado. Esta guía se centra en el diagnóstico y el tratamiento de las valvulopatías adquiridas, no trata la endocarditis ni las enfermedades valvulares congénitas como la enfermedad valvular pulmonar, ya que la ESC ha publicado guías específicas sobre ellas.

\subsection{Nuevo formato de la guía}

Esta nueva edición de la guía se ha adaptado para facilitar su uso en la práctica clínica y responder a las necesidades de los lectores centrándose en recomendaciones condensadas y presentadas con claridad. Al final de cada apartado, los «Puntos clave» resumen los aspectos más importantes y en "Lagunas en la evidencia» se proponen áreas de futuros estudios. El texto de la guía está coordinado con un manual suplementario publicado por la ESC, que se encuentra disponible gratuitamente en Internet (https://academic.oup.com/eurheartj/articlelookup/doi/10.1093/eurheartj/ehx391\#supplementary-data). La guía y dicho manual son complementarios. La información básica y las dis- cusiones detalladas sobre los datos que sirven de base para las recomendaciones se encuentran en las correspondientes secciones del manual suplementario.

\subsection{Cómo usar esta guía}

El comité responsable de elaborar esta guía quiere señalar que hay numerosos factores que, en último término, determinan el tratamiento más adecuado para cada paciente individual de una población determinada. Entre ellos, la disponibilidad de equipos diagnósticos, la experiencia de cardiólogos y cirujanos, especialmente en el campo de la reparación valvular y las intervenciones percutáneas, y el deseo de los pacientes bien informados. Por otra parte, debido a la falta de datos basados en la evidencia en el campo de las valvulopatías, la mayoría de las recomendaciones se derivan en gran medida de la opinión y el consenso de expertos. Por lo tanto, en algunas situaciones clínicas puede ser necesario desviarse de las recomendaciones aquî establecidas.

\section{ASPECTOS GENERALES}

El objetivo de la evaluación de los pacientes con valvulopatías es diagnosticar, cuantificar y determinar el mecanismo subyacente, asî como sus consecuencias. La decisión sobre las intervenciones debe ser valorada por un equipo cardiológico multidisciplinario con experiencia en valvulopatías, que incluya cardiólogos, cirujanos cardiacos, especialistas en imagen cardiaca, anestesistas y, si es necesario, médicos de atención primaria, geriatras y especialistas en insuficiencia cardiaca, electrofisiología y cuidados intensivos. La valoración del equipo cardiológico es particularmente recomendable para los pacientes en alto riesgo y también es importante para otros subgrupos, como los pacientes asintomáticos, para los que evaluar la posibilidad de reparar la válvula es un componente clave en la toma de decisiones. Los aspectos más importantes en la evaluación de pacientes para una intervención valvular se resumen en la tabla 3.

\subsection{Evaluación del paciente}

La evaluación minuciosa de la historia del paciente y el estado sintomático, así como la exploración física con especial atención a la auscultación y la búsqueda de signos de insuficiencia cardiaca, son cruciales para el diagnóstico y el tratamiento de las valvulopatías.

Tabla 3

Preguntas esenciales en la evaluación de pacientes para una intervención valvular

\begin{tabular}{l}
\hline Preguntas \\
\hline • ¿Qué gravedad presenta la valvulopatía? \\
\hline • ¿Cuál es la etiología de la valvulopatía? \\
\hline • ¿El paciente tiene síntomas? \\
\hline • ¿Los síntomas están relacionados con la valvulopatía? \\
\hline • En pacientes asintomáticos, ¿hay algún signo que indique peores resultados si se \\
retrasa la intervención? \\
\hline • ¿Cuál es la esperanza de vida del paciente y la calidad de vida esperada?* \\
\hline • ¿Los beneficios de la intervención (frente a la evolución espontánea) esperados \\
son superiores a sus riesgos? \\
\hline • ¿Cuál es la modalidad óptima de tratamiento: reemplazo quirúrgico de válvula \\
(mecánica o bioprótesis), reparación quirúrgica o intervención percutánea? \\
\hline • ¿Los recursos locales (experiencia y resultados para una intervención dada) son \\
óptimos para la intervención planificada?
\end{tabular}

*La esperanza de vida debe estimarse según la edad, el sexo, las comorbilidades y la esperanza de vida específica por países. 
Además, la evaluación del estado extracardiaco -comorbilidades y estado general- requiere también una atención especial.

\subsubsection{Ecocardiografía}

Después de la evaluación clínica inicial, la ecocardiografía es la técnica que se emplea para confirmar el diagnóstico de enfermedad valvular, así como para evaluar la gravedad y el pronóstico. Debe realizarla e interpretarla personal adecuadamente entrenado ${ }^{1}$.

Los criterios ecocardiográficos para definir la gravedad de la estenosis y la insuficiencia valvular se tratan en documentos específi$\cos ^{2-4}$. Las recomendaciones sobre lesiones estenóticas se encuentran en los apartados correspondientes y la cuantificación de las lesiones regurgitantes se resume en la tabla 4. Para ello, se recomienda un abordaje integral que incluya distintos criterios, en vez de emplear mediciones únicas. La ecocardiografía es también una técnica fundamental para evaluar la morfología y la función valvular, además de la viabilidad y las indicaciones de una intervención específica.

Los índices de dilatación y función del ventrículo izquierdo (VI) son factores pronósticos importantes. Se debe estimar la presión arterial pulmonar y la función del ventrículo derecho $(\mathrm{VD})^{5}$. Debe considerarse la ecocardiografía transesofágica (ETE) cuando el examen transtorácico (ETT) no tenga una calidad óptima o cuando se sospeche trombosis, disfunción protésica o endocarditis. La ETE intraoperatoria se emplea para guiar las intervenciones percutáneas de válvula mitral o aórtica y para monitorizar los resultados de todas las intervenciones quirúrgicas o percutáneas de reparación o implante valvular.

\subsubsection{Otras pruebas no invasivas}

\subsubsection{Prueba de estrés}

El objetivo principal de la prueba de esfuerzo es desenmascarar la aparición de síntomas objetivos en pacientes considerados asintomáticos y es particularmente útil para la estratificación del riesgo en la estenosis aórtica ${ }^{8}$. La prueba de esfuerzo sirve también para determinar el grado de actividad física recomendado, incluida la participación en deportes.

La ecocardiografía de esfuerzo puede identificar el origen cardiaco de la disnea, cuyo impacto pronóstico se ha demostrado fundamentalmente en la estenosis aórtica y la insuficiencia mitral ${ }^{9}$.

La determinación de la reserva de flujo (llamada también «reserva contráctil») mediante ecocardiografía de esfuerzo con dosis bajas de dobutamina es útil para evaluar la gravedad de la estenosis aórtica y la estratificación operatoria del riesgo en la estenosis aórtica de gradiente bajo con la función del VI disminuida, además de evaluar el potencial para el remodelado inverso en pacientes con insuficiencia cardiaca e insuficiencia mitral funcional tras un procedimiento mitral ${ }^{10,11}$.

Tabla 4

Criterios ecocardiográficos para la definición de la insuficiencia valvular grave: un abordaje integral

\begin{tabular}{|c|c|c|c|}
\hline & Insuficiencia aórtica & Insuficiencia mitral & Insuficiencia tricuspídea \\
\hline \multicolumn{4}{|l|}{ Cualitativos } \\
\hline Morfología valvular & $\begin{array}{c}\text { Anomalías/rotura/defecto de coaptación } \\
\text { grande }\end{array}$ & $\begin{array}{l}\text { Rotura de valvas/rotura de músculo } \\
\text { papilar/defecto de coaptación grande }\end{array}$ & $\begin{array}{c}\text { Anomalías/rotura/defecto de coaptación } \\
\text { grande }\end{array}$ \\
\hline $\begin{array}{l}\text { Chorro de flujo regurgitante (Doppler } \\
\text { color) }\end{array}$ & $\begin{array}{l}\text { Grande en chorros centrales, variable } \\
\text { en chorros excéntricos }\end{array}$ & $\begin{array}{l}\text { Chorro central muy grande o chorro } \\
\text { excéntrico que se adhiere, arremolina y } \\
\text { alcanza la pared posterior de la AI }\end{array}$ & $\begin{array}{l}\text { Chorro central muy grande o chorro } \\
\text { excéntrico que incide en la pared }\end{array}$ \\
\hline Señal de DC del chorro regurgitante & Densa & Densa/triangular & $\begin{array}{l}\text { Densa/triangular con pico prematuro } \\
\text { (pico }<2 \mathrm{~m} / \mathrm{s} \text { en IT masiva) }\end{array}$ \\
\hline
\end{tabular}

\begin{tabular}{|c|c|c|c|}
\hline Otros & $\begin{array}{l}\text { Flujo holodiastólico invertido en la aorta } \\
\text { descendente (VTD }>20 \mathrm{~cm} / \mathrm{s} \text { ) }\end{array}$ & Zona grande del flujo de convergencia ${ }^{a}$ & - \\
\hline \multicolumn{4}{|l|}{ Semicuantitativos } \\
\hline Anchura de vena contracta & $>6 \mathrm{~mm}$ & 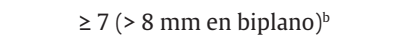 & $\geq 7 \mathrm{~mm}^{\mathrm{a}}$ \\
\hline Flujo venoso invertidoc & - & $\begin{array}{l}\text { Flujo sistólico invertido en las venas } \\
\text { pulmonares }\end{array}$ & $\begin{array}{l}\text { Flujo sistólico invertido en las venas } \\
\text { hepáticas }\end{array}$ \\
\hline Flujo de entrada & - & Onda $\mathrm{E}$ dominante $\geq 1,5 \mathrm{~m} / \mathrm{s}^{\mathrm{d}}$ & Onda $\mathrm{E}$ dominante $\geq 1 \mathrm{~m} / \mathrm{s}^{\mathrm{e}}$ \\
\hline Otros & Tiempo de hemipresión $<200$ ms $^{\mathrm{f}}$ & IVT mitral/IVT aórtica > 1,4 & Radio PISA > $9 \mathrm{~mm}^{\mathrm{g}}$ \\
\hline Cuantitativos & & Secundaria $^{\mathrm{h}}$ & \\
\hline $\operatorname{AEOR}\left(\mathrm{mm}^{2}\right)$ & $\geq 30$ & $\geq 40$ & $\geq 40$ \\
\hline Volumen regurgitante (ml/latido) & $\geq 60$ & $\geq 60$ & $\geq 45$ \\
\hline + dilatación de cámaras o vasos cardiacos & VI & VI, AI & $V D, A D$, vena cava inferior \\
\hline
\end{tabular}

Adaptado de Lancellotti et al. 2,6,7. $^{2}$

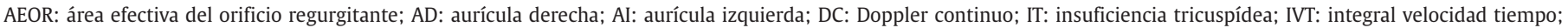

PISA: área proximal de superficie de isovelocidad; VD: ventrículo derecho; VI: ventrículo izquierdo; VTD: velocidad telediastólica.

aA un límite de Nyquist de $50-60 \mathrm{~cm} / \mathrm{s}$.

bPara la media entre los planos apicales de 4 y 2 cámaras.

‘Excepto si hay otras causas que produzcan una amortiguación sistólica (fibrilación auricular, presión auricular elevada).

dEn ausencia de otras causas de la presión elevada de la AI y la estenosis mitral.

eEn ausencia de otras causas para la presión elevada de la AD.

fEl tiempo de hemipresión se acorta con el aumento de la presión diastólica del VI, el tratamiento vasodilatador y en pacientes con aorta dilatada distensible o alargada en la insuficiencia aórtica crónica.

gUn cambio en el límite Nyquist basal de $28 \mathrm{~cm} / \mathrm{s}$.

${ }^{\text {h}}$ Se emplean diferentes umbrales en la insuficiencia mitral secundaria cuando a partir de un AEOR $>20$ mm $^{2}$ y un volumen regurgitante $>30$ ml se identifica a un subgrupo de pacientes con mayor riesgo de complicaciones cardiacas. 


\subsubsection{Resonancia magnética cardiaca}

Cuando los resultados ecocardiográficos sean inadecuados o inconsistentes, debe emplearse la resonancia magnética cardiaca (RMC) para evaluar la gravedad de las lesiones valvulares, sobre todo en caso de lesiones regurgitantes, y para evaluar los volúmenes ventriculares, la función sistólica, las anomalías de la aorta ascendente y la fibrosis miocárdica. La RMC es el método de referencia para la evaluación de los volúmenes y la función del VD y, por lo tanto, es especialmente útil para evaluar las consecuencias de la insuficiencia tricuspídea ${ }^{12}$.

\subsubsection{Tomografía computarizada}

La tomografía computarizada (TC) multicorte (TCMC) puede contribuir a la evaluación de la gravedad de la enfermedad valvular, particularmente en la estenosis aórtica ${ }^{13,14}$ y de la aorta torácica. La TCMC tiene un papel importante en el proceso diagnóstico de los pacientes con enfermedad valvular valorados para una intervención transcatéter, particularmente para el implante percutáneo de válvula aórtica (TAVI), y proporciona información útil para la planificación preoperatoria. Dado su alto valor predictivo negativo, la TCMC puede ser útil también para descartar enfermedad arterial coronaria (EAC) en pacientes con riesgo de ateroesclerosis bajo.

\subsubsection{Fluoroscopia}

La fluoroscopia es particularmente útil para la evaluación cinética de la parte móvil de una prótesis mecánica.

\subsubsection{Biomarcadores}

La concentración sérica de péptido natriurético cerebral (BNP) se relaciona con la clase funcional de la New York Heart Association (NYHA) y el pronóstico, particularmente en la estenosis aórtica y la insuficiencia mitral ${ }^{15}$. La determinación de péptidos natriuréticos puede ser útil para la estratificación del riesgo y para decidir el momento más adecuado para la intervención, sobre todo en pacientes asintomáticos.

\subsubsection{Pruebas invasivas}

\subsubsection{Coronariografía}

La coronariografía está indicada para evaluar la EAC cuando se planifica un procedimiento quirúrgico o intervencionista con el objetivo de determinar si está indicada la revascularización coronaria concomitante (véase la siguiente tabla de recomendaciones) ${ }^{16}$. Opcionalmente, la TC coronaria puede emplearse para descartar una EAC en pacientes con bajo riesgo de esta entidad.

\subsubsection{Cateterismo cardiaco}

La determinación de las presiones y el gasto cardiaco o la evaluación de la función ventricular y la insuficiencia valvular mediante ventriculografía o aortografía debe restringirse a situaciones en que las pruebas no invasivas no sean concluyentes o sean discordantes con los hallazgos clínicos. Cuando el único criterio para la indicación de cirugía sea la presión pulmonar elevada, se recomienda confirmar los datos de la ecocardiografía mediante la determinación invasiva.

\subsubsection{Evaluación de comorbilidades}

La elección de pruebas específicas para evaluar las comorbilidades se decide basándose en la evaluación clínica.
Tratamiento de la enfermedad arterial coronaria de pacientes con valvulopatías

\begin{tabular}{|c|c|c|}
\hline Recomendaciones & Clase $^{\mathrm{a}}$ & Nivel $^{\mathrm{b}}$ \\
\hline \multicolumn{3}{|l|}{ Diagnóstico de enfermedad arterial coronaria } \\
\hline $\begin{array}{l}\text { Se recomienda la coronariografía antes de la cirugía valvular } \\
\text { en pacientes con valvulopatía grave y cualquiera de los } \\
\text { siguientes factores: } \\
\text { - Historia de enfermedad cardiovascular } \\
\text { - Sospecha de isquemia miocárdica }{ }^{\mathrm{d}} \\
\text { - Disfunción sistólica del VI } \\
\text { - Varones mayores de } 40 \text { años y mujeres posmenopáusicas } \\
\text { - Uno o más factores de riesgo cardiovascular }\end{array}$ & I & $\mathrm{C}$ \\
\hline $\begin{array}{l}\text { La coronariografía está recomendada para evaluar la } \\
\text { insuficiencia mitral secundaria de moderada a grave }\end{array}$ & I & C \\
\hline $\begin{array}{l}\text { Debe considerarse la angio-TC como alternativa a la } \\
\text { coronariografía antes de la cirugía valvular en pacientes con } \\
\text { valvulopatía grave y baja probabilidad de EAC o para los que la } \\
\text { coronariografía convencional no es técnicamente factible o se } \\
\text { asocia con alto riesgo }\end{array}$ & Ila & C \\
\hline
\end{tabular}

Indicaciones para la revascularización miocárdica

Se recomienda la CABG para pacientes con una indicación primaria de cirugía aórtica/mitral y de estenosis coronaria $\geq 70 \%$ del diámetro

Debe considerarse la CABG para pacientes con una indicación primaria de cirugía valvular aórtica/mitral y una estenosis coronaria $\geq 50-70 \%$ del diámetro

Debe considerarse la ICP para pacientes con una indicación primaria para TAVI y estenosis coronaria $>70 \%$ del diámetro en segmentos proximales

Debe considerarse la ICP para pacientes con una indicación primaria de intervención percutánea de válvula mitral y estenosis coronaria $>70 \%$ del diámetro en segmentos proximales

Adaptado de Windecker et al. ${ }^{16}$.

CABG: cirugía de revascularización coronaria; EAC: enfermedad arterial coronaria; ICP: intervención coronaria percutánea; TAVI: implante percutáneo de válvula aórtica; TC: tomografía computarizada; VI: ventrículo izquierdo.

aClase de recomendación.

bivel de evidencia.

cLa TC multicorte puede utilizarse para excluir la EAC en pacientes con bajo riesgo de ateroesclerosis.

dDolor torácico, resultados anormales en pruebas no invasivas.

ePuede considerarse $\geq 50 \%$ en estenosis de tronco común izquierdo.

\subsection{Estratificación del riesgo}

La estratificación del riesgo se aplica a cualquier tipo de intervención y es necesaria para sopesar los riesgos de una intervención frente a la historia natural esperada de la valvulopatía como base para tomar decisiones. La mayoría de la experiencia acumulada se refiere a la cirugía y el TAVI. El EuroSCORE I (http://www.euroscore.org/calc. html) sobrestima la mortalidad operatoria y su calibración del riesgo es deficiente. Consecuentemente, no debe emplearse para guiar la toma de decisiones. El EuroSCORE II y la escala de la Society of Thoracic Surgeons (STS) (http://riskcalc.sts.org/stswebriskcalc/\#/) permiten discriminar con más precisión a los pacientes con riesgo quirúrgico alto o bajo y muestra una mejor calibración para predecir el resultado posoperatorio después de la cirugía valvular ${ }^{17,18}$. Las escalas de riesgo tienen limitaciones importantes a la hora de usarlas en la práctica, ya que subestiman la gravedad de la enfermedad y no incluyen factores de riesgo importantes, como la fragilidad, la aorta de porcelana y la radiación, entre otros. Aunque el EuroSCORE I sobrestima claramente la mortalidad a los 30 días y por ello se debe reemplazar por el EuroSCORE II, que es más preciso, se ha incluido en esta guía para su comparación, ya que se ha utilizado en numerosos estudios y registros sobre TAVI y podría ser útil para identificar a subgrupos de pacientes en los que hay que decidir el tipo de intervención y para 
predecir la mortalidad a 1 año. Ambas escalas han mostrado resultados variables en la predicción de los resultados del TAVI, pero son útiles para identificar a los pacientes con bajo riesgo quirúrgico. Se han desarrollado nuevas escalas con más precisión y capacidad de discriminación para estimar el riesgo a los 30 días en pacientes tratados con TAVI, aunque tienen limitaciones importantes ${ }^{19,20}$.

Se ha acumulado experiencia sobre la estimación del riesgo para otros procedimientos intervencionistas, como la reparación mitral de «borde con borde». Sigue siendo esencial no basarse en una sola escala de riesgo a la hora de evaluar a los pacientes o determinar incondicionalmente la indicación y el tipo de intervención. Hay que tener en cuenta la esperanza de vida del paciente, la calidad de vida que puede esperar y sus preferencias, así como los recursos locales. Además, hay que considerar la inutilidad de intervenciones en pacientes que probablemente no se beneficien del tratamiento, especialmente con TAVI y reparación mitral de «borde con borde» ${ }^{21}$. El papel del equipo cardiológico es fundamental para valorar todos estos factores y adoptar una decisión final sobre la mejor estrategia de tratamiento. Por último, el paciente y su familia deben ser debidamente informados y asesorados para tomar la decisión sobre la mejor opción de tratamiento ${ }^{22}$.

\subsection{Consideraciones especiales con pacientes ancianos}

La movilidad deficiente, determinada por la prueba de 6 min de marcha, y la dependencia de oxígeno son los factores más importantes asociados con un aumento de la mortalidad tras el TAVI y otros tratamientos de las valvulopatías ${ }^{23,24}$. La combinación de enfermedad pulmonar grave, dolor posoperatorio por la esternotomía o la toracotomía y largo tiempo de anestesia en pacientes sometidos a un procedimiento tradicional de reemplazo quirúrgico de válvula aórtica (RQVA) puede contribuir al desarrollo de complicaciones pulmonares. Existe una relación gradual entre la afección de la función renal y el aumento de la mortalidad después de la cirugía valvular, el TAVI y la reparación mitral transcatéter de «borde con borde» ${ }^{25}$, particularmente cuando la tasa de filtrado glomerular (TFG) es $<30 \mathrm{ml} / \mathrm{min}$. La enfermedad arterial coronaria, cerebrovascular y periférica tiene un impacto negativo en la supervivencia a corto y largo plazo tras la cirugía y el TAVI ${ }^{22}$.

Además de las comorbilidades orgánicas específicas, aumenta el interés en la evaluación de la fragilidad, un marcador total de la afección del estado funcional, cognitivo y nutricional. La fragilidad se asocia con un aumento de la morbimortalidad tras la cirugía y el TAVI ${ }^{26}$. La evaluación de la fragilidad no debe partir de un enfoque subjetivo, como una evaluación rápida y superficial, sino de la combinación de una serie de determinaciones objetivas. Actualmente están disponibles varias herramientas para evaluar la fragilidad ${ }^{23,26,27}$.

\subsection{Profilaxis de la endocarditis}

La profilaxis con antibióticos debe considerarse para procedimientos de alto riesgo en pacientes con válvulas protésicas, incluidas las percutáneas, reparaciones con material protésico y pacientes con episodios previos de endocarditis infecciosa ${ }^{28}$. Para esta población se deben considerar las recomendaciones sobre higiene dental y cutánea y medidas asépticas estrictas durante cualquier procedimiento invasivo. Además, la profilaxis con antibióticos debe considerarse para procedimientos dentales que impliquen la manipulación de la región gingival o periapical y la manipulación de la mucosa oral ${ }^{28}$.

\subsection{Profilaxis de la fiebre reumática}

La prevención de la enfermedad cardiaca reumática debe orientarse preferiblemente a evitar el primer ataque de fiebre reumática aguda. El tratamiento antibiótico para la infección de garganta por estreptococos del grupo A es clave en la prevención primaria. Para los pacientes con enfermedad cardiaca reumática, se recomienda la pro- filaxis a largo plazo para la prevención secundaria de la fiebre reumática. Debe considerarse la profilaxis crónica para los pacientes en alto riesgo, dependiendo de la gravedad de la valvulopatía y la exposición a estreptococos del grupo $\mathrm{A}^{29-31}$.

\subsection{Concepto de equipo cardiológico multidisciplinario (heart team) y centros especializados en valvulopatías}

El objetivo principal de los centros especializados en valvulopatías como centros de excelencia para el tratamiento de estas enfermedades es proporcionar una atención de alta calidad. Esto se puede lograr con un alto volumen de casos que permita y potencie la especialización del entrenamiento, la formación continua y el interés clínico. La especialización también posibilita la derivación del paciente en el momento más adecuado, antes de que ocurran eventos adversos irreversibles, y la evaluación de valvulopatías complejas. Además, las técnicas que requieren una intensa fase de aprendizaje pueden obtener mejores resultados en hospitales de alto volumen y más experien$\mathrm{cia}^{32}$. Los aspectos más importantes sobre esta cuestión se resumen en la tabla 5 .

Los centros especializados en valvulopatías deben disponer de programas estructurados de entrenamiento ${ }^{32}$. Los cirujanos y cardiólogos que realicen cualquier tipo de intervención deben participar en programas específicos de entrenamiento para obtener la certificación básica de su institución. El aprendizaje de nuevas técnicas requiere la supervisión de un mentor para minimizar los efectos de la curva de aprendizaje.

La relación entre el volumen de casos y los resultados en la cirugía y las intervenciones percutáneas es compleja, pero no se debe recha$\mathrm{zar}^{33-35}$. El número preciso de procedimientos por operador individual o por hospital requerido para proporcionar una atención de alta calidad sigue siendo una cuestión controvertida, y hacen falta más datos científicos para que puedan establecerse recomendaciones. No obstante, se han publicado estándares para la provisión de cirugía cardiaca como requisitos mínimos ${ }^{36}$. El centro debe disponer de experiencia en todo el espectro de procedimientos quirúrgicos, entre ellos: el reemplazo valvular, la cirugía de raíz aórtica, la reparación mitral, tricuspídea y aórtica, la reparación de endocarditis valvular compleja (como los abscesos de raíz), el tratamiento de la fibrilación auricular y la revascularización miocárdica quirúrgica. El espectro de procedimientos intervencionistas, además del TAVI, debe incluir: val-

\section{Tabla 5}

Requisitos recomendados para un centro especializado en valvulopatías (modificada de Chambers et al.) $)^{32}$

\begin{tabular}{l} 
Requisitos \\
\hline Equipos multidisciplinarios con competencia en reemplazo valvular, cirugía de \\
raíz aórtica, reparación mitral, tricuspídea y aórtica, así como técnicas percutáneas \\
para las válvulas aórtica y mitral que incluyan la reoperación y la reintervención. \\
Los equipos multidisciplinarios (heart team) deben reunirse periódicamente \\
y trabajar con procedimientos operativos estandarizados \\
\hline Técnicas de imagen, que incluyan imagen tridimensional y ecocardiografía de \\
estrés, ETE perioperatoria, TC cardiaca, RMC y TC por emisión de positrones \\
\hline Consultas regulares con centros comunitarios, otros hospitales y departamentos \\
no cardiacos y entre cardiólogos no invasivos, cirujanos y cardiólogos \\
intervencionistas \\
\hline Servicios de apoyo que incluyan a otros cardiólogos, cirujanos cardiacos, cuidados \\
intensivos y otras especialidades médicas \\
\hline Revisión de datos: \\
- Procesos establecidos de auditorías internas que incluyan la mortalidad y las \\
complicaciones, las tasas de reparación, la durabilidad de la reparación y las tasas \\
de reoperación con un seguimiento mínimo de 1 año \\
• Los resultados deben estar disponibles para revisiones internas o externas \\
\hline
\end{tabular}

ETE: ecocardiografía transesofágica; RMC: resonancia magnética cardiaca; TC: tomo- uู grafía computarizada. 
vuloplastia mitral, reparación mitral (método «borde con borde»), cierre de comunicación interauricular, cierre de fuga paravalvular y cierre de apéndice auricular izquierdo, así como intervencionismo coronario percutáneo (ICP). Asimismo, se debe disponer de experiencia en el tratamiento quirúrgico e intervencionista de complicaciones y enfermedades vasculares. Es esencial mantener un registro completo de las intervenciones y los resultados del centro y la participación en registros nacionales o de la ESC/EACTS.

\subsection{Tratamiento de comorbilidades}

\subsubsection{Enfermedad arterial coronaria}

No se recomienda el uso de pruebas de esfuerzo para detectar la EAC asociada con enfermedad valvular grave debido a su bajo valor diagnóstico y a los riesgos potenciales. Un resumen sobre el tratamiento de la EAC asociada con enfermedad valvular se encuentra en el apartado 3.1.3.1 (véase la tabla de recomendaciones) y se trata ampliamente en guías específicas ${ }^{16}$.

\subsubsection{Fibrilación auricular}

Los nuevos anticoagulantes orales no dependientes de la vitamina $\mathrm{K}$ (NACO) solo están aprobados para la fibrilación auricular (FA) no valvular, aunque no existe una definición uniforme de este término ${ }^{37}$. Varios análisis recientes de subgrupos de estudios aleatorizados sobre FA respaldan el uso de rivaroxabán, apixabán, dabigatrán y edoxabán en pacientes con fibrilación auricular y estenosis aórtica o insuficiencia mitral o aórtica ${ }^{38-41}$. Se desaconseja el uso de NACO para pacientes con FA y estenosis mitral de moderada a grave, debido a la falta de datos y el riesgo tromboembólico particularmente alto. A pesar de la falta de datos, los NACO pueden emplearse en pacientes con FA asociada con una bioprótesis aórtica más de 3 meses después de su implante, pero están estrictamente contraindicados para los pacientes con cualquier tipo de prótesis mecánica ${ }^{42,43}$.

La ablación quirúrgica de la FA combinada con cirugía mitral es efectiva para reducir la incidencia de la FA, pero a costa de un mayor número de implantes de marcapasos, y no tiene impacto alguno en la supervivencia a corto plazo ${ }^{44}$. Se debe considerar la ablación quirúrgica para los pacientes con FA sintomática y podría ser una opción terapéutica para los pacientes con FA asintomática siempre que se pueda realizar con un riesgo mínimo. En esta decisión hay que tener en cuenta otras variables importantes, como la edad, la duración de la FA y el tamaño de la aurícula izquierda (AI). Se puede considerar la escisión quirúrgica o el grapado externo del apéndice de la AI en combinación con la cirugía valvular, aunque no hay datos que confirmen la reducción del riesgo tromboembólico. Para pacientes con FA y factores de riesgo de accidente cerebrovascular (ACV), actualmente se recomienda mantener la anticoagulación oral, aunque se haya realizado la ablación quirúrgica de la FA o la escisión/exclusión quirúrgica del apéndice de la $\mathrm{AI}^{37}$. Las recomendaciones sobre el tratamiento de la FA asociada con valvulopatías se resumen en la siguiente tabla.

\section{Puntos clave}

- La evaluación minuciosa de la historia del paciente y su estado sintomático y una exploración física adecuada son esenciales para el diagnóstico y el tratamiento de las valvulopatías.

- La ecocardiografía es la técnica más importante para el diagnóstico de las valvulopatías y la evaluación de la gravedad y el pronóstico. Otras pruebas no invasivas, como la prueba de esfuerzo, RMC, TC, fluoroscopia y determinación de biomarcadores, son complementarias. Las pruebas invasivas distintas de la coronariografía preoperatoria deben restringirse a las situaciones en que los estudios no invasivos no sean concluyentes.
Tratamiento de la fibrilación auricular en pacientes con valvulopatías

\begin{tabular}{lcc}
\hline Recomendaciones & Clase $^{\mathrm{a}}$ & Nivel $^{\mathrm{b}}$ \\
\hline Anticoagulación & & \\
\hline $\begin{array}{l}\text { Los NACO deben considerarse como una alternativa a los AVK } \\
\text { para pacientes con estenosis aórtica, insuficiencia aórtica } \\
\text { o insuficiencia mitral que presentan fibrilación auricular }\end{array}$ & Ila & B \\
\hline $\begin{array}{l}\text { Los NACO deben considerarse como una alternativa a los } \\
\text { AVK después del tercer mes del implante en pacientes que } \\
\text { presentan fibrilación auricular asociada con una bioprótesis } \\
\text { aórtica quirúrgica o percutánea }\end{array}$ & IIa & C \\
\hline $\begin{array}{l}\text { No se recomienda el uso de NACO para pacientes con fibrilación } \\
\text { auricular y estenosis mitral de moderada a grave }\end{array}$ & III & C \\
\hline $\begin{array}{l}\text { Los NACO están contraindicados para los pacientes con válvulas } \\
\text { mecánicas }\end{array}$ & III & B \\
\hline
\end{tabular}

Intervenciones quirúrgicas

Debe considerarse la ablación quirúrgica de la fibrilación auricular en pacientes con fibrilación auricular sometidos a cirugía valvular ${ }^{37}$

Puede considerarse la ablación quirúrgica de la fibrilación auricular en pacientes con fibrilación auricular asintomática sometidos a cirugía valvular siempre que sea viable con un riesgo mínimo

Puede considerarse la escisión quirúrgica o el grapado

externo del apéndice de la AI en pacientes sometidos a cirugía valvular $^{46}$

AI: aurícula izquierda; AVK: antagonista de la vitamina K; NACO: nuevos anticoagulantes orales no dependientes de la vitamina K.

aClase de recomendación.

${ }^{\mathrm{b}}$ Nivel de evidencia.

- La estratificación del riesgo es un componente esencial en la toma de decisiones sopesando el riesgo de una intervención frente a la historia natural estimada de la valvulopatía.

- La toma de decisiones sobre pacientes ancianos requiere consideraciones especiales, como la esperanza de vida y la calidad de vida esperada, relacionadas con la presencia de comorbilidades y el estado general del paciente (fragilidad).

- Para proporcionar una atención de alta calidad y un entrenamiento adecuado, son necesarios centros especializados en valvulopatías con equipos multidisciplinarios altamente especializados, equipamiento completo y un volumen suficiente de procedimientos.

- Los NACO pueden emplearse en pacientes con FA y estenosis aórtica, insuficiencia aórtica, insuficiencia mitral o bioprótesis aórtica tras más de 3 meses del implante, pero están contraindicados en la estenosis mitral y las válvulas mecánicas.

\section{Lagunas en la evidencia}

- Es necesario desarrollar métodos para la estratificación del riesgo, especialmente para decidir entre la cirugía y las intervenciones percutáneas y para evitar intervenciones innecesarias.

- Es preciso definir el volumen mínimo de procedimientos por operador y hospital que sería necesario para obtener los óptimos resultados del tratamiento.

- Hay que investigar la seguridad y la eficacia de los NACO en pacientes con bioprótesis quirúrgicas o transcatéter en los primeros 3 meses desde el implante.

\section{INSUFICIENCIA AÓRTICA}

La insuficiencia aórtica puede estar causada por una enfermedad primaria de las cúspides aórticas o por anomalías en la raíz aórtica o la geometría de la aorta ascendente. La insuficiencia aórtica degenerativa tricuspídea o bicuspídea es la etiología más frecuente en países 
occidentales, y en Euro Heart Survey es la etiología subyacente a la insuficiencia aórtica en $2 / 3 \operatorname{casos}^{47}$. La endocarditis infecciosa o la enfermedad reumática puede ser otra causa. La insuficiencia aórtica aguda grave suele estar causada por endocarditis infecciosa y, menos frecuentemente, por disección aórtica ${ }^{20}$.

\subsection{Evaluación}

\subsubsection{Ecocardiografía}

La ecocardiografía (ETT/ETE) es la prueba más importante para describir la anatomía valvular, cuantificar la insuficiencia aórtica, evaluar sus mecanismos, definir la morfología de la aorta y determinar la viabilidad de una intervención quirúrgica de conservación o de reparación valvular ${ }^{48,49}$.

Los aspectos más importantes de esta evaluación son:

- La evaluación de la morfología de la válvula: tricúspide, bicúspide, unicúspide o cuadricúspide.

- La determinación de la dirección del chorro de regurgitación aórtica en el plano longitudinal (central o excéntrico) y su origen en el plano corto (central o comisural).

- Identificación del mecanismo subyacente, siguiendo el mismo principio que en la insuficiencia mitral: cúspides normales pero coaptación insuficiente debido a la dilatación de la raíz aórtica con chorro central (tipo 1), prolapso de cúspides con chorro excéntrico (tipo 2) o retracción con una calidad deficiente del tejido valvular y chorro central o excéntrico grande (tipo 3$)^{48}$.

- La cuantificación de la insuficiencia aórtica debe seguir un abordaje integral que tenga en cuenta todos los parámetros cualitativos, semicuantitativos y cuantitativos (tabla 4$)^{2,6}$.

- Medición de la función y la dimensión del VI. Se recomienda indexar los diámetros del VI por área de superficie corporal (ASC) en pacientes con tamaño corporal pequeño (ASC $\left.<1,68 \mathrm{~m}^{2}\right)^{50}$. Los nuevos parámetros obtenidos con ecocardiografía tridimensional (3D), Doppler tisular e imagen con strain rate pueden ser útiles, particularmente en pacientes con fracción de eyección del ventrículo izquierdo (FEVI) en el límite, pues pueden ayudar a decidir respecto a la cirugía ${ }^{51}$.

- Medición de la raíz aórtica y de la aorta ascendente en modo bidimensional (2D) en 4 niveles: anillo, senos de Valsalva, unión sinotubular y porción tubular de la aorta ascendente ${ }^{52}$. Las mediciones se realizan en el plano paraesternal longitudinal del borde anterior al borde anterior de la pared de la aorta en telediástole, excepto para el anillo aórtico, que se mide en sístole media. Debido a sus consecuencias para la cirugía, es importante diferenciar 3 fenotipos de la aorta ascendente: aneurisma de la raíz aórtica (senos de Valsalva $>45 \mathrm{~mm}$ ), aneurisma tubular de la aorta ascendente (senos de Valsalva $<40-45 \mathrm{~mm}$ ) e insuficiencia aórtica aislada (todos los diámetros $<40 \mathrm{~mm}$ ). El cálculo de valores indexados se ha recomendado teniendo en cuenta el tamaño corporal ${ }^{53}$.

- La definición de la anatomía de las cúspides aórticas y la evaluación de la posibilidad de reparación valvular se pueden obtener mediante la ETE preoperatoria cuando se considera la reparación de válvula aórtica o la cirugía de conservación valvular de la raíz aórtica.

- La evaluación intraoperatoria del resultado quirúrgico mediante ETE es indispensable para pacientes a los que se conserva o se repara la válvula aórtica durante el procedimiento.

\subsubsection{Tomografía computarizada y resonancia magnética cardiaca}

Debe emplearse la RMC para cuantificar la fracción regurgitante cuando las mediciones ecocardiográficas sean equívocas. Para

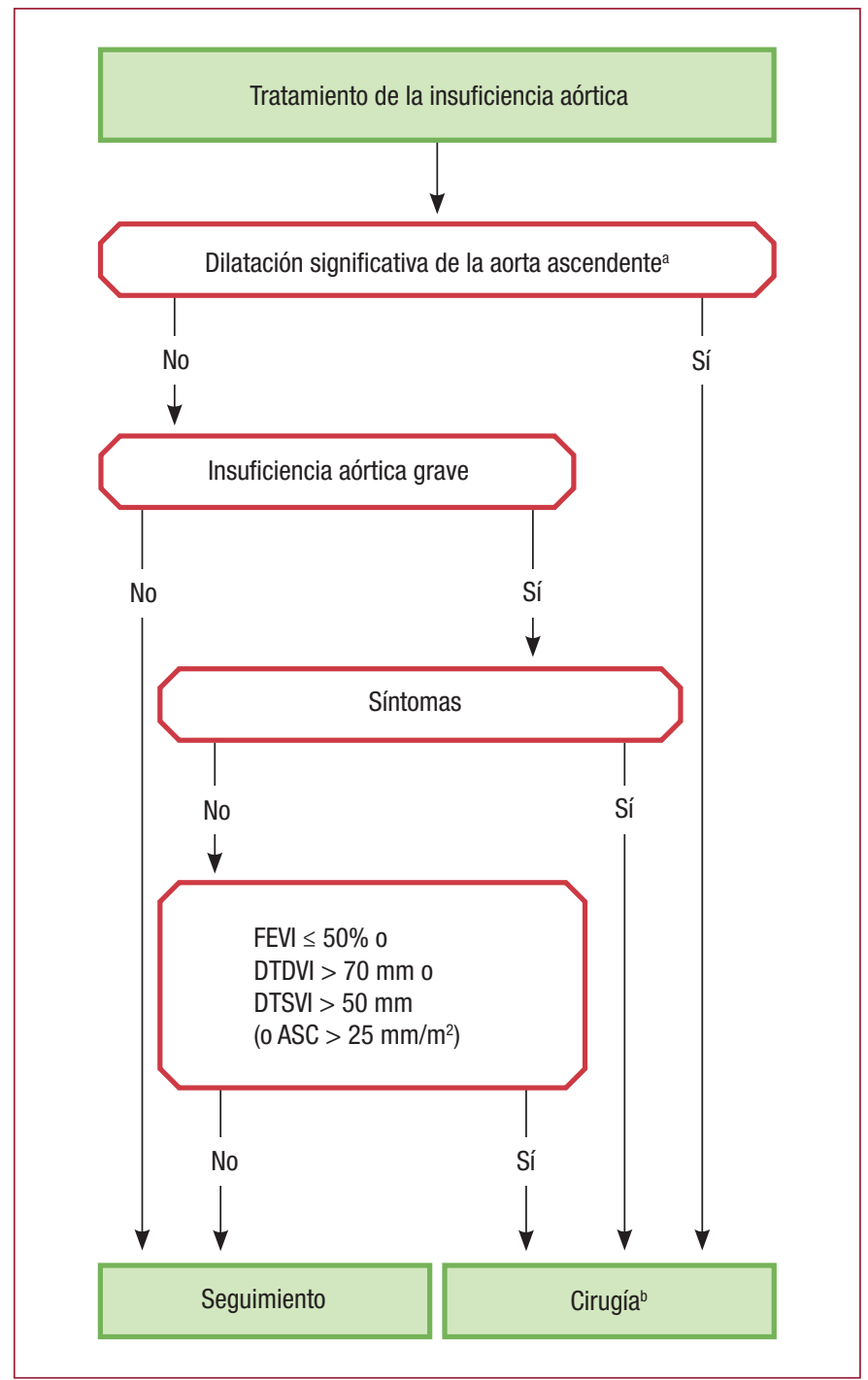

Figura 1. Tratamiento de la insuficiencia aórtica. ASC: área de superficie corporal; DTDVI: diámetro telediastólico del ventrículo izquierdo; DTSVI: diámetro telesistólico del ventrículo izquierdo; FEVI: fracción de eyección del ventrículo izquierdo.

aéase la tabla de recomendaciones sobre las indicaciones de cirugía en la insuficiencia aórtica grave y en la enfermedad de la raíz aórtica para su definición.

bTambién debe considerarse la cirugía en caso de cambios significativos en el tamaño del ventrículo izquierdo y la aorta que ocurren durante el seguimiento (véase en el apartado 4.2 la tabla de recomendaciones sobre las indicaciones de cirugía en la insuficiencia aórtica grave y en la enfermedad de la raíz aórtica).

pacientes con dilatación aórtica, se recomienda la TCMC sincronizada para determinar el diámetro máximo. La RMC puede emplearse durante el seguimiento, pero la indicación de cirugía debe basarse preferiblemente en las mediciones de TC. Existen distintos métodos para la medición de la aorta, y estos pueden tener discrepancias de 2-3 mm en los diámetros que podrían influir en las decisiones sobre la terapia. Para mejorar la reproducibilidad, se recomienda medir los diámetros usando la técnica de borde interior a borde interior al final de la diástole en el plano estrictamente transversal, con reconstrucción doble oblicua perpendicular al eje del flujo sanguíneo del segmento correspondiente. Deben registrarse los diámetros a nivel del anillo, senos de Valsalva, unión senotubular, aorta ascendente tubular y arco aórtico. El diámetro máximo de la raíz debe tomarse de seno a seno, en lugar del diámetro máximo de seno a comisura, ya que esta medida se correlaciona mejor con los diámetros máximos en el plano largo de borde exterior a borde exterior medidos por ecocardiografía 54,55 . 


\subsection{Indicaciones para la intervención}

La insuficiencia aórtica aguda puede requerir cirugía urgente. Sus causas principales son la endocarditis infecciosa y la disección aórtica. Estas entidades se tratan en guías específicas ${ }^{28,56}$. Las indicaciones de intervención en la insuficiencia aórtica crónica se resumen en la siguiente tabla (recomendaciones sobre las indicaciones para cirugía en la insuficiencia aórtica grave y en la enfermedad de la raíz aórtica) y en la figura 1, y pueden estar relacionadas con los síntomas, el estado del VI o la dilatación de la aorta.

Para los pacientes sintomáticos, la cirugía está recomendada independientemente de la FEVI, excepto en casos extremos, siempre que la insuficiencia aórtica sea grave y el riesgo operatorio, no excesivamente alto ${ }^{57}$.

En los pacientes asintomáticos con insuficiencia aórtica grave, la función del VI disminuida (FEVI $\leq 50 \%$ ) y la dilatación del VI con un diámetro telediastólico $>70 \mathrm{~mm}$ o un diámetro telesistólico (DTSVI) > $50 \mathrm{~mm}$ se asocian con un resultado desfavorable y, por lo tanto, se debe intentar la cirugía cuando se alcancen estos valores de corte ${ }^{58}$. En pacientes con tamaño corporal pequeño, el DTSVI debe relacionarse con el ASC, y un valor de corte de $25 \mathrm{~mm} / \mathrm{m}^{2}$ parece ser el más apropiado $^{50}$. Para los pacientes que no alcanzan los umbrales para cirugía, es necesario un seguimiento estrecho y realizar pruebas de esfuerzo para identificar a los sintomáticos con valores en el límite. Para los pacientes verdaderamente asintomáticos, la evaluación periódica de la función del VI y el estado físico son esenciales para identificar el momento más adecuado para la cirugía. La rápida progresión de las dimensiones ventriculares o la disminución de la función ventricular determinadas en pruebas seriadas son motivo para considerar la cirugía.

En pacientes con aorta dilatada, las indicaciones para cirugía se han definido mejor en pacientes con síndrome de Marfan y dilatación de la raíz ${ }^{59}$. Los aneurismas de raíz requieren el reemplazo de la raíz, pero siempre con reimplante coronario. Por el contrario, los aneurismas de la aorta ascendente tubular, con o sin conservación de la válvula aórtica nativa, requieren únicamente el reemplazo con injerto tubular supracomisural, sin reimplante coronario. Ante pacientes con diámetros aórticos en valores límite para la cirugía, hay que tener en cuenta la historia familiar, la edad y el riesgo estimado del procedimiento. Para los individuos con válvula aórtica bicúspide sin insuficiencia significativa, debe considerarse la cirugía profiláctica si los diámetros aórticos son $\geq 550 \geq 50 \mathrm{~mm}$ en presencia de factores adicionales de riesgo o coartación (véase la tabla de recomendaciones sobre las indicaciones para cirugía en la insuficiencia aórtica grave y la enfermedad de raíz aórtica). La cirugía está indicada para todo paciente con síndrome de Marfan y un diámetro aórtico máximo $\geq 50 \mathrm{~mm}$. Para los pacientes con síndrome de Marfan y factores de riesgo adicionales y los pacientes con mutación de TGFBR1 o TGFBR2 (incluido el síndrome de Loeys-Dietz), debe considerarse la cirugía si el diámetro aórtico máximo es $\geq 45 \mathrm{~mm}^{60}$. En este último grupo, las mujeres con ASC baja, los pacientes con mutación en TGFBR2 o los pacientes con enfermedad grave no relacionada con la aorta tienen un riesgo especialmente elevado y puede considerarse la cirugía en umbrales $<40 \mathrm{~mm}^{60}$. Para los pacientes con raíz aórtica $\geq 55 \mathrm{~mm}$, debe considerarse la cirugía independientemente del grado de insuficiencia aórtica o el tipo de enfermedad valvular ${ }^{61}$. En los pacientes que tienen una indicación para cirugía de válvula aórtica, un diámetro aórtico $\geq 45 \mathrm{~mm}$ se considera indicación para cirugía concomitante de la raíz aórtica o de la aorta ascendente tubular. Deben considerarse la estatura del paciente y la etiología de la valvulopatía (válvula bicúspide), además de la forma y el grosor de la pared de la aorta ascendente determinados durante el procedimiento, para tomar decisiones individualizadas.

Aunque el reemplazo valvular es el procedimiento estándar para la mayoría de los pacientes con insuficiencia aórtica, debe considerarse el reemplazo valvular o la cirugía con conservación de la válvula para los pacientes con válvula tricúspide o bicúspide flexible y no calcificada, con mecanismo subyacente de tipo I (dilatación de la raíz aórtica con movilidad normal de las cúspides) o de tipo II (prolapso de cúspides) $)^{6,48,49}$. En centros con experiencia, con el reemplazo de la raíz y conservación de la válvula y la reparación valvular, si es factible, se han demostrado buenos resultados a largo plazo, con tasas bajas de complicaciones relacionadas con la válvula y mejor calidad de vida ${ }^{62-65}$.

Indicaciones para la cirugía en (A) la insuficiencia aórtica grave y (B) la enfermedad de la raíz aórtica (independientemente de la gravedad de la insuficiencia aórtica)

\begin{tabular}{|c|c|c|}
\hline Indicaciones para cirugía & Clase $^{\mathrm{a}}$ & Nivel $^{\mathrm{b}}$ \\
\hline \multicolumn{3}{|l|}{ A. Insuficiencia aórtica grave } \\
\hline La cirugía está indicada para pacientes sintomáticos ${ }^{57,58,66,67}$ & I & B \\
\hline $\begin{array}{l}\text { La cirugía está indicada para pacientes asintomáticos con FEVI } \\
\text { en reposo } \leq 50 \%^{57,58}\end{array}$ & I & B \\
\hline $\begin{array}{l}\text { La cirugía está indicada para pacientes que van a someterse } \\
\text { a CABG o cirugía de la aorta ascendente o de otra válvula }\end{array}$ & I & $\mathrm{C}$ \\
\hline $\begin{array}{l}\text { El equipo cardiológico debe valorar los casos de pacientes } \\
\text { seleccionados }{ }^{\mathrm{C}} \text { para los que la reparación de válvula aórtica } \\
\text { puede ser una alternativa viable al reemplazo valvular }\end{array}$ & I & $\mathrm{C}$ \\
\hline $\begin{array}{l}\text { Debe considerarse la cirugía para pacientes asintomáticos con } \\
\text { FEVI en reposo > 50\% y dilatación del VI grave: DTDVI }>70 \mathrm{~mm} \\
\text { o DTSVI }>50 \mathrm{~mm}\left(\text { o DTSVI }>25 \mathrm{~mm} / \mathrm{m}^{2} \text { de ASC en pacientes }\right. \\
\text { de tamaño pequeño })^{58,66}\end{array}$ & IIa & B \\
\hline
\end{tabular}

B. Enfermedad de la raíz aórtica o aneurisma en aorta ascendente tubulard (independientemente de la gravedad de la insuficiencia aórtica)

Se recomienda la reparación de válvula aórtica mediante la técnica de reimplante o remodelado con anuloplastia aórtica para pacientes jóvenes con dilatación de la raíz aórtica y válvula aórtica tricúspide, siempre que cirujanos con experiencia realicen la intervención

La cirugía está indicada para pacientes con síndrome de Marfan y enfermedad de la raíz aórtica con un diámetro máximo de aorta ascendente $\geq 50 \mathrm{~mm}$

La cirugía debe considerarse para pacientes con enfermedad de la raíz aórtica con un diámetro máximo de la aorta ascendente:

$\bullet \geq 45 \mathrm{~mm}$ en presencia de síndrome de Marfan y factores de riesgo adicionales ${ }^{\mathrm{e}}$ o pacientes con mutación en TGFBR1 o TGFBR2 (incluido el síndrome de Loeys-Dietz) ${ }^{\mathrm{f}}$

$\bullet \geq 50 \mathrm{~mm}$ en presencia de válvula bicúspide con factores de riesgo adicionales ${ }^{\mathrm{e}} \mathrm{o}$ coartación

$\bullet 255 \mathrm{~mm}$ para los demás pacientes

Cuando la cirugía sea la indicación primaria para la válvula aórtica, debe considerarse el reemplazo de la raíz aórtica o la aorta ascendente cuando el diámetro sea $\geq 45 \mathrm{~mm}$, especialmente en presencia de una válvula bicúspideg

ASC: área de superficie corporal; CABG: cirugía de revascularización coronaria; DTDVI: diámetro telediastólico del ventrículo izquierdo; DTSVI: diámetro telesistólico del ventrículo izquierdo; ECG: electrocardiograma; FEVI: fracción de eyección del ventrículo izquierdo; TC: tomografía computarizada; VI: ventrículo izquierdo.

aClase de recomendación.

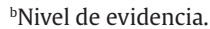

cPacientes con válvulas bicúspides o tricúspides flexibles no calcificadas con mecanismo de tipo I (dilatación de la raíz aórtica con movilidad normal de las cúspides) o de tipo II (prolapso de las cúspides) 6,48,49.

'Para la toma de decisiones clínicas, deben confirmarse las dimensiones de la aorta mediante TC con ECG sincronizado.

eHistoria familiar de disección aórtica (o historia personal de disección vascular espontánea), insuficiencia aórtica grave o insuficiencia mitral, deseo de embarazo, hipertensión sistémica o un aumento del tamaño aórtico $>3 \mathrm{~mm} / \mathrm{año}$ (en mediciones repetidas mediante la misma técnica de imagen con ECG sincronizado, medidas al mismo nivel de la aorta con comparación de lado a lado y confirmadas por otra técnica).

fPuede considerarse un umbral de $40 \mathrm{~mm}$ en mujeres con una ASC baja, pacientes con mutación en TGFBR2 o con características graves no relacionadas con enfermedad aórtica ${ }^{60}$.

'Teniendo en cuenta edad, ASC, etiología de la enfermedad valvular, presencia de válvula aórtica bicúspide y la evaluación intraoperatoria de la forma y el grosor de la aorta ascendente. 
La elección del procedimiento quirúrgico debe adaptarse a la experiencia del equipo, la presencia de aneurisma de raíz aórtica, las características de las cúspides, la esperanza de vida y al estado de anticoagulación deseado. Se debe remitir a equipos quirúrgicos con experiencia en el procedimiento a todo paciente para el que el equipo cardiológico interdisciplinario considere viable la reparación de la válvula aórtica.

\subsection{Tratamiento médico}

El tratamiento médico puede mejorar los síntomas de los individuos con insuficiencia aórtica grave crónica que no son candidatos a cirugía. Para los pacientes que después de la cirugía siguen sufriendo insuficiencia cardiaca o hipertensión, son útiles los inhibidores de la enzima de conversión de la angiotensina (IECA), los antagonistas del receptor de la angiotensina II (ARA-II) y los bloqueadores beta ${ }^{68,69}$.

En pacientes con síndrome de Marfan, los bloqueadores beta y el losartán pueden reducir la dilatación de la raíz aórtica y el riesgo de complicaciones aórticas, por lo que se debe considerarlos antes y después de la cirugía ${ }^{70-72}$. Por analogía, y a pesar de que no hay estudios que proporcionen pruebas, en la práctica clínica se recomienda frecuentemente el tratamiento con bloqueadores beta o losartán para pacientes con válvula aórtica bicúspide si la raíz aórtica o la aorta ascendente están dilatadas.

Para las mujeres con síndrome de Marfan y un diámetro aórtico $>45 \mathrm{~mm}$, se desaconseja la gestación antes de la reparación de la válvula debido al alto riesgo de disección. Aunque un diámetro aórtico $<40 \mathrm{~mm}$ se asocia raramente con la disección aórtica, no existe un diámetro completamente seguro. Si el diámetro de la aorta es de 40-45 mm, el crecimiento aórtico previo y la historia familiar son aspectos importantes para aconsejar a las pacientes sobre la gestación con o sin reparación aórtica previa ${ }^{73}$. Aunque el riesgo real de disección no está bien documentado en los casos de válvulas bicúspides, se recomienda desaconsejar la gestación a las pacientes con diámetros aórticos $>50 \mathrm{~mm}^{74}$.

El nivel de actividad física y deportiva en presencia de dilatación aórtica sigue siendo una cuestión de juicio médico debido a la falta de datos. Las guías actuales son muy restrictivas, en particular en lo que se refiere al ejercicio isométrico, para evitar acontecimientos irreversibles $^{75}$. Esta actitud está claramente justificada en presencia de enfermedad del tejido conectivo.

Dado el riesgo familiar de aneurisma de aorta torácica, está indicado el cribado y remitir para pruebas genéticas y de imagen a los familiares de primer grado de los pacientes con enfermedad del tejido conectivo. Para pacientes con válvulas bicúspides, es apropiado realizar un cribado ecocardiográfico de los familiares de primer grado.

\subsection{Pruebas seriadas}

Todos los pacientes asintomáticos con insuficiencia aórtica grave y función normal del VI deben tener una consulta de seguimiento como mínimo una vez al año. Para los pacientes con un primer diagnóstico o si el diámetro o la FEVI muestran cambios significativos o se acercan a los umbrales para cirugía, el seguimiento debe realizarse en intervalos de 3-6 meses. En los casos no concluyentes, puede ser útil determinar las concentraciones de BNP, ya que su elevación durante el seguimiento se ha asociado con deterioro de la función del $\mathrm{VI}^{76}$. Para los pacientes con insuficiencia aórtica de leve a moderada, el seguimiento debe realizarse anualmente y la ecocardiografía, cada 2 años.

En los casos de dilatación de la aorta ascendente (> $40 \mathrm{~mm}$ ), la TC o RMC están recomendadas. La evaluación de seguimiento de las dimensiones de la aorta debe realizarse mediante ecocardiografía o RMC. Cualquier aumento $>3 \mathrm{~mm}$ debe validarse mediante angio-TC/RMC y compararse con los datos basales.

\subsection{Grupos especiales de pacientes}

Si la insuficiencia aórtica que requiere cirugía concurre con insuficiencia mitral grave, se deben intervenir ambas en el mismo procedimiento.

En el caso del paciente con insuficiencia aórtica moderada sometido a cirugía de revascularización coronaria (CABG) o de válvula mitral, la decisión de tratar la válvula aórtica es controvertida, ya que los datos muestran que la insuficiencia aórtica moderada progresa lentamente en pacientes sin dilatación aórtica ${ }^{77}$. La decisión del equipo cardiológico debe estar basada en la etiología de la insuficiencia aórtica, otros factores clínicos, la esperanza de vida y el riesgo operatorio del paciente.

\section{Puntos clave}

- La evaluación de la insuficiencia aórtica incluye la evaluación de la morfología de la válvula, el mecanismo subyacente y el grado de insuficiencia, así como la evaluación minuciosa de la dilatación aórtica.

- Para los pacientes asintomáticos con insuficiencia aórtica grave, es indispensable realizar un seguimiento del estado sintomático y del tamaño y la función del VI.

- La indicación más clara para cirugía valvular es la presencia de síntomas (espontáneos o en la prueba de esfuerzo), FEVI documentada $<50 \%$ o un DTSVI $>50 \mathrm{~mm}$.

- En pacientes con dilatación aórtica, la determinación de la enfermedad aórtica y la medición precisa de los diámetros aórticos son esenciales para guiar la decisión sobre el momento más adecuado para la cirugía y el tipo de procedimiento quirúrgico.

- Deben considerarse la reparación valvular aórtica y la cirugía con conservación de válvula, en lugar del reemplazo de válvula aórtica, en algunos casos seleccionados y en centros con experiencia.

\section{Lagunas en la evidencia}

- Es preciso investigar el impacto de los marcadores de disfunción del VI en los resultados posoperatorios tempranos.

- Todavía se tienen que perfeccionar los criterios para guiar la decisión entre el reemplazo o la reparación valvular.

- Hay que estudiar las diferencias potenciales en el riesgo de complicaciones aórticas según los subtipos de aneurisma aórtico (lugar y morfología).

- Hay que investigar el efecto del tratamiento médico en la dilatación aórtica de los pacientes con válvula aórtica bicúspide.

\section{ESTENOSIS AÓRTICA}

La estenosis aórtica es la más frecuente valvulopatía que requiere tratamiento quirúrgico o intervencionista en Europa y Norteamérica, y su prevalencia aumenta debido al envejecimiento de la población.

\subsection{Evaluación}

\subsubsection{Ecocardiografía}

La ecocardiografía es la herramienta diagnóstica más importante. Permite confirmar la presencia de estenosis aórtica, evaluar el grado de calcificación de la válvula, la función del VI y el grosor de la pared, detectar otras valvulopatías concomitantes o enfermedad aórtica y obtener información pronóstica. La ecocardiografía con Doppler es la técnica preferida para evaluar la gravedad de la estenosis aórtica 4 .

En la figura 2 y la tabla 6 se describe un abordaje práctico y gradual para la evaluación de la gravedad de la estenosis aórtica. La European Association of Cardiovascular Imaging acaba de publicar un artículo con información ampliada sobre este tema ${ }^{4}$. 


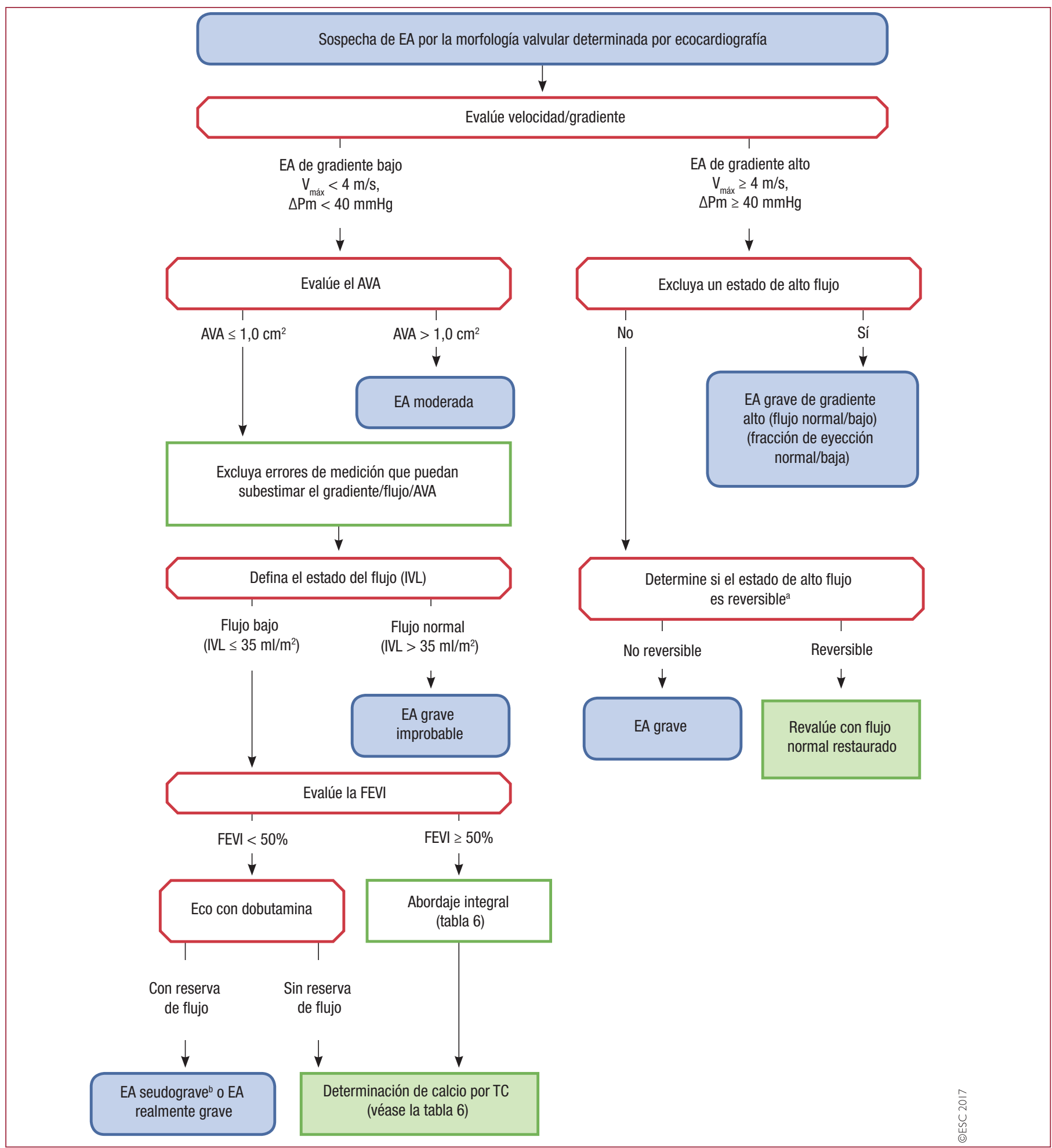

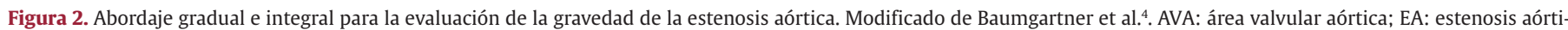

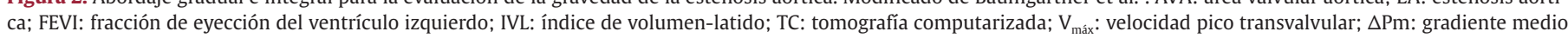
de presión transvalvular.

${ }^{a}$ El alto flujo puede ser reversible en situaciones como anemia, hipertiroidismo o cortocircuitos arteriovenosos.

bLa EA seudograve se define como un incremento del AVA $>1,0 \mathrm{~cm}^{2}$ con normalización de flujo.

Aunque desde una perspectiva teórica el área valvular representa la medida ideal para evaluar la gravedad de la estenosis aórtica, en la práctica clínica tiene algunas limitaciones técnicas. Para tomar decisiones clínicas, siempre se deben considerar, junto con la tasa de flujo, el gradiente medio de presión (la medición más robusta), la función, el tamaño y el grosor ventriculares, el grado de calcificación valvular, la presión arterial y el estado funcional ${ }^{4}$. Se debe revaluar a los pacientes hipertensos cuando la presión arterial alcance valores normales ${ }^{4}$. La estenosis aórtica se puede clasificar en 4 categorías:

- Estenosis aórtica de gradiente alto (área valvular $<1 \mathrm{~cm}^{2}$, gradiente medio $>40 \mathrm{mmHg}$ ). Se puede confirmar la presencia de estenosis 
Tabla 6

Criterios que incrementan la posibilidad de estenosis aórtica grave en pacientes con $\mathrm{AVA}<1,0 \mathrm{~cm}^{2}$ y gradiente medio $<40$ mmHg en presencia de fracción de eyección conservada (modificada de Baumgartner et al. $)^{4}$

\begin{tabular}{|c|c|}
\hline Criterios & \\
\hline \multirow[t]{2}{*}{ Criterios clínicos } & - Síntomas típicos que no se explican por otras razones \\
\hline & - Paciente anciano (> 70 años) \\
\hline \multirow[t]{2}{*}{ Datos cualitativos en pruebas de imagen } & • Hipertrofia del VI (considere además una historia de hipertensión) \\
\hline & - Reducción de la función sistólica longitudinal sin otra explicación \\
\hline \multirow[t]{4}{*}{ Datos cuantitativos en pruebas de imagen } & - Gradiente medio, 30-40 mmHga \\
\hline & - $\mathrm{AVA} \leq 0,8 \mathrm{~cm}^{2}$ \\
\hline & $\begin{array}{l}\text { - Flujo bajo }\left(\mathrm{IVL}<35 \mathrm{ml} / \mathrm{m}^{2}\right) \text { confirmado por una técnica distinta del Doppler } \\
\text { estándar (TSVI medido por ETE tridimensional o TC multicorte; RMC, datos } \\
\text { invasivos) }\end{array}$ \\
\hline & $\begin{array}{l}\text { - Determinación de calcio por TC multicorte } \\
\text { Estenosis aórtica grave muy probable: varones, } \geq 3.000 ; \text { mujeres, } \geq 1.600 \\
\text { Estenosis aórtica probable: varones, } \geq 2.000 ; \text { mujeres, } \geq 1.200 \\
\text { Estenosis aórtica improbable: varones, }<1.600 ; \text { mujeres, }<800\end{array}$ \\
\hline
\end{tabular}

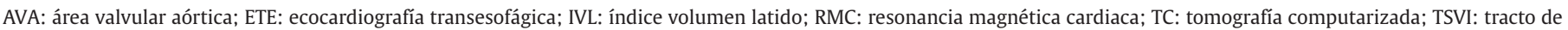
salida del ventrículo izquierdo; VI: ventrículo izquierdo.

aParámetros hemodinámicos medidos cuando el paciente se encuentra normotenso.

bValores expresados en unidades arbitrarias siguiendo el método de Agatston para cuantificar la calcificación valvular.

aórtica grave independientemente de que la FEVI o el flujo sean normales o reducidos.

- Estenosis aórtica con flujo y gradiente bajos y FEVI reducida (área valvular $<1 \mathrm{~cm}^{2}$, gradiente medio $<40 \mathrm{mmHg}$, FEVI $<50 \%$, índice volumen-latido [IVL] $\leq 35 \mathrm{ml} / \mathrm{m}^{2}$ ). En este contexto se recomienda la ecocardiografía con dosis bajas de dobutamina para diferenciar la estenosis aórtica grave de la seudograve, que se define como un aumento del área valvular aórtica $>1,0 \mathrm{~cm}^{2}$ con normalización del flujo. Además, la presencia de reserva de flujo (también llamada reserva contráctil; aumento del volumen latido $>20 \%$ ) tiene implicaciones pronósticas, ya que se asocia con mejores resultados ${ }^{10,78}$.

- Estenosis aórtica con flujo y gradiente bajos y FEVI conservada (área valvular $<1 \mathrm{~cm}^{2}$, gradiente medio $<40 \mathrm{mmHg}, \mathrm{FEVI} \geq 50 \%$, $\mathrm{IVL} \leq 35 \mathrm{ml} / \mathrm{m}^{2}$ ). Se encuentra típicamente en ancianos y se asocia con un tamaño ventricular pequeño, hipertrofia del VI significativa y frecuentemente con historia de hipertensión ${ }^{79,80}$. En este contexto, el diagnóstico de estenosis aórtica grave sigue siendo complejo y requiere la exclusión minuciosa de errores de medición y otras razones para estos hallazgos ecocardiográficos (tabla 6). El grado de calcificación valvular, determinado por TCMC, se relaciona con la gravedad de la estenosis aórtica y con los resulta$\operatorname{dos}^{13,14,81}$, y por ello ha aumentado la importancia de evaluarlo en este contexto.

- Estenosis aórtica con flujo normal, gradiente bajo y FEVI conservada (área valvular $<1 \mathrm{~cm}^{2}$, gradiente medio $<40 \mathrm{mmHg}$, FEVI $\left.\geq 50 \%, \mathrm{IVL}>35 \mathrm{ml} / \mathrm{m}^{2}\right)$. Generalmente, estos pacientes presentan solo estenosis aórtica moderada ${ }^{14,82-84}$.

\subsubsection{Aspectos adicionales sobre el diagnóstico, incluida la evaluación de parámetros pronósticos}

Para los pacientes físicamente activos, se recomienda la prueba de esfuerzo para desenmascarar los síntomas y estratificar el riesgo de los pacientes asintomáticos con estenosis aórtica grave ${ }^{85}$.

La ecocardiografía de estrés puede proporcionar información pronóstica de los pacientes con estenosis aórtica asintomática grave mediante la evaluación del aumento del gradiente medio de presión y cambios en la función del VI durante el ejercicio ${ }^{86}$.

La ETE permite evaluar alteraciones concomitantes de la válvula mitral y ha aumentado su importancia en la evaluación previa y posterior al TAVI o la cirugía ${ }^{87}$.
La TCMC y la RMC proporcionan información adicional sobre las dimensiones y la geometría de la raíz aórtica y la aorta ascendente, además del grado de calcificación. Se han convertido en técnicas importantes para la cuantificación de la calcificación valvular a la hora de valorar la gravedad de la estenosis aórtica con gradiente bajo $^{13,14,81}$. La RMC puede ser útil para detectar y cuantificar la fibrosis miocárdica, además de proporcionar información pronóstica adicional independientemente de la presencia de $\mathrm{EAC}^{88}$.

Se ha demostrado que las concentraciones de péptidos natriuréticos tienen valor predictivo de la supervivencia libre de síntomas y la evolución de la enfermedad en la estenosis aórtica grave con flujo bajo $^{89,90}$ y pueden ser útiles en pacientes asintomáticos para determinar el momento más adecuado para la intervención.

El cateterismo del VI por acceso retrógrado ya no se usa habitualmente para evaluar la gravedad de la estenosis aórtica. Su uso está restringido a pacientes con resultados no concluyentes en pruebas no invasivas.

\subsubsection{Proceso diagnóstico antes del implante percutáneo de válvula aórtica}

La TCMC es la técnica de imagen preferida para evaluar la anatomía y las dimensiones de la raíz aórtica, el tamaño y la forma del anillo aórtico, su distancia hasta el ostium coronario, la distribución de la calcificación y el número de cúspides de la válvula aórtica. Es fundamental evaluar la viabilidad de varias rutas de acceso, ya que así se obtiene información sobre los diámetros luminales mínimos, la carga ateroesclerótica, la presencia de aneurismas o trombos, la tortuosidad vascular y la anatomía apical torácica y del VI. En este contexto, la RMC, como técnica alternativa, es inferior a la TCMC para la determinación de las dimensiones y las calcificaciones en el interior de los vasos. La ETE 3D puede usarse también para determinar las dimensiones del anillo aórtico, aunque sigue siendo más dependiente del operador y de la calidad de imagen que la TCMC. La ETE, no obstante, es una herramienta importante para la monitorización del procedimiento y la evaluación de los resultados, especialmente cuando se presentan complicaciones.

\subsection{Indicaciones para la intervención}

Las indicaciones para las intervenciones de válvula aórtica se resumen en los siguientes apartados (véanse la tabla de indicaciones para 


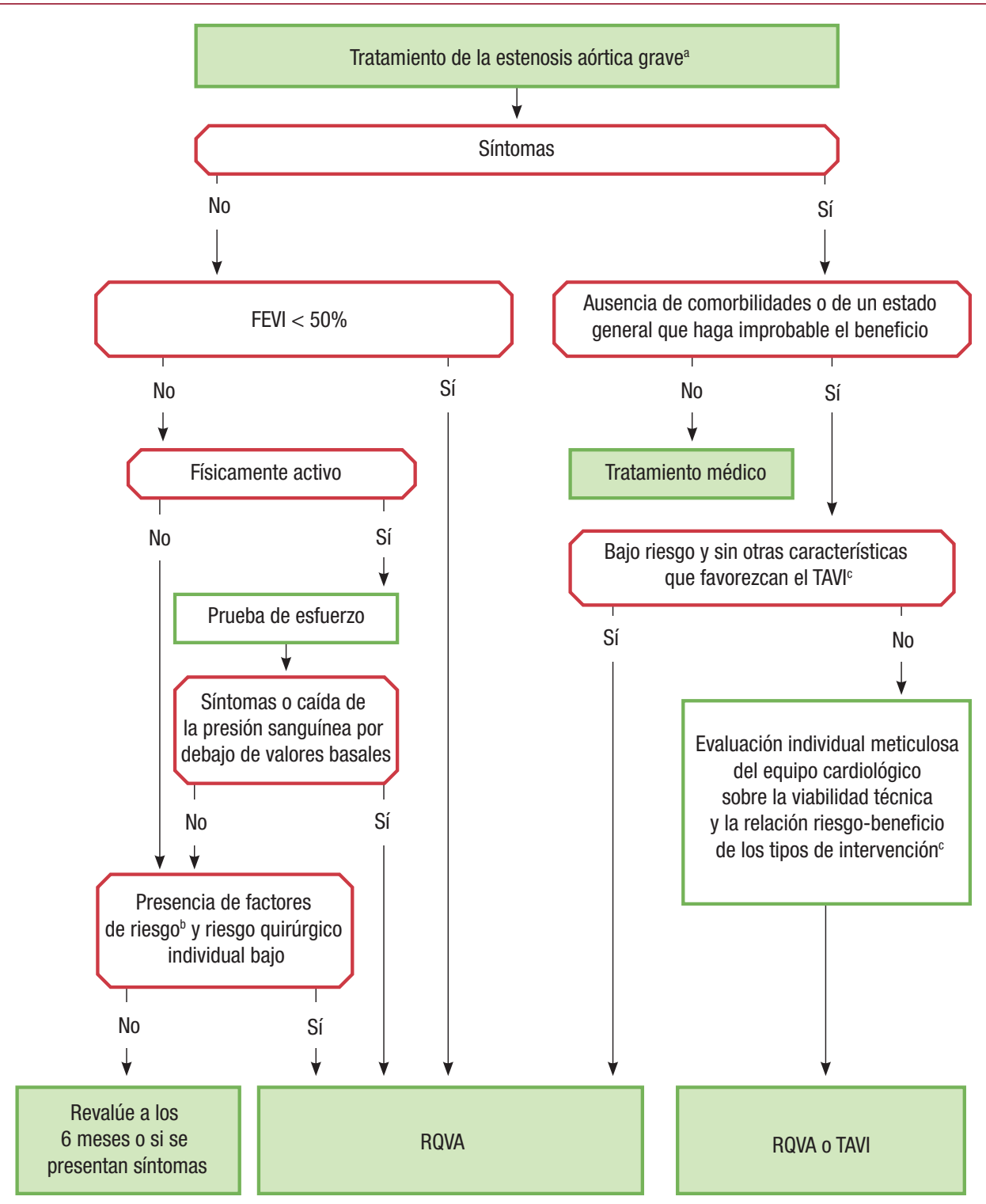

Figura 3. Tratamiento de la estenosis aórtica grave. EA: estenosis aórtica; FEVI: fracción de eyección del ventrículo izquierdo; RQVA: reemplazo quirúrgico de válvula aórtica; TAVI: implante percutáneo de válvula aórtica.

aVéanse la figura 2 y la tabla 6 para la definición de la estenosis aórtica grave.

'Debe considerarse la cirugía (IIa C) si está presente uno de los siguientes factores: velocidad pico > 5,5 m/s; calcificación valvular grave + progresión de la velocidad pico $\geq 0,3 \mathrm{~m} / \mathrm{s}$ por año; elevación marcada de neurohormonas (más de 3 veces el intervalo normal corregido por edad y sexo) sin otra explicación; hipertensión pulmonar grave (presión arterial pulmonar sistólica $>60 \mathrm{mmHg}$ ).

'Véanse la tabla 7 y la tabla de recomendaciones del apartado 5.2: «Indicaciones para la intervención en la estenosis aórtica».

la intervención en la estenosis aórtica y las recomendaciones sobre la elección del tipo de intervención), en la tabla 7 y la figura 3.

\subsubsection{Indicaciones para la intervención de la estenosis aórtica sintomática}

El tratamiento precoz está claramente recomendado para todo paciente sintomático con estenosis aórtica grave debido al pronóstico espontáneo muy desfavorable. La solas excepciones son que haya comorbilidades graves que indiquen una supervivencia $<1$ año y que las comorbilidades graves o el estado general y la edad avanzada del paciente hagan improbable que la intervención mejore la calidad de vida o la supervivencia. Siempre que el gradiente medio sea $>40 \mathrm{mmHg}$, no existe un umbral inferior de fracción de eyección que limite la indicación de intervenir, ya sea con cirugía o TAVI. El trata- miento de los pacientes con estenosis aórtica con gradiente bajo presenta más dificultades:

- En pacientes con estenosis aórtica con flujo y gradiente bajos y fracción de eyección reducida, cuya depresión de la fracción de eyección esté causada fundamentalmente por una poscarga excesiva, la función del VI generalmente mejora tras la intervención ${ }^{10,104}$. Por el contrario, la mejoría de la función ventricular después de la intervención es incierta cuando la causa principal es la presencia de tejido cicatricial producido por un infarto de miocardio extenso o por una miocardiopatía. La intervención es definitivamente aconsejable cuando la estenosis aórtica se confirma durante un aumento de flujo (estenosis aórtica verdaderamente grave $)^{10}$, mientras que los pacientes con estenosis aórtica seudograve durante un aumento de flujo deben recibir tratamiento con- 
Indicaciones para la intervención en la estenosis aórtica y recomendaciones sobre la elección del tipo de intervención

\begin{tabular}{|c|c|c|}
\hline A. Estenosis aórtica sintomática & Clase $^{\mathrm{a}}$ & Nivel $^{\mathrm{b}}$ \\
\hline $\begin{array}{l}\text { La intervención está indicada para pacientes sintomáticos con estenosis aórtica grave de gradiente alto (gradiente medio } \geq 40 \text { mmHg o velocidad pico } \\
\geq 4,0 \mathrm{~m} / \mathrm{s})^{91-93}\end{array}$ & I & B \\
\hline $\begin{array}{l}\text { La intervención está indicada para pacientes sintomáticos con estenosis aórtica grave de flujo y gradiente bajos ( }<40 \text { mmHg) con fracción de eyección } \\
\text { reducida y evidencia de reserva de flujo (reserva contráctil) que excluye la estenosis aórtica seudograve }\end{array}$ & I & C \\
\hline $\begin{array}{l}\text { Debe considerarse la intervención para pacientes sintomáticos con estenosis aórtica de flujo y gradiente bajos ( }<40 \text { mmHg) con fracción de eyección } \\
\text { normal tras la confirmación meticulosa de estenosis aórtica gravec (véanse la figura } 2 \text { y la tabla } 6 \text { ) }\end{array}$ & IIa & C \\
\hline $\begin{array}{l}\text { Debe considerarse la intervención para pacientes sintomáticos con estenosis aórtica de flujo y gradiente bajos con fracción de eyección reducida } \\
\text { sin reserva de flujo (reserva contráctil), particularmente cuando se confirma su gravedad mediante la determinación de calcio por TC }\end{array}$ & IIa & C \\
\hline $\begin{array}{l}\text { No debe realizarse la intervención a pacientes con comorbilidades graves cuando no sea probable que la intervención mejore la calidad de vida o la } \\
\text { supervivencia }\end{array}$ & III & $\mathrm{C}$ \\
\hline
\end{tabular}

B. Elección de la intervención en la estenosis aórtica sintomática

Las intervenciones de válvula aórtica solo deben realizarse en centros con servicios de cardiología y cirugía cardiaca en el propio centro y que cuenten con una colaboración estructurada entre ambos departamentos que incluya un equipo cardiológico (centros especializados en valvulopatías cardiacas)

La elección de la intervención debe basarse en una evaluación individual minuciosa de la viabilidad técnica y de los riesgos y beneficios de cada modalidad de intervención (los aspectos que hay que valorar se encuentran en la tabla 7). Además, hay que considerar la experiencia del centro y los resultados de cada intervención específica

Se recomienda el RQVA para pacientes con riesgo quirúrgico bajo (STS o EuroSCORE II $<4 \%$ o EuroSCORE I logístico $<10 \%$ y sin otros factores de riesgo que no se incluyan en estas escalas, como la fragilidad, la aorta de porcelana y las secuelas de la radiación torácica $)^{93}$

Se recomienda el TAVI para pacientes que no son candidatos a RQVA según la valoración del equipo cardiológico ${ }^{91,94}$

Para los pacientes con riesgo quirúrgico aumentado (STS o EuroSCORE II $\geq 4 \%$ o EuroSCORE I logístico $\geq 10 \%$ u otros factores de riesgo que no se incluyan en estas escalas, como la fragilidad, la aorta de porcelana y las secuelas de la radiación torácica), la decisión entre RQVA y TAVI debe tomarse en el equipo cardiológico teniendo en cuenta las características individuales del paciente (véase la tabla 7); se favorece el TAVI para los pacientes ancianos con acceso femoral posible ${ }^{11,94-102}$

Puede considerarse la valvulotomía aórtica con balón como puente a RQVA o TAVI para pacientes hemodinámicamente inestables o con estenosis aórtica sintomática grave que requieren cirugía mayor no cardiaca urgente

Puede considerarse la valvulotomía aórtica con balón como herramienta diagnóstica para los pacientes con estenosis aórtica grave u otras causas potenciales de los síntomas (p. ej., enfermedad pulmonar) y pacientes con disfunción miocárdica grave, insuficiencia prerrenal u otra disfunción orgánica, reversible mediante valvulotomía aórtica con balón cuando se realiza en centros en los que esta técnica puede seguirse de TAVI

C. Pacientes asintomáticos con estenosis aórtica grave (solo para pacientes candidatos a RQVA)

El RQVA está indicado para pacientes asintomáticos con estenosis aórtica grave y disfunción sistólica del VI (FEVI < 50\%) que no se debe a otra causa

El RQVA está indicado para pacientes asintomáticos con estenosis aórtica grave y resultados anormales en la prueba de esfuerzo que muestran síntomas durante el ejercicio claramente relacionados con la estenosis aórtica

Debe considerarse el RQVA para pacientes asintomáticos con estenosis aórtica grave y resultados anormales en la prueba de esfuerzo que muestran una disminución de la presión arterial por debajo de valores basales

Debe considerarse el RQVA para pacientes asintomáticos con fracción de eyección normal y ninguno de los resultados de la prueba de esfuerzo mencionados antes, siempre que el riesgo quirúrgico sea bajo y esté presente uno de los siguientes hallazgos:

- Estenosis aórtica muy grave definida por un $\mathrm{V}_{\text {máx }}>5,5 \mathrm{~ms}$

- Calcificación valvular grave y una tasa de progresión de $V_{\text {máx }} \geq 0,3 \mathrm{~m} / \mathrm{s} / \mathrm{año}$

- Cifras de BNP significativamente elevadas (más de 2 veces el valor normal corregido por edad y sexo), confirmadas en mediciones repetidas y que no se explican por otra causa

- Hipertensión pulmonar grave (presión arterial pulmonar sistólica en reposo > 60 mmHg confirmada de manera invasiva) que no se explica por otra causa

D. Cirugía concomitante de válvula aórtica durante otro procedimiento quirúrgico cardiaco o de la aorta ascendente

El RQVA está indicado para pacientes con estenosis aórtica grave sometidos a CABG o cirugía de la aorta ascendente o de otra válvula

Debe considerarse el RQVA para pacientes con estenosis aórtica moderadae sometidos a CABG o a cirugía de la aorta ascendente o de otra válvula tras la valoración por el equipo cardiológico

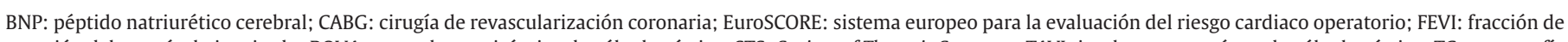

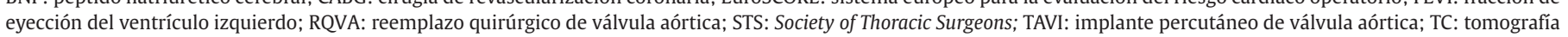
computarizada; VI: ventrículo izquierdo; $\mathrm{V}_{\text {máx }}$ : velocidad pico transvalvular.

aClase de recomendación.

bNivel de evidencia.

'En pacientes con un área valvular pequeña pero con gradiente bajo a pesar de la FEVI conservada, las explicaciones para este hallazgo distintas de la estenosis aórtica grave son frecuentes y deben ser minuciosamente descartadas. Véanse la figura 2 y la tabla 6.

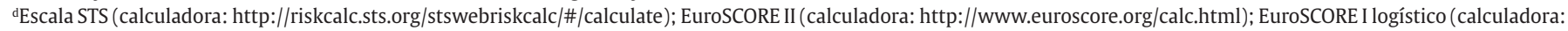

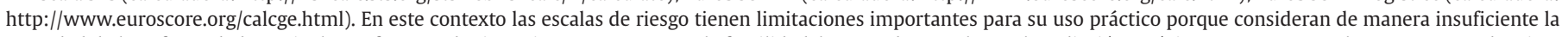

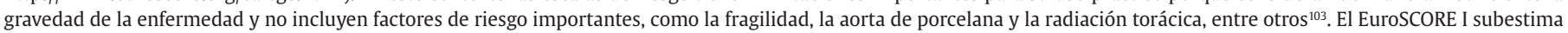

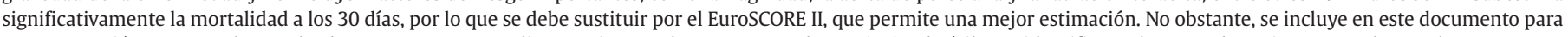

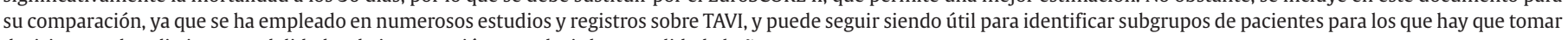
decisiones sobre distintas modalidades de intervención y predecir la mortalidad al año.

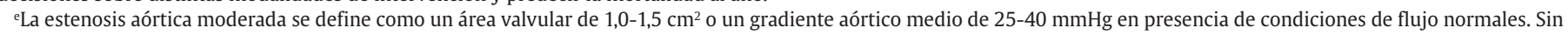
embargo, es preciso aplicar el juicio médico. 
vencional para la insuficiencia cardiaca ${ }^{105}$. Aunque el resultado en pacientes sin reserva de flujo está comprometido por la mayor mortalidad operatoria, se ha demostrado que el RQVA (y también el TAVI) puede mejorar la fracción de eyección y el estado clínico de estos pacientes ${ }^{10,78,104}$. En la toma de decisiones hay que tener en cuenta el estado clínico (particularmente las comorbilidades), el grado de calcificación valvular, el grado de enfermedad coronaria y la viabilidad de la revascularización al mismo tiempo o en etapas. La capacidad de la TC con determinación de calcio para identificar a los pacientes con estenosis aórtica grave en este subgrupo y la disponibilidad del TAVI han reducido el umbral para la indicación de intervención.

- Los pacientes con estenosis aórtica, flujo y gradiente bajos y FEVI conservada constituyen el subgrupo más complejo. Los datos sobre la historia natural y los resultados después de la intervención quirúrgica o percutánea siguen siendo controvertidos ${ }^{80,83,84}$. En estos casos, solo se debe intervenir si los síntomas están presentes y si la evaluación minuciosa indica obstrucción valvular significativa (véanse la figura 2 y la tabla 6).

- Se debe revaluar a los pacientes con estenosis aórtica, flujo normal, gradiente bajo y FEVI conservada. Si se confirma el flujo normal y el gradiente bajo, estos pacientes, en general, no tendrán un diagnóstico de estenosis aórtica grave y no se beneficiarán de la intervención ${ }^{82,83}$.

\subsubsection{Elección del tipo de intervención en la estenosis aórtica sintomática}

En la elección del tipo de intervención se debe tener en cuenta las características cardiacas y extracardiacas de los pacientes, el riesgo quirúrgico individual, evaluado por el equipo cardiológico multidisciplinario además de su estimación mediante escalas de riesgo, la viabilidad del TAVI, la experiencia del centro y los datos sobre resultados. Son muy escasos los datos sobre el TAVI en pacientes menores de 75 años o con riesgo quirúrgico bajo, para los que el RQVA sigue siendo el método de referencia. Hay que señalar que los pacientes más jóvenes presentan diferencias en cuanto a la anatomía (mayor número de válvulas bicúspides), que afectan a los resultados del TAVI (además, por lo general, las válvulas bicúspides se excluyen de los estudios clínicos), y que faltan datos sobre la durabilidad a largo plazo de las válvulas protésicas para TAVI.

Los datos recabados en estudios aleatorizados con grupo de control y en grandes registros sobre pacientes ancianos con riesgo quirúrgico elevado muestran que el TAVI es superior al tratamiento médico en cuanto a la mortalidad de los pacientes con riesgo extremo ${ }^{91}$, no es inferior o es superior a la cirugía para los pacientes con alto riesgo ${ }^{94-97}$ y no es inferior a la cirugía, o incluso es superior, cuando el acceso transfemoral es viable en pacientes con riesgo intermedio ${ }^{98-102}$. En los 2 grandes estudios sobre pacientes con riesgo intermedio, las medias de edad de los pacientes eran 82 y 80 años $^{99,102}$, las puntuaciones medias de la STS fueron 5,8 y 4,5\%99,102 y se consideró frágil a un gran porcentaje de pacientes. Por lo tanto, estos resultados solo son válidos para grupos de pacientes comparables. En general, las tasas de complicaciones vasculares, implante de marcapasos e insuficiencia paravalvular fueron significativamente más altas con el TAVI, mientras que el grado de exceso dependió del dispositivo empleado ${ }^{101,102}$. Por otra parte, las incidencias de hemorragias mayores, insuficiencia renal aguda y fibrilación auricular de nueva aparición fueron significativamente más frecuentes en la cirugía, mientras que no se observaron diferencias en las tasas de complicaciones cerebrovasculares ${ }^{101,102}$. Los resultados favorables del TAVI se han reproducido en registros nacionales múltiples y a gran escala, lo cual respalda la generalización de los resultados obtenidos en estudios aleatorizados. Todo ello favorece el uso del TAVI frente a la cirugía en pacientes ancianos con riesgo quirúrgico elevado. No obstante, la decisión final entre RQVA y TAVI (incluida la elección de la vía de acceso) debe ser responsabili- dad del equipo cardiológico multidisciplinario tras una cuidadosa evaluación de cada caso individual. La tabla 7 presenta los aspectos que se deben considerar durante la toma de decisiones. La valvuloplastia con balón puede considerarse como tratamiento puente a la cirugía o el TAVI o durante el proceso diagnóstico.

Tabla 7

Aspectos que debe considerar el equipo cardiológico multidisciplinario para decidir entre RQVA y TAVI para pacientes con riesgo quirúrgico elevado (véase la tabla de recomendaciones del apartado 5.2)

\begin{tabular}{|c|c|c|}
\hline & $\begin{array}{l}\text { A favor } \\
\text { de TAVI }\end{array}$ & $\begin{array}{l}\text { A favor } \\
\text { de RQVA }\end{array}$ \\
\hline \multicolumn{3}{|l|}{ Características clínicas } \\
\hline \multicolumn{3}{|l|}{ STS/EuroSCORE II $<4 \%$} \\
\hline \multicolumn{3}{|l|}{$($ EuroSCORE I logístico < 10\%) } \\
\hline \multicolumn{3}{|l|}{ STS/EuroSCORE II $\geq 4 \%$} \\
\hline \multicolumn{3}{|l|}{ (EuroSCORE I logístico $\geq 10 \%)^{a}$} \\
\hline \multicolumn{3}{|l|}{$\begin{array}{l}\text { Presencia de comorbilidad grave (que no se refleja } \\
\text { adecuadamente en las escalas) }\end{array}$} \\
\hline \multicolumn{2}{|l|}{ Edad $<75$ años } & + \\
\hline \multicolumn{3}{|l|}{ Edad $\geq 75$ años } \\
\hline \multicolumn{3}{|l|}{ Cirugía cardiaca previa } \\
\hline \multicolumn{3}{|l|}{ Fragilidad $^{\mathrm{b}}$} \\
\hline \multicolumn{3}{|l|}{$\begin{array}{l}\text { Movilidad restringida y otras condiciones que podrían } \\
\text { afectar al proceso de rehabilitación tras el procedimiento }\end{array}$} \\
\hline \multicolumn{2}{|l|}{ Sospecha de endocarditis } & + \\
\hline \multicolumn{3}{|l|}{ Aspectos anatómicos y técnicos } \\
\hline \multicolumn{3}{|l|}{ Acceso favorable para el TAVI, transfemoral } \\
\hline \multicolumn{2}{|l|}{ Acceso desfavorable (cualquiera) para TAVI } & + \\
\hline \multicolumn{3}{|l|}{ Secuelas de la radiación torácica } \\
\hline \multicolumn{3}{|l|}{ Aorta de porcelana } \\
\hline \multicolumn{3}{|l|}{$\begin{array}{l}\text { Presencia de injertos coronarios intactos que corren riesgo } \\
\text { si se realiza una esternotomía }\end{array}$} \\
\hline \multicolumn{3}{|l|}{ Disparidad prevista entre el paciente y la prótesis } \\
\hline \multicolumn{3}{|l|}{ Deformación torácica grave o escoliosis } \\
\hline \multicolumn{2}{|l|}{ Poca distancia entre el ostium coronario y el anillo aórtico } & + \\
\hline \multicolumn{2}{|l|}{ Tamaño del anillo aórtico inadecuado para el TAVI } & + \\
\hline \multicolumn{2}{|l|}{ Morfología de la raíz aórtica desfavorable para TAVI } & + \\
\hline \multicolumn{2}{|l|}{$\begin{array}{l}\text { Morfología valvular (bicúspide, grado de calcificación, tipo } \\
\text { de calcificación) desfavorable para TAVI }\end{array}$} & + \\
\hline \multicolumn{2}{|l|}{ Presencia de trombos en la aorta o el VI } & + \\
\hline
\end{tabular}

Entidades cardiacas, además de la estenosis aórtica, que

requieren que se considere una intervención concomitante

\begin{tabular}{ll}
\hline EAC grave que requiere revascularización mediante CABG \\
\hline $\begin{array}{l}\text { Valvulopatía mitral primaria grave que se puede tratar } \\
\text { quirúrgicamente }\end{array}$ \\
\hline Valvulopatía tricuspídea grave \\
\hline Aneurisma de la aorta ascendente
\end{tabular}

CABG: cirugía de revascularización coronaria; EAC: enfermedad arterial coronaria; EuroSCORE: sistema europeo para la evaluación del riesgo cardiaco operatorio; RQVA: reemplazo quirúrgico de válvula aórtica; STS: Society of Thoracic Surgeons; TAVI: implante percutáneo de válvula aórtica; VI: ventrículo izquierdo.

aEscala TS (calculadora: http://riskcalc.sts.org/stswebriskcalc/\#/calculate); EuroSCORE II (calculadora: http://www.euroscore.org/calc.html); EuroSCORE I logístico (calculadora: http://www.euroscore.org/calcge.html). En este contexto las escalas de riesgo tienen limitaciones importantes para su uso práctico porque consideran de manera insuficiente la gravedad de la enfermedad y no incluyen factores de riesgo importantes, como la fragilidad, la aorta de porcelana y la radiación torácica, entre otros ${ }^{103}$. El EuroSCORE I subestima significativamente la mortalidad a los 30 días, por lo que se debe sustituir por el EuroSCORE II, que permite una mejor estimación. No obstante, se incluye en este documento para su comparación, ya que se ha empleado en numerosos estudios y registros sobre TAVI, y puede seguir siendo útil para identificar subgrupos de pacientes para los que hay que tomar decisiones sobre distintas modalidades de intervención y predecir la mortalidad al año.

bVéase el apartado 3.3, comentarios generales sobre la valoración de la fragilidad. 


\subsubsection{Estenosis aórtica asintomática}

El tratamiento de la estenosis aórtica asintomática grave sigue siendo controvertido. Los estudios realizados no proporcionan datos convincentes que permitan establecer recomendaciones generales sobre el RQVA precoz, ni siquiera en el caso de los pacientes con estenosis aórtica asintomática muy grave ${ }^{92,106}$. La decisión de operar a pacientes asintomáticos requiere sopesar cuidadosamente los beneficios y los riesgos del procedimiento. Esta sección se refiere únicamente a los pacientes que son candidatos a RQVA, ya que el TAVI no está recomendado para pacientes asintomáticos. La cirugía electiva temprana está indicada para los pacientes asintomáticos con función del VI reducida por otras causas y pacientes que sufren síntomas durante la prueba de esfuerzo ${ }^{85,107}$.

Entre los predictores de la aparición de síntomas y de resultados adversos en pacientes asintomáticos, se incluyen las características clínicas (edad avanzada, factores de riesgo ateroesclerótico), los parámetros ecocardiográficos (calcificación valvular, pico de velocidad del chorro aórtico ${ }^{92,108}$, FEVI, tasa de progresión hemodinámica ${ }^{92}$, aumento del gradiente medio $>20 \mathrm{mmHg}$ durante el ejercicio ${ }^{86}$, hipertrofia del VI excesiva ${ }^{109}$, función longitudinal del VI anormal ${ }^{110}$ e hipertensión pulmonar ${ }^{111}$ ) y la concentración de biomarcadores (altas concentraciones plasmáticas de péptidos natriuréticos, aunque los valores de corte concretos todavía no están claramente definidos) ${ }^{89,90}$. Cuando se considere la cirugía electiva temprana para pacientes con resultados normales en la prueba de esfuerzo, debido a la presencia de dichos predictores de los resultados, el riesgo operatorio debería ser bajo (véase la tabla de recomendaciones «Indicaciones para la intervención en la estenosis aórtica» en el apartado 5.2). Para pacientes sin factores de predicción de riesgo, la cirugía temprana probablemente no sea beneficiosa y parece seguro vigilar atentamente la evolución.

\subsection{Tratamiento médico}

Ningún tratamiento médico para la estenosis aórtica puede mejorar los resultados de la historia natural. Los estudios aleatorizados han coincidido en demostrar que las estatinas no tienen efecto alguno en la progresión de la estenosis aórtica ${ }^{112}$. Los pacientes con síntomas de insuficiencia cardiaca que no son candidatos para cirugía o TAVI o que están a la espera de una intervención quirúrgica o percutánea deben recibir tratamiento médico acorde con la guía sobre insuficiencia cardiaca $^{113}$. Debe tratarse la hipertensión si está presente. El tratamiento médico debe ajustarse gradualmente y con precaución para evitar hipotensión; se debe revaluar con frecuencia a los pacientes. Es importante mantener el ritmo sinusal.

\subsection{Pruebas seriadas}

En los pacientes asintomáticos, la gran variabilidad en la tasa de progresión de la estenosis aórtica subraya la necesidad de que reciban adecuada instrucción sobre la importancia del seguimiento y la necesidad de informar de los síntomas en cuanto aparezcan. Las pruebas de estrés deben determinar el grado recomendado de actividad física. La evaluación durante el seguimiento debe centrarse en la progresión hemodinámica, la función y la hipertrofia del VI y las dimensiones de la aorta ascendente.

Se debe revaluar a los pacientes con estenosis aórtica asintomática grave como mínimo cada 6 meses, para vigilar la aparición de síntomas (cambios en la tolerancia al ejercicio, preferiblemente con una prueba de esfuerzo si los síntomas son dudosos) y los cambios en los parámetros ecocardiográficos. Debe considerarse la determinación de péptidos natriuréticos.

En los casos de calcificación valvular significativa, se debe revaluar anualmente a los pacientes con estenosis aórtica de leve a moderada. Para los pacientes jóvenes con estenosis leve y sin calcificación significativa, este intervalo se puede extender a 2 o 3 años.

\subsection{Grupos especiales de pacientes}

El RQVA combinado con CABG tiene más riesgo que el reemplazo solo. No obstante, el RQVA que se realiza tiempo después de la CABG también se asocia con un aumento significativo del riesgo.

Los datos obtenidos de análisis retrospectivos indican que los pacientes para los que está indicada la CABG y que tienen estenosis aórtica moderada pueden, en general, beneficiarse del RQVA en el momento de la cirugía de revascularización. Además, también se ha señalado que si la edad es < 70 años y, lo más importante, si se documenta una tasa media de progresión de la estenosis aórtica de $5 \mathrm{mmHg}$, los pacientes pueden beneficiarse del reemplazo valvular al mismo tiempo que la cirugía coronaria una vez que se haya excedido el pico de gradiente basal en $30 \mathrm{mmHg}^{114}$. Sin embargo, se recomienda un juicio individualizado que tenga en cuenta el ASC, los datos hemodinámicos, la calcificación de las valvas, la tasa de progresión de la estenosis aórtica, la esperanza de vida y las comorbilidades asociadas, así como el riesgo individual del reemplazo valvular o de una posible reoperación ${ }^{93}$. No debe denegarse la posibilidad de RQVA o TAVI a los pacientes con estenosis aórtica sintomática grave y EAC difusa a los que no se pueda revascularizar.

Se ha demostrado que la ICP combinada con TAVI es factible, pero son necesarios más datos para que puedan establecerse recomendaciones. La cronología de las intervenciones debe discutirse de forma individualizada teniendo en cuenta el estado clínico del paciente, el grado de EAC y el miocardio en riesgo.

Cuando la insuficiencia mitral se asocia con estenosis aórtica grave, su gravedad se podría sobrestimar en presencia de presiones ventriculares elevadas, por lo que se requiere una cuantificación minuciosa. Cuando no haya anomalías morfológicas en las valvas (rotura o prolapso, cambios posreumáticos o signos de endocarditis infecciosa), dilatación del anillo mitral o anomalías importantes en la geometría del VI, generalmente la intervención quirúrgica de la válvula mitral no es necesaria. La insuficiencia mitral secundaria no grave suele mejorar después del tratamiento de la válvula aórtica. En pacientes con insuficiencia mitral grave, el TAVI combinado o secuencial y la reparación mitral percutánea con la técnica de «borde con borde» son factibles, pero no hay suficientes datos para realizar recomendaciones.

La dilatación o el aneurisma de la aorta ascendente concomitantes requieren el mismo tratamiento que la insuficiencia aórtica (véase la sección 4).

La estenosis aórtica congénita se trata en la guía de la ESC sobre las enfermedades cardiacas congénitas del adulto ${ }^{115}$.

\section{Puntos clave}

- En el diagnóstico de la estenosis aórtica grave deben considerarse el área valvular aórtica, el volumen de flujo, los gradientes de presión (la medición más robusta), la función, el tamaño y el grosor de la pared del VI, el grado de calcificación valvular, la presión arterial y el estado funcional del paciente.

- La evaluación de la gravedad de la estenosis aórtica de los pacientes con gradiente bajo y FEVI conservada sigue siendo particularmente compleja.

- La indicación más sólida para una intervención sigue siendo los síntomas de estenosis aórtica (espontáneos o en la prueba de esfuerzo).

- La presencia de predictores de rápida aparición de síntomas puede justificar la cirugía temprana en pacientes asintomáticos, especialmente si el riesgo quirúrgico es bajo.

- Aunque los datos actuales favorecen el TAVI para los pacientes ancianos que tengan alto riesgo quirúrgico, especialmente cuando el acceso transfemoral es viable, la decisión entre TAVI y RQVA se debe tomar en el equipo cardiológico después de una evaluación 
minuciosa y completa del paciente, que incluya la valoración del riesgo individual y el beneficio esperado.

\section{Lagunas en la evidencia}

- El impacto de los marcadores tempranos de disfunción del VI en los resultados posoperatorios requiere más estudio.

- Es preciso mejorar la identificación de los pacientes con estenosis aórtica grave y gradiente bajo que podrían beneficiarse de una intervención.

- Los criterios para la identificación de pacientes que podrían beneficiarse de la cirugía electiva temprana en la estenosis aórtica asintomática grave requiere más estudio.

- Es necesario el seguimiento a largo plazo de los pacientes tratados con TAVI y, particularmente, hay que estudiar la durabilidad de las válvulas a largo plazo.

- Se deben mejorar los criterios para decidir entre TAVI y RQVA para pacientes con riesgo operatorio alto candidatos a ambos tratamientos y hay que estudiarlos en pacientes con riesgo quirúrgico bajo.

- Es preciso definir mejor los criterios sobre cuándo ya no es necesario practicar un TAVI porque no sería útil.

\section{INSUFICIENCIA MITRAL}

La insuficiencia mitral es la segunda indicación para cirugía valvular más frecuente en Europa ${ }^{47}$. Es fundamental diferenciar la insuficiencia mitral primaria de la secundaria, especialmente a la hora de valorar la indicación de una intervención quirúrgica o percutánea ${ }^{116}$.

\subsection{Insuficiencia mitral primaria}

En la insuficiencia mitral primaria, uno o varios componentes de la válvula mitral están directamente afectados. La etiología más frecuente es la enfermedad degenerativa (prolapso o rotura de las valvas). La endocarditis, como una de las causas de la insuficiencia mitral primaria, se trata en una guía específica de la $\mathrm{ESC}^{28}$.

\subsubsection{Evaluación}

La ecocardiografía es la prueba más importante para evaluar la gravedad y el mecanismo de la insuficiencia mitral, sus consecuencias para el VI (función y remodelado), la circulación de la AI y pulmonar, así como la posibilidad de reparación.

La cuantificación debe ser integral e incluir parámetros cualitativos, semicuantitativos y cuantitativos. Los criterios que definen la insuficiencia mitral primaria grave se resumen en la tabla $4^{2,7}$.

Se precisa una descripción minuciosa de las lesiones empleando la anatomía segmentaria y funcional de acuerdo con la clasificación de Carpentier ${ }^{2,7}$ para valorar la posibilidad de reparación. La ETT permite además evaluar las dimensiones del anillo mitral y la presencia de calcificación.

En la mayoría de los casos, la ETT es diagnóstica, aunque se recomienda la ETE, especialmente cuando la calidad de la imagen no sea óptima ${ }^{117}$. La ecocardiografía 3D proporciona información adicional para seleccionar la estrategia de reparación más adecuada.

El impacto de la insuficiencia mitral en la función ventricular se evalúa determinando el tamaño del VI y la FEVI. Otros parámetros importantes son el volumen de la AI, la presión arterial pulmonar sistólica (PAPs), la insuficiencia tricuspídea, el tamaño del anillo y la función del VD.

La determinación de la capacidad funcional y los síntomas mediante la prueba de esfuerzo cardiopulmonar puede ser útil en pacientes asintomáticos. La ecocardiografía de esfuerzo es útil para cuantificar los cambios inducidos por el ejercicio en la insuficiencia mitral $^{118}$, la PAPs y la función del VI. Puede ser especialmente útil en pacientes sintomáticos cuando haya incertidumbre sobre la gravedad de la insuficiencia mitral según las mediciones en reposo. En pacientes asintomáticos, el aumento significativo de la presión arterial pulmonar con el ejercicio (> $60 \mathrm{mmHg}$ ) tiene valor pronóstico ${ }^{119}$. El uso del strain longitudinal general podría ser interesante para la detección de disfunción del VI subclínica, aunque su uso está limitado por la heterogeneidad de los algoritmos empleados en distintos sistemas ecocardiográficos.

En la insuficiencia mitral se observa activación neurohormonal, y la elevación o los cambios en las concentraciones de BNP podrían tener valor predictivo de la evolución (particularmente de la aparición de síntomas). Más específicamente, las concentraciones plasmáticas de BNP bajas tienen valor predictivo negativo y su determinación puede ser útil en el seguimiento de pacientes asintomáticos ${ }^{120}$.

Debido a las discrepancias que existen entre las mediciones ecocardiográficas y las invasivas de la presión pulmonar, si esta fuese la única indicación para cirugía, la medición debe confirmarse de manera invasiva mediante cateterismo de corazón derecho.

\subsubsection{Indicaciones de la intervención}

La cirugía urgente está indicada para pacientes con insuficiencia mitral aguda grave. En general, si la rotura del músculo papilar es la causa subyacente, es necesario reemplazar la válvula.

Las indicaciones para cirugía en la insuficiencia mitral primaria grave y crónica se muestran en la siguiente tabla de recomendaciones y la figura 4. Obviamente, la cirugía está indicada para la insuficiencia mitral primaria grave en pacientes sintomáticos ${ }^{121}$. La FEVI $\leq 60 \%$ o el DTSVI $\geq 45 \mathrm{~mm}^{122}$, la fibrilación auricular ${ }^{123} \mathrm{y}$ una PAPs $\geq 50 \mathrm{mmHg}^{124}$ predicen un resultado posoperatorio menos favorable, independientemente del estado sintomático, y por ello se han convertido en motivo de cirugía para pacientes asintomáticos. En pacientes con rotura de valvas, un DTSVI de 40-44 mm es un predictor de peores resultados que un DTSVI $<40 \mathrm{~mm}^{125}$. Se ha observado también que la dilatación significativa de la AI, a pesar del ritmo sinusal, es un predictor de los resultados ${ }^{124}$. En presencia de estos 2 últimos desencadenantes, la cirugía solo debe considerarse en centros con experiencia en valvulopatías y siempre que el riesgo quirúrgico sea bajo. También se ha propuesto un aumento de la PAPs $>60 \mathrm{mmHg}$ en la ecocardiografía de esfuerzo para la estratificación del riesgo ${ }^{119}$. No obstante, hasta la fecha no se han descrito suficientemente los criterios para la indicación de cirugía y, por lo tanto, no se pueden incluir en las recomendaciones actuales.

Para los pacientes asintomáticos con insuficiencia mitral primaria grave y ninguna de las indicaciones de cirugía citadas, la estrategia más segura es la espera vigilante ${ }^{126}$; el seguimiento debería realizarse, preferiblemente, en un centro especializado en valvulopatías ${ }^{32}$.

Pese a la falta de datos de estudios aleatorizados que comparen los resultados del reemplazo y la reparación valvular, generalmente se acepta que, siempre que sea viable, la reparación valvular es el tratamiento preferido. Es fundamental lograr una reparación valvular duradera. La insuficiencia mitral degenerativa causada por prolapso valvular segmentario puede repararse con bajo riesgo de recurrencia de la insuficiencia y reintervención. La posibilidad de reparación de lesiones reumáticas, prolapso extenso de valvas e incluso más, de insuficiencia mitral con calcificación de valvas o con calcificación extensa del anillo, es mucho más compleja. Los pacientes en los que se prevé una reparación compleja deben ser operados en centros con experiencia, altas tasas de reparación, baja mortalidad operatoria y registros de resultados duraderos ${ }^{127,128}$. Cuando la reparación no sea posible, el reemplazo de válvula mitral conservando el aparato subvalvular es la alternativa. La reparación adicional de la válvula tricúspide debe realizarse como se indica en el apartado 8.2 (véanse las recomendaciones sobre las indicaciones de cirugía de válvula tricúspide).

Las intervenciones percutáneas de válvula mitral se han desarrollado para corregir la insuficiencia mitral primaria por vía transeptal o 


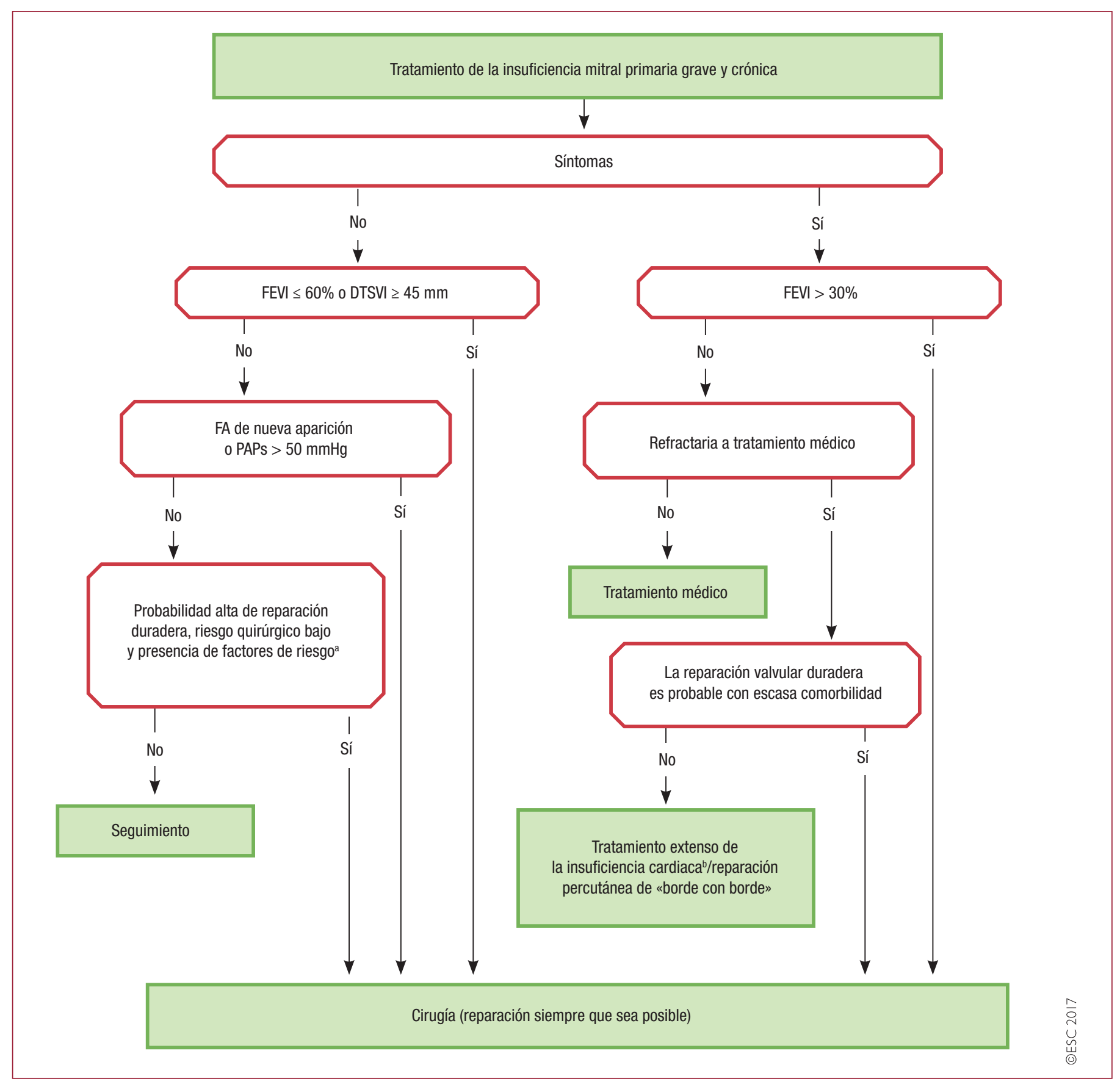

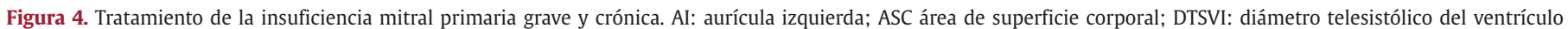
izquierdo; FA: fibrilación auricular; FEVI: fracción de eyección del ventrículo izquierdo; PAPs: presión arterial pulmonar sistólica; TRC: terapia de resincronización cardiaca.

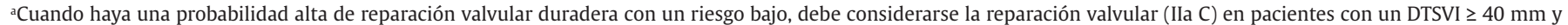
uno de los siguientes factores: rotura de valvas o volumen de la $\mathrm{AI} \geq 60 \mathrm{ml} / \mathrm{m}^{2}$ del ASC en ritmo sinusal.

bEl tratamiento extenso de la insuficiencia cardiaca incluye: TRC, dispositivos de asistencia ventricular, dispositivos del control del ritmo cardiaco y trasplante cardiaco.

transapical. Actualmente, entre los distintos procedimientos percutáneos, la reparación mitral con el método de «borde con borde» es el más utilizado ${ }^{129}$. La experiencia con la anuloplastia transcatéter, el implante cordal transapical o el reemplazo valvular sigue siendo escasa y, por el momento, no se pueden establecer recomendaciones generales. El tratamiento transcatéter de la válvula mitral de pacientes sintomáticos con alto riesgo quirúrgico o inoperables debe valorarse en el equipo cardiológico. La reparación percutánea con la técnica de «borde con borde» generalmente es segura y puede mejorar los síntomas y facilitar el remodelado del VI. No obstante, la tasa de insuficiencia mitral residual hasta los 5 años es más alta que con la reparación quirúrgica ${ }^{130}$.

\subsubsection{Tratamiento médico}

En la insuficiencia mitral aguda se emplean nitratos y diuréticos para reducir las presiones de llenado. El nitroprusiato de sodio reduce la poscarga y la fracción regurgitante. Los fármacos inotrópicos y el balón de contrapulsación intraaórtico son útiles en caso de hipotensión e inestabilidad hemodinámica. 
Indicaciones para la intervención en la insuficiencia mitral primaria grave

\begin{tabular}{|c|c|c|}
\hline Recomendaciones & Clase $^{\mathrm{a}}$ & Nivel $^{\mathrm{b}}$ \\
\hline $\begin{array}{l}\text { La reparación de válvula mitral debe ser la técnica preferida } \\
\text { cuando se espera que los resultados sean duraderos }\end{array}$ & I & C \\
\hline $\begin{array}{l}\text { La cirugía está indicada para pacientes sintomáticos con FEVI } \\
>30 \% 121,131,132\end{array}$ & I & B \\
\hline $\begin{array}{l}\text { La cirugía está indicada para pacientes asintomáticos } \\
\left.\text { con disfunción del VI (DTSVI } \geq 45 \mathrm{~mm}^{\mathrm{c}} \text { o FEVI } \leq 60 \%\right)^{122,131}\end{array}$ & I & B \\
\hline $\begin{array}{l}\text { Debe considerarse la cirugía para pacientes asintomáticos } \\
\text { con función del VI conservada (DTSVI }<45 \mathrm{~mm} \text { y FEVI } \leq 60 \% \text { ) } \\
\text { y fibrilación auricular secundaria a insuficiencia mitral o } \\
\text { hipertensión pulmonard } \text { (presión pulmonar sistólica en reposo } \\
>50 \mathrm{mmHg})^{123,124}\end{array}$ & IIa & B \\
\hline $\begin{array}{l}\text { Debe considerarse la cirugía para pacientes asintomáticos con } \\
\text { FEVI conservada (> } 60 \% \text { ) y DTSVI de } 40-44 \mathrm{~mm}^{\mathrm{c}} \text { cuando sea } \\
\text { probable una reparación duradera, el riesgo quirúrgico sea bajo, } \\
\text { la reparación se lleve a cabo en un centro con experiencia } \\
\text { y haya al menos } 1 \text { de los siguientes hallazgos: } \\
\text { - Rotura de cuerdas tendinosas o } \\
\text { - Dilatación de la AI significativa (índice de volumen } \\
\geq 60 \mathrm{ml} / \mathrm{m}^{2} \text { del ASC) en ritmo sinusal }\end{array}$ & IIa & C \\
\hline $\begin{array}{l}\text { Debe considerarse la reparación de válvula mitral de los } \\
\text { pacientes sintomáticos con disfunción del VI grave (FEVI } \\
<30 \% \text { o DTSVI > } 55 \mathrm{~mm} \text { ) refractaria a tratamiento médico si las } \\
\text { probabilidades de reparación eficaz son altas y la comorbilidad } \\
\text { es baja }\end{array}$ & IIa & $\mathrm{C}$ \\
\hline $\begin{array}{l}\text { Puede considerarse el reemplazo de la válvula mitral de } \\
\text { pacientes con disfunción del VI grave (FEVI < 30\% o DTSVI } \\
\text { > } 55 \mathrm{~mm} \text { ) refractaria a tratamiento médico si la probabilidad } \\
\text { de la reparación valvular y la comorbilidad son bajas }\end{array}$ & IIb & C \\
\hline $\begin{array}{l}\text { Puede considerarse el procedimiento percutáneo de «borde } \\
\text { con borde» para pacientes con insuficiencia mitral primaria } \\
\text { grave sintomática que cumplan los criterios ecocardiográficos } \\
\text { de elegibilidad y el equipo cardiológico considere inoperables } \\
\text { o con alto riesgo quirúrgico, evitando realizar procedimientos } \\
\text { inútiles }\end{array}$ & IIb & C \\
\hline
\end{tabular}

AI: aurícula izquierda; ASC: área de superficie corporal; DTSVI: diámetro telesistólico del ventrículo izquierdo; FEVI: fracción de eyección del ventrículo izquierdo; VI: ventrículo izquierdo.

aClase de recomendación.

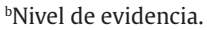

cLos valores de corte se refieren a adultos de talla media, por lo que podría ser necesario adaptarlos en caso de pacientes de estatura inusualmente alta o baja.

${ }^{\text {d}} \mathrm{Si}$ la PAPs elevada es la única indicación de cirugía, el valor debe confirmarse mediante mediciones invasivas.

En la insuficiencia mitral crónica con la función ventricular conservada, no hay datos que respalden el uso profiláctico de vasodilatadores, incluidos los IECA. Sin embargo, debe considerarse el uso de IECA si ha aparecido insuficiencia cardiaca en un paciente inoperable o cuando persistan los síntomas después de la cirugía. Debe considerarse la administración de bloqueadores beta y espironolactona (o eplerenona), cuando proceda.

\subsubsection{Pruebas seriadas}

Los pacientes asintomáticos con insuficiencia mitral grave y FEVI $>60 \%$ deben tener un seguimiento clínico y ecocardiográfico cada 6 meses, preferiblemente en un centro especializado en valvulopatías. Está indicado un seguimiento más estrecho si no se dispone de evaluaciones previas y cuando las variables medidas muestren cambios dinámicos significativos o se encuentren cerca de los umbrales. Cuando se alcancen las indicaciones de cirugía según las recomendaciones de las guías, la cirugía temprana (en los primeros 2 meses) se asocia con mejores resultados ${ }^{133}$. Los pacientes asintomáticos con insuficiencia mitral moderada y función del VI conservada deben tener un seguimiento clínico anual y seguimiento ecocardiográfico cada 1 o 2 años.

\subsection{Insuficiencia mitral secundaria}

En la insuficiencia mitral secundaria (referida previamente como «insuficiencia mitral funcional»), las valvas y las cuerdas tendinosas son estructuralmente normales y la insuficiencia mitral se produce por un desequilibrio entre las fuerzas de cierre y de anclaje secundario a alteraciones en la geometría del VI ${ }^{134}$. Se observa más frecuentemente en la miocardiopatía dilatada o la cardiopatía isquémica. La dilatación anular en pacientes con FA crónica y engrosamiento de la AI también puede ser uno de los mecanismos subyacentes.

\subsubsection{Evaluación}

La ecocardiografía es la técnica fundamental para establecer el diagnóstico de insuficiencia mitral secundaria. Se han propuesto umbrales más bajos para definir la insuficiencia mitral grave comparada con la insuficiencia mitral primaria $\left(20 \mathrm{~mm}^{2}\right.$ para el área efectiva del orificio regurgitante y $30 \mathrm{ml}$ para el volumen regurgitante), según su relación con el pronóstico ${ }^{135}$. Sin embargo, no está claro que la insuficiencia mitral afecte al pronóstico de manera independiente comparada con la disfunción del VI. Hasta la fecha no se ha confirmado ningún beneficio derivado de la reducción de la insuficiencia mitral secundaria.

Para el tratamiento aislado de válvula mitral (cirugía o reparación percutánea de «borde con borde»), los umbrales de gravedad de la insuficiencia mitral para la intervención todavía deben validarse en estudios clínicos. La gravedad de la insuficiencia mitral secundaria se debe revaluar después del tratamiento médico óptimo. También debe evaluarse la gravedad de la insuficiencia tricuspídea y el tamaño y la función del VD.

La insuficiencia mitral secundaria es una entidad dinámica; la cuantificación ecocardiográfica de la insuficiencia mitral durante el ejercicio puede proporcionar información pronóstica de las características dinámicas. Las pruebas para determinar la viabilidad miocárdica pueden ser útiles en pacientes con insuficiencia mitral isquémica secundaria que son candidatos a tratamiento de revascularización.

\subsubsection{Indicaciones para la intervención}

La presencia de insuficiencia mitral secundaria crónica se asocia con mal pronóstico ${ }^{135}$. Sin embargo, y al contrario de lo que ocurre en la insuficiencia mitral primaria, no hay pruebas de que la reducción de la insuficiencia mitral secundaria mejore la supervivencia. Debido a la falta de datos sobre la insuficiencia mitral secundaria, los niveles de evidencia son bajos para establecer recomendaciones sobre el tratamiento (véase la tabla de recomendaciones para la indicación de intervenciones de válvula mitral en la insuficiencia mitral secundaria crónica), por lo que es importante que el equipo cardiológico tome las decisiones, con la colaboración de especialistas en insuficiencia cardiaca y electrofisiología.

En caso de pacientes con EAC a los que se va a revascularizar, la evaluación y la decisión de tratar (o no tratar) la insuficiencia mitral isquémica deben producirse antes de la cirugía, ya que la anestesia general podría reducir significativamente el grado de insuficiencia. Cuando se evalúa la gravedad de la insuficiencia mitral de forma intraoperatoria, puede ser útil emplear una sobrecarga aguda de fluidos o un aumento de la poscarga.

La estrategia quirúrgica óptima sigue siendo una cuestión controvertida $^{136}$. Mientras que la reparación de válvula mitral con anillo completo de menor dimensión para restaurar la coaptación de las valvas y la competencia valvular es la técnica preferida, debe considerarse el reemplazo valvular para los pacientes con factores ecocardiográficos de riesgo de insuficiencia mitral residual o recurrente ${ }^{2}$.

Las indicaciones para cirugía en la insuficiencia mitral secundaria son particularmente restrictivas cuando la revascularización conco- 
mitante no sea una opción, dadas la mortalidad operatoria significativamente alta, la alta tasa de insuficiencia mitral recurrente y la ausencia de beneficios probados en relación con la supervivencia ${ }^{137,138}$.

La reparación percutánea de «borde con borde» para la insuficiencia mitral secundaria es una opción de bajo riesgo, pero su eficacia para reducir la insuficiencia mitral sigue siendo inferior a la de la cirugía ${ }^{139}$. Este tratamiento puede mejorar los síntomas, la capacidad funcional y la calidad de vida e inducir el remodelado inverso del $\mathrm{VI}^{140}$. Al igual que la cirugía, todavía no se ha probado su beneficio en cuanto a la supervivencia comparado con el tratamiento médico "óptimo» según las guías actuales ${ }^{113}$.

Para los pacientes con una reducción marcada de la función del VI (FEVI $\leq 30 \%$ ) que no son candidatos a tratamiento de revascularización y siguen sintomáticos pese a recibir tratamiento médico óptimo para la insuficiencia cardiaca (incluida la terapia de resincronización cardiaca [TRC] cuando proceda), la decisión entre un tratamiento paliativo de la insuficiencia mitral (percutáneo o quirúrgico, con dispositivos de asistencia ventricular, trasplante cardiaco) o continuar con tratamiento conservador se debe tomar en el equipo cardiológico tras una cuidadosa evaluación del paciente. Generalmente, la intervención valvular no es una opción cuando la FEVI sea $<15 \%$.

El tratamiento de la insuficiencia mitral isquémica moderada en pacientes que van a someterse a CABG sigue siendo una cuestión abierta a debate. Un reciente estudio aleatorizado y con grupo de control no pudo demostrar beneficios de la cirugía valvular concomitante ${ }^{141}$. Es más probable que se considere la cirugía en presencia de viabilidad miocárdica y comorbilidad baja. En pacientes con capacidad de ejercicio, la disnea inducida por el esfuerzo y el aumento significativo en la gravedad de la insuficiencia mitral y de la PAPs favorecen la indicación de cirugía combinada.

Indicaciones para la intervención de válvula mitral en la regurgitación mitral secundaria crónica ${ }^{a}$

\begin{tabular}{l|cc}
\hline Recomendaciones & Clase $^{\text {b }}$ & Nivel $^{c}$ \\
\hline $\begin{array}{l}\text { La cirugía está indicada para pacientes con insuficiencia mitral } \\
\text { secundaria grave y FEVI > 30\% que van a someterse a CABG }\end{array}$ & I \\
\hline $\begin{array}{l}\text { Debe considerarse la cirugía para los pacientes sintomáticos } \\
\text { con insuficiencia mitral secundaria grave y FEVI < 30\%, pero } \\
\text { con una opción de revascularización y evidencia de viabilidad } \\
\text { miocárdica }\end{array}$ & Ila & C \\
\hline $\begin{array}{l}\text { Cuando la revascularización no está indicada, puede } \\
\text { considerarse la cirugía para los pacientes con insuficiencia } \\
\text { mitral secundaria grave y FEVI > 30\% que siguen sintomáticos } \\
\text { a pesar del tratamiento médico óptimo (incluida la TRC si está } \\
\text { indicada) y tienen un riesgo quirúrgico bajo }\end{array}$ & \\
\hline $\begin{array}{l}\text { Cuando la revascularización no esté indicada y el riesgo } \\
\text { quirúrgico no sea bajo, puede considerarse el procedimiento } \\
\text { percutáneo de «borde con borde» para pacientes con } \\
\text { insuficiencia mitral secundaria grave y FEVI > 30\% que siguen } \\
\text { sintomáticos a pesar del tratamiento médico óptimo (incluida } \\
\text { la TRC si está indicada) y tienen una morfología valvular } \\
\text { adecuada según los resultados ecocardiográficos, evitando los } \\
\text { procedimientos inútiles }\end{array}$ & C \\
\hline $\begin{array}{l}\text { Para los pacientes con insuficiencia mitral secundaria grave } \\
\text { y FEVI < 30\% que sigan sintomáticos a pesar del tratamiento } \\
\text { médico óptimo (incluida la TRC si está indicada) y no tengan } \\
\text { opción de revascularización, el equipo cardiológico puede } \\
\text { considerar la indicación de un procedimiento de «borde con } \\
\text { borde» o de cirugía valvular después de evaluar la necesidad de } \\
\text { un dispositivo de asistencia ventricular o trasplante cardiaco } \\
\text { según las características individuales del paciente }\end{array}$ & \\
\hline
\end{tabular}

CABG: cirugía de revascularización coronaria; FEVI: fracción de eyección del ventrículo izquierdo; TRC: terapia de resincronización cardiaca.

aéase el apartado 6.2.1 para la cuantificación de la insuficiencia mitral secundaria, que siempre debe realizarse con tratamiento médico óptimo.

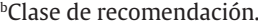

"Nivel de evidencia.

\subsubsection{Tratamiento médico}

El tratamiento médico óptimo según la guía sobre insuficiencia cardiaca ${ }^{113}$ debe ser el primer paso en el tratamiento de todo paciente con insuficiencia mitral secundaria. Las indicaciones para la TRC deben evaluarse según las guías específicas ${ }^{113}$. Si persisten los síntomas tras la optimización del tratamiento convencional para la insuficiencia cardiaca, deben evaluarse las opciones para la intervención de válvula mitral.

\section{Puntos clave}

- La ecocardiografía es fundamental para evaluar la etiología de la insuficiencia mitral, la anatomía y la función de la válvula. Es necesario un abordaje integral para evaluar la gravedad de la insuficiencia mitral.

- La indicación de intervención en la insuficiencia mitral primaria está guiada por los síntomas y la estratificación del riesgo, que incluye la evaluación de la función y el tamaño del VI, la FA, la PAPs y el tamaño de la AI.

- En la insuficiencia mitral secundaria, no hay pruebas concluyentes sobre el beneficio relativo a la supervivencia después de una intervención de válvula mitral. La cirugía mitral concomitante está recomendada para pacientes con una indicación para CABG y se puede considerar para los que siguen sintomáticos pese a recibir tratamiento médico óptimo (incluida la TRC, si está indicada) o tienen un riesgo quirúrgico bajo cuando la revascularización no esté indicada.

- La reparación de válvula mitral es el método preferido, pero debe considerarse el reemplazo valvular para los pacientes con características morfológicas desfavorables.

- Los resultados de la reparación de válvula mitral dependen de la experiencia del cirujano y el volumen de casos del centro.

- Puede considerarse la reparación percutánea de «borde con borde» para los pacientes con riesgo quirúrgico alto, para evitar intervenciones inútiles.

\section{Lagunas en la evidencia}

- Es preciso investigar en un estudio aleatorizado y controlado el papel potencial de la cirugía electiva de válvula mitral en pacientes asintomáticos con insuficiencia mitral primaria grave y tamaño y función del VI conservados, que están en ritmo sinusal y no han adquirido una presión arterial pulmonar alta.

- El impacto de los marcadores de disfunción del VI en los resultados posoperatorios requiere más estudio.

- Los umbrales para definir la insuficiencia mitral secundaria grave son controvertidos y habría que evaluar el impacto que podrían tener en el pronóstico después de una intervención de válvula mitral.

- Es preciso evaluar el impacto potencial de las intervenciones de válvula mitral (cirugía o intervención percutánea) en la supervivencia de los pacientes con insuficiencia mitral secundaria.

- Las nuevas técnicas de reparación e implante valvular requieren más estudio.

\section{ESTENOSIS MITRAL}

La incidencia de la estenosis mitral reumática ha disminuido de manera importante en los países industrializados ${ }^{142}$. La valvulopatía mitral por calcificación afecta fundamentalmente a pacientes ancianos $^{143}$. La comisurotomía mitral percutánea (CMP) ha tenido un impacto significativo en el tratamiento de la estenosis mitral de origen reumático.

\subsection{Evaluación}

La ecocardiografía es el método preferido para el diagnóstico de la estenosis mitral y la evaluación de su gravedad y sus consecuencias 


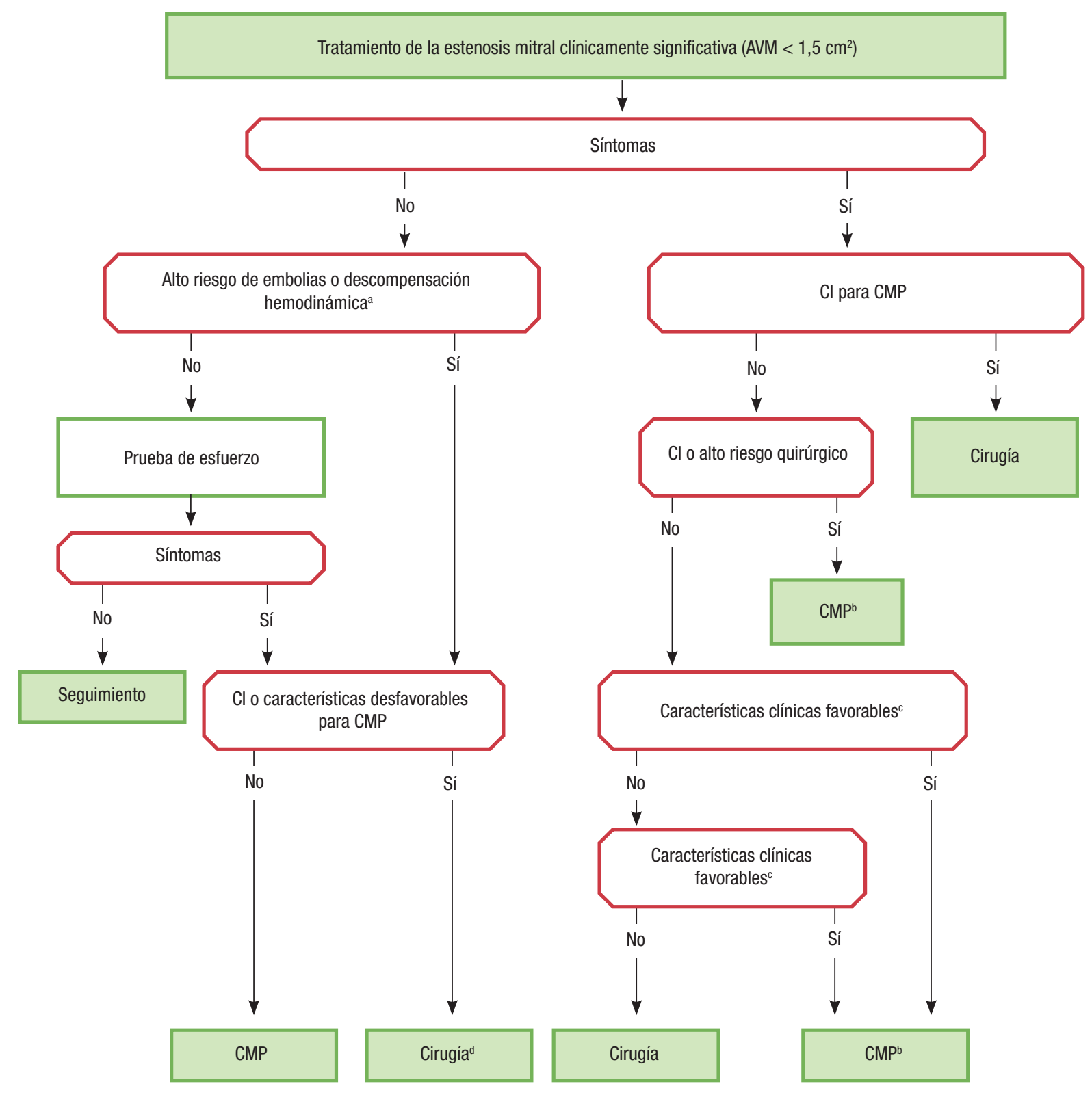

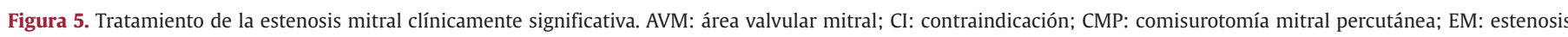
mitral.

aRiesgo tromboembólico alto: historia de embolia sistémica, concentración densa espontánea de contraste en la aurícula izquierda, fibrilación de nueva aparición. Alto riesgo de descompensación hemodinámica: presión pulmonar sistólica en reposo > $50 \mathrm{mmHg}$, necesidad de cirugía no cardiaca mayor, deseo de gestar.

bPuede considerarse la comisurotomía quirúrgica si la realiza un equipo quirúrgico experimentado o para pacientes con contraindicaciones para la CMP.

'Véase la tabla de recomendaciones sobre las indicaciones para CMP y cirugía de válvula mitral en la estenosis mitral significativa en el apartado 7.2.

${ }^{\text {d} C i r u g i ́ a ~ e n ~ c a s o ~ d e ~ q u e ~ a p a r e z c a n ~ s i ́ n t o m a s ~ c o n ~ u n ~ n i v e l ~ b a j o ~ d e ~ e j e r c i c i o ~ s i ~ e l ~ r i e s g o ~ q u i r u ́ r g i c o ~ e s ~ b a j o . ~}$

hemodinámicas. No obstante, hay que tener en cuenta diversos aspectos específicos. El área valvular calculada mediante planimetría es la medida de referencia de la gravedad de la estenosis mitral, mientras que el gradiente transvalvular medio y las presiones pulmonares reflejan sus consecuencias y, por lo tanto, tienen un valor pronóstico ${ }^{3}$. Normalmente, la ETT proporciona suficiente información para el tratamiento habitual.

Se han desarrollado distintos sistemas de puntuación para ayudar a evaluar la viabilidad de la CMP144-146. Debe realizarse un estudio con ETE para excluir trombos en la AI antes de la CMP o después de un episodio embólico. La ecocardiografía también es importante para monitorizar los resultados de la CMP durante el procedimiento. La prueba de esfuerzo está indicada para pacientes sin síntomas o con síntomas ambiguos o discordantes con la gravedad de la estenosis mitral. La ecocardiografía de esfuerzo puede proporcionar información adicional objetiva, ya que permite evaluar los cambios en el gradiente mitral y en la presión arterial pulmonar.

\subsection{Indicaciones para la intervención}

El tipo de tratamiento, así como el momento más adecuado para realizarlo, debe decidirse basándose en las características clínicas, la anatomía de la válvula y la experiencia del centro. En general, la indicación de intervención debe limitarse a los pacientes con estenosis 
mitral clínicamente significativa (de moderada a grave; área valvular $<1,5 \mathrm{~cm}^{2}$ ). Sin embargo, la CMP puede considerarse para pacientes sintomáticos con un área valvular $>1,5 \mathrm{~cm}^{2}$ si los síntomas no se explican por ninguna otra causa y si la anatomía es favorable.

El tratamiento de la estenosis mitral clínicamente significativa aparece resumido en la figura 5 y las indicaciones y contraindicaciones para la CMP, en la tabla de recomendaciones («Indicaciones para CMP y cirugía de válvula mitral en la estenosis mitral clínicamente significativa») y la tabla 8 . La intervención debe realizarse en pacientes sintomáticos. Actualmente, se trata con CMP a la mayoría de los pacientes con una anatomía valvular favorable; no obstante, para pacientes jóvenes con insuficiencia mitral de leve a moderada, puede ser preferible la comisurotomía abierta, siempre que la realicen cirujanos expertos.

Para los pacientes con una anatomía desfavorable, la toma de decisiones sobre el tipo de intervención sigue siendo motivo de debate $\mathrm{y}$, además, debe tener en cuenta la naturaleza multifactorial de la predicción de los resultados de la CMP147-149. Debe considerarse la CMP como tratamiento inicial para pacientes seleccionados con calcificación leve o moderada o aparato subvalvular afectado que por lo demás tengan características clínicas favorables. La cirugía, que por lo general es de reemplazo valvular, está indicada para los demás pacientes.

Debido al riesgo pequeño pero claro inherente a la CMP, los pacientes verdaderamente asintomáticos evaluados mediante prueba de esfuerzo no suelen ser candidatos para este procedimiento, excepto en los casos en que haya alto riesgo de embolia sistémica o descompensación hemodinámica. En estos pacientes, la CMP solo debe realizarse si las características son favorables y la practican operadores experimentados.

En pacientes asintomáticos con estenosis mitral, la cirugía se limita a casos excepcionales de pacientes con alto riesgo de complicaciones cardiacas que tienen contraindicaciones para la CMP y un riesgo quirúrgico bajo.

La contraindicación más importante para la CMP es la trombosis de la AI (tabla 8). Sin embargo, cuando el trombo se encuentra en el

Indicaciones para la CMP y la cirugía de válvula mitral en la estenosis mitral clínicamente significativa (moderada o grave; área valvular $\leq 1,5 \mathrm{~cm}^{2}$ )

\begin{tabular}{|c|c|c|}
\hline Recomendaciones & Clase $^{\mathrm{a}}$ & Nivel $^{b}$ \\
\hline $\begin{array}{l}\text { La CMP está indicada para pacientes sintomáticos sin } \\
\text { características desfavorables para este procedimiento }{ }^{144,146,148}\end{array}$ & I & B \\
\hline $\begin{array}{l}\text { La CMP está indicada para todo paciente sintomático } \\
\text { con contraindicaciones o alto riesgo quirúrgico }\end{array}$ & I & C \\
\hline $\begin{array}{l}\text { La cirugía de válvula mitral está indicada para pacientes } \\
\text { sintomáticos que no son candidatos a CMP }\end{array}$ & I & C \\
\hline $\begin{array}{l}\text { Debe considerarse la CMP como tratamiento inicial para } \\
\text { pacientes sintomáticos con anatomía subóptima pero sin } \\
\text { características clínicas desfavorables para la CMPc }\end{array}$ & Ila & C \\
\hline $\begin{array}{l}\text { Debe considerarse la CMP para pacientes asintomáticos } \\
\text { sin características clínicas y anatómicas desfavorables } \\
\text { para la CMP y: } \\
\text { - Riesgo tromboembólico alto (historia de embolias sistémicas, } \\
\text { contraste denso espontáneo en la AI, fibrilación auricular } \\
\text { de nueva aparición o paroxística) o } \\
\text { - Alto riesgo de descompensación hemodinámica (presión } \\
\text { pulmonar sistólica en reposo > } 50 \text { mmHg, necesidad } \\
\text { de cirugía no cardiaca mayor, deseo de gestar) }\end{array}$ & Ila & C \\
\hline
\end{tabular}

AI: aurícula izquierda; CMP: comisurotomía mitral percutánea.

${ }^{a}$ Clase de recomendación.

bNivel de evidencia.

Las características desfavorables para la CMP pueden definirse por varias de las siguientes características. Características clínicas: edad avanzada, historia de comisurotomía, NYHA IV, fibrilación auricular permanente e hipertensión pulmonar grave. Características anatómicas: escala ecocardiográfica $>8$, escala Cormier 3 (calcificación de válvula mitral de cualquier grado determinada por fluoroscopia), área valvular mitral muy pequeña e insuficiencia tricuspídea grave. Para la definición de las escalas, consulte la tabla 9.
Tabla 8

Contraindicaciones para la comisurotomía mitral percutánea*

\begin{tabular}{l} 
Contraindicaciones \\
\hline Área valvular mitral* $>1,5 \mathrm{~cm}^{2}$ \\
\hline Trombo en aurícula izquierda \\
\hline Insuficiencia mitral mayor que leve \\
\hline Calcificación grave o bicomisural \\
\hline Ausencia de fusión comisural \\
\hline Valvulopatía aórtica grave concomitante o estenosis e insuficiencia tricuspídea \\
graves combinadas que requieren cirugía \\
\hline EAC concomitante que requiere cirugía de revascularización coronaria
\end{tabular}

CMP: comisurotomía mitral percutánea; EAC: enfermedad arterial coronaria.

*Puede considerarse la CMP para pacientes con un área valvular $>1,5 \mathrm{~cm}^{2}$ y síntomas que no pueden explicarse por otra causa siempre que la anatomía sea favorable.

apéndice de la AI, la CMP puede considerarse para pacientes que no requieran una intervención urgente, siempre que la ETE muestre que el trombo ha desaparecido 1-3 meses después de la administración de anticoagulación oral. La cirugía está indicada si el trombo persiste.

\subsection{Tratamiento médico}

El tratamiento con diuréticos, bloqueadores beta, digitálicos o bloqueadores de los canales del calcio que regulan la frecuencia cardiaca puede mejorar los síntomas temporalmente. La anticoagulación, con un cociente internacional normalizado (INR) entre 2 y 3 , está indicada para pacientes con FA de nueva aparición o paroxística.

En pacientes en ritmo sinusal, la anticoagulación oral está indicada si hay antecedentes de embolia sistémica o cuando se localicen trombos en la AI (recomendación de clase I, nivel de evidencia C) y también se debe considerar cuando la ETE muestre una concentración densa y espontánea de contraste o dilatación de la $\mathrm{AI}$ (diámetro en modo $\mathrm{M}>50 \mathrm{~mm}$ o volumen de la $\mathrm{AI}>60 \mathrm{ml} / \mathrm{m}^{2}$; recomendación de clase IIa, nivel de evidencia C). Los pacientes con estenosis mitral grave y FA persistente deben recibir tratamiento mantenido con antagonistas de la vitamina K (AVK) y evitar el uso de NACO.

La cardioversión no está indicada antes de la intervención en pacientes con estenosis mitral grave, ya que normalmente no restablece el ritmo sinusal de modo duradero. Si la FA ha comenzado recientemente y la AI solo está moderadamente aumentada, la cardioversión debe realizarse pronto tras una intervención con éxito.

\subsection{Pruebas seriadas}

Los pacientes asintomáticos con estenosis mitral clínicamente significativa que no han sido intervenidos deben pasar por un seguimiento cada año mediante exámenes clínicos y ecocardiográficos y a intervalos más largos (2-3 años) cuando la estenosis sea moderada.

El tratamiento de los pacientes después de una CMP eficaz es similar al de los pacientes asintomáticos. El seguimiento debe ser más frecuente si se produce una reestenosis asintomática. Cuando la CMP sea fallida, debe considerarse la cirugía temprana siempre que no haya contraindicaciones.

\subsection{Grupos especiales de pacientes}

Cuando se produce una reestenosis sintomática después de la comisurotomía quirúrgica o CMP, la reintervención en la mayoría de los casos requiere reemplazo valvular, aunque la CMP se puede considerar para algunos pacientes seleccionados con características favorables y cuando el mecanismo predominante de la reestensosis sea la refusión comisural ${ }^{151}$. 
Tabla 9

Métodos ecocardiográficos de puntuación: Wilkins ${ }^{145}$, Cormier $^{150}$ y Echo Score Revisited, de Nunes et al. ${ }^{146}$

\begin{tabular}{|c|c|c|c|c|}
\hline \multicolumn{5}{|c|}{ Evaluación de la anatomía de la válvula mitral mediante la escala de Wilkins ${ }^{145}$} \\
\hline Grado & Movilidad & Engrosamiento & Calcificación & Engrosamiento subvalvular \\
\hline 1 & $\begin{array}{l}\text { Válvula con movilidad alta y } \\
\text { restricción únicamente en los } \\
\text { extremos de las valvas }\end{array}$ & $\begin{array}{l}\text { Valvas con grosor casi normal } \\
(4-5 \mathrm{~mm})\end{array}$ & $\begin{array}{l}\text { Una sola área de brillo } \\
\text { ecocardiográfico aumentado }\end{array}$ & $\begin{array}{l}\text { Engrosamiento mínimo justo debajo } \\
\text { de las valvas mitrales }\end{array}$ \\
\hline 2 & $\begin{array}{l}\text { Las zonas media y basal de las valvas } \\
\text { tienen movilidad normal }\end{array}$ & $\begin{array}{l}\text { La zona media de las valvas es normal, } \\
\text { con engrosamiento considerable en los } \\
\text { márgenes }(5-8 \mathrm{~mm})\end{array}$ & $\begin{array}{l}\text { Áreas dispersas de brillo confinadas } \\
\text { en los márgenes de las valvas }\end{array}$ & $\begin{array}{l}\text { Engrosamiento de las cuerdas } \\
\text { tendinosas que se extiende hasta un } \\
\text { tercio de la longitud cordal }\end{array}$ \\
\hline 3 & $\begin{array}{l}\text { La válvula sigue moviéndose adelante } \\
\text { en diástole, principalmente desde la } \\
\text { base }\end{array}$ & $\begin{array}{l}\text { Engrosamiento que se extiende } \\
\text { por toda la valva }(5-8 \mathrm{~mm})\end{array}$ & $\begin{array}{l}\text { Brillo que alcanza las zonas medias } \\
\text { de las valvas }\end{array}$ & $\begin{array}{l}\text { Engrosamiento que se extiende } \\
\text { hasta el tercio distal de las cuerdas }\end{array}$ \\
\hline 4 & $\begin{array}{l}\text { Movimiento mínimo o nulo de las } \\
\text { valvas en diástole }\end{array}$ & $\begin{array}{l}\text { Engrosamiento considerable de todo el } \\
\text { tejido de la valva }(>8-10 \mathrm{~mm})\end{array}$ & $\begin{array}{l}\text { Brillo extenso en gran parte del tejido } \\
\text { de la valva }\end{array}$ & $\begin{array}{l}\text { Engrosamiento extenso y } \\
\text { acortamiento de todas las estructuras } \\
\text { cordales que se extiende hasta los } \\
\text { músculos papilares }\end{array}$ \\
\hline
\end{tabular}

La puntuación total es la suma de 4 componentes y varía de 4 a 16

Evaluación de la anatomía de la válvula mitral mediante la escala de Cormier ${ }^{150}$

Grupo ecocardiográfico

Grupo 1

Grupo 2

Grupo 3

Echo Score Revisited, de Nunes et al. ${ }^{146}$

Variables ecocardiográficas

Área valvular mitral $\leq 1 \mathrm{~cm}^{2}$

Desplazamiento máximo de valvas $\leq 12 \mathrm{~mm}$

Cociente del área comisural $\geq 1,25$

Afección subvalvular

Anatomía de la válvula mitral

Valva mitral anterior flexible y no calcificada y enfermedad subvalvular leve

(p. ej., cuerdas tendinosas delgadas de longitud $\geq 10 \mathrm{~mm}$ )

Valva mitral anterior flexible y no calcificada y enfermedad subvalvular grave (p. ej., cuerdas tendinosas engrosadas de longitud $<10 \mathrm{~mm}$ )

Calcificación de la válvula mitral en mayor o menor grado, determinada por fluoroscopia, independientemente del estado del aparato subvalvular

Grupos de riesgo según Echo Score Revisited: riesgo bajo (puntuación 0-3); riesgo intermedio (puntuación 4-5); riesgo alto (puntuación 6-11).

Para los pacientes ancianos con estenosis mitral reumática y riesgo quirúrgico alto, la CMP es una opción útil, aunque solo sea paliativa. Para otros pacientes ancianos, es preferible la cirugía ${ }^{146,148,149}$. No obstante, en este grupo de pacientes con estenosis mitral degenerativa y calcificación grave del anillo mitral, la cirugía presenta un riesgo muy alto. Dado que en estos casos no hay fusión comisural, la estenosis mitral degenerativa no se puede tratar mediante $\mathrm{CMP}^{143}$. Si la estenosis mitral degenerativa es grave, un estudio preliminar indica que es factible el TAVI en posición mitral para los pacientes ancianos sintomáticos considerados inoperables si la anatomía es adecuada ${ }^{152}$.

Para los pacientes con estenosis mitral grave combinada con valvulopatía aórtica grave, es preferible la cirugía siempre que no esté contraindicada. El tratamiento de los pacientes con contraindicaciones para la cirugía es complejo y requiere una evaluación completa e individualizada por el equipo cardiológico.

En los casos de estenosis mitral grave combinada con valvulopatía aórtica moderada, puede realizarse una CMP con el objetivo de posponer el tratamiento quirúrgico de ambas válvulas.

Para los pacientes con insuficiencia tricuspídea grave, puede considerarse la CMP en pacientes seleccionados que estén en ritmo sinusal y presenten un aumento auricular moderado e insuficiencia tricuspídea funcional secundaria a hipertensión pulmonar. En otros casos es preferible la cirugía de las 2 válvulas ${ }^{153}$.

El reemplazo valvular es la única opción de tratamiento para los casos raros de estenosis mitral grave de origen distinto del reumático sin fusión comisural.

\section{Puntos clave}

- La mayoría de los pacientes con estenosis mitral grave y una anatomía valvular favorable reciben tratamiento con CMP.

- La toma de decisiones sobre el tipo de intervención en pacientes con anatomía desfavorable sigue suscitando debate y debe tener en cuenta la naturaleza multifactorial de la predicción de los resultados de la CMP.

\section{Lagunas en la evidencia}

- Es preciso mejorar los métodos de predicción de resultados y complicaciones de la CMP, especialmente en relación con la insuficiencia mitral grave.

- El papel potencial del implante percutáneo de válvula mitral en pacientes de alto riesgo está por determinar, particularmente en los pacientes con estenosis mitral degenerativa grave.

\section{INSUFICIENCIA TRICUSPÍDEA}

La insuficiencia tricuspídea patológica suele ser secundaria a la disfunción del VD que se produce por una sobrecarga de presión o volumen en presencia de valvas estructuralmente normales ${ }^{2}$. Entre las causas posibles de la insuficiencia tricuspídea primaria, se encuentran la endocarditis infecciosa (especialmente en adictos a drogas intravenosas $)^{154}$, la enfermedad cardiaca reumática, el síndrome carci- 
noide, la enfermedad mixomatosa, la fibrosis endomiocárdica, la anomalía de Ebstein y la displasia valvular congénita, las valvulopatías inducidas por fármacos, el traumatismo torácico y el daño valvular iatrogénico.

\subsection{Evaluación}

La ecocardiografía es la técnica ideal para evaluar la insuficiencia tricuspídea. En la insuficiencia tricuspídea primaria, normalmente la etiología puede identificarse a partir de anomalías específicas de la estructura valvular ${ }^{28,115}$. En la insuficiencia tricuspídea secundaria, debe medirse el grado de dilatación del anillo, la dimensión y la función del VD y el grado de deformación de la válvula². La evaluación de la gravedad de la insuficiencia tricuspídea (integración de múltiples parámetros cualitativos y cuantitativos) y de la presión pulmonar sistólica debe realizarse según las recomendaciones actuales (tabla 4$)^{2}$. Hay que señalar que la elevación de la resistencia vascular pulmonar puede estar enmascarada en presencia de insuficiencia tricuspídea grave, ya que la velocidad puede ser menor que la esperada en los casos de hipertensión pulmonar.

A pesar de las limitaciones actuales de los índices de función del $\mathrm{VD}$, deben evaluarse sus dimensiones y su función ${ }^{53}$. Asimismo hay que evaluar la concomitancia de lesiones (examen meticuloso de lesiones valvulares concomitantes, particularmente en el lado izquierdo) y la función del VI.

En laboratorios con experiencia, puede considerarse la medición tridimensional de los volúmenes del VD, que podrían ser similares a los obtenidos mediante RMC ${ }^{155}$. No obstante, la RMC, si está disponible, es el método preferido para la evaluación del tamaño y la función del VD y es la técnica de referencia para evaluar los volúmenes y la función del VD ${ }^{155}$.

El cateterismo cardiaco no es necesario para el diagnóstico de insuficiencia tricuspídea o para estimar su gravedad, pero se debe practicar a los pacientes para quienes se esté considerando la cirugía solo de válvula tricúspide para evaluar los parámetros hemodinámicos, en particular la resistencia vascular pulmonar.

\subsection{Indicaciones de la intervención}

Decidir el mejor momento para la intervención quirúrgica sigue siendo controvertido, debido a los pocos datos disponibles y su naturaleza heterogénea (véanse la tabla de recomendaciones sobre las indicaciones de cirugía de válvula tricúspide y la figura 6) ${ }^{156-160}$. Para evitar una disfunción irreversible del VD, la cirugía debe realizarse pronto.

En la insuficiencia tricuspídea primaria grave, la cirugía está recomendada no solo para los pacientes sintomáticos, sino que también se debe considerar para los pacientes asintomáticos si se observa una dilatación progresiva o una disminución de la función del VD. Aunque estos pacientes suelen responder bien al tratamiento diurético, el retraso de la cirugía puede producir un daño irreversible del VD, fallo orgánico y peores resultados de la intervención quirúrgica tardía.

En la insuficiencia tricuspídea secundaria, la combinación de reparación de la válvula, si está indicada, con la cirugía de lado izquierdo no aumenta el riesgo quirúrgico y se ha demostrado que puede favorecer el remodelado inverso del VD y mejorar el estado funcional, incluso en ausencia de insuficiencia tricuspídea significativa si hay dilatación del anillo ${ }^{156,157,160}$. Por lo tanto, debe considerarse sistemáticamente en estos casos.

La reoperación de la válvula tricúspide en los casos de insuficiencia tricuspídea persistente tras la cirugía de válvula mitral implica alto riesgo, fundamentalmente debido a una indicación tardía del tratamiento y, consecuentemente, a un peor estado clínico de los pacientes. Para mejorar el pronóstico de los pacientes en esta situación compleja, debe considerarse con más antelación el tratamiento de la insuficiencia tricuspídea grave tardía tras la cirugía valvular izquierda, incluso para pacientes asintomáticos si hay signos de dilatación progresiva o deterioro funcional del VD, en ausencia de disfunción valvular izquierda, disfunción grave del VD o el VI y enfermedad vascular pulmonar o hipertensión pulmonar graves.

Si es posible, la reparación valvular es preferible al reemplazo valvular. La anuloplastia, preferiblemente con prótesis anular, es clave para la cirugía en la insuficiencia tricuspídea secundaria ${ }^{156,161}$. Debe considerarse el reemplazo valvular cuando haya un engrosamiento significativo de las valvas y dilatación anular grave. En presencia de electrodos de marcapasos en la región transtricuspídea, la técnica quirúrgica debe adaptarse al estado del paciente y la experiencia del cirujano. Por el momento se están dando los primeros pasos en técnicas percutáneas de reparación valvular que aún hay que evaluar antes de que puedan establecerse recomendaciones.

Indicaciones para la cirugía de válvula tricúspide

\begin{tabular}{|c|c|c|}
\hline Recomendaciones & Clase $^{\mathrm{a}}$ & Nivel $^{\text {b }}$ \\
\hline \multicolumn{3}{|l|}{ Recomendaciones en la estenosis tricuspídea } \\
\hline $\begin{array}{l}\text { La cirugía está indicada para pacientes sintomáticos } \\
\text { con estenosis tricuspídea grave }{ }^{c}\end{array}$ & I & $\mathrm{C}$ \\
\hline $\begin{array}{l}\text { La cirugía está indicada para pacientes con estenosis } \\
\text { tricuspídea grave que van a someterse a una intervención } \\
\text { de válvula izquierda }^{d}\end{array}$ & I & C \\
\hline \multicolumn{3}{|l|}{ Recomendaciones en la insuficiencia tricuspídea primaria } \\
\hline $\begin{array}{l}\text { La cirugía está indicada para pacientes con insuficiencia } \\
\text { tricuspídea primaria grave que van a someterse a una } \\
\text { intervención de válvula izquierda }\end{array}$ & I & $\mathrm{C}$ \\
\hline $\begin{array}{l}\text { La cirugía está indicada para pacientes sintomáticos con } \\
\text { insuficiencia tricuspídea primaria grave aislada sin disfunción } \\
\text { grave del VD }\end{array}$ & I & $\mathrm{C}$ \\
\hline $\begin{array}{l}\text { Debe considerarse la cirugía para pacientes con insuficiencia } \\
\text { tricuspídea primaria moderada que van a someterse a cirugía } \\
\text { de válvula izquierda }\end{array}$ & Ila & $\mathrm{C}$ \\
\hline $\begin{array}{l}\text { Debe considerarse la cirugía para pacientes asintomáticos o } \\
\text { con síntomas leves de insuficiencia tricuspídea primaria grave } \\
\text { aislada y dilatación progresiva o deterioro de la función } \\
\text { del VD }\end{array}$ & Ila & $\mathrm{C}$ \\
\hline
\end{tabular}

Recomendaciones en la insuficiencia tricuspídea secundaria

La cirugía está indicada para pacientes con insuficiencia tricuspídea secundaria grave que van a someterse a cirugía de válvula izquierda

Debe considerarse la cirugía para pacientes con insuficiencia tricuspídea secundaria de leve a moderada con anillo dilatado ( $\geq 40 \mathrm{~mm}$ o $21 \mathrm{~mm} / \mathrm{m}^{2}$ determinado por ecocardiografía bidimensional) que van a someterse a cirugía de válvula izquierda

Debe considerarse la cirugía para pacientes con insuficiencia tricuspídea secundaria de leve a moderada que van a someterse a cirugía de válvula izquierda, incluso en ausencia de dilatación anular si se ha documentado recientemente insuficiencia de corazón derecho

Después de la cirugía de válvula izquierda y en ausencia de disfunción valvular izquierda recurrente, debe considerarse la cirugía para pacientes con insuficiencia tricuspídea grave que están sintomáticos o tienen dilatación/disfunción progresiva del VD o disfunción del VI y enfermedad vascular pulmonar/ hipertensión pulmonar graves

CMP: comisurotomía mitral percutánea; VD: ventrículo derecho; VI: ventrículo izquierdo.

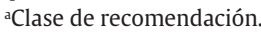

bNivel de evidencia.

cPuede intentarse una valvuloplastia percutánea con balón como primer abordaje si la estenosis tricuspídea es aislada.

dPuede intentarse una valvuloplastia percutánea con balón si se puede realizar una CMP en la válvula mitral. 


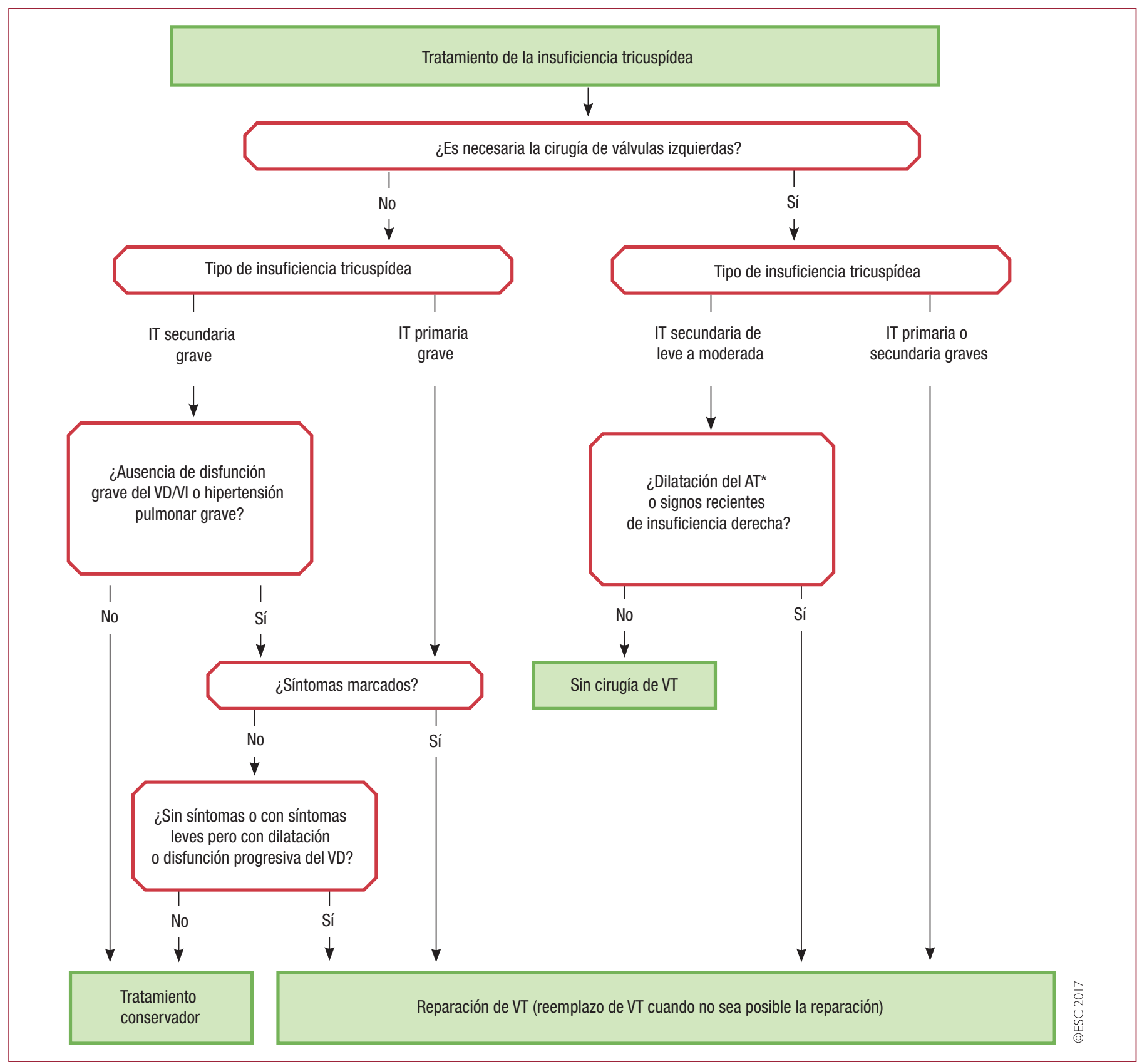

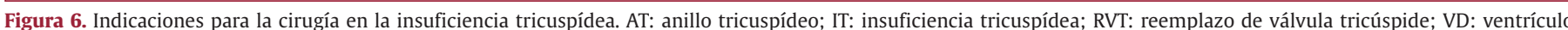
derecho; VI: ventrículo izquierdo; VT: válvula tricúspide.

${ }^{*} \mathrm{AT} \geq 40 \mathrm{~mm}$ o $>21 \mathrm{~mm} / \mathrm{m}^{2}$.

\section{ESTENOSIS TRICUSPÍDEA}

La estenosis tricuspídea suele aparecer combinada con insuficiencia tricuspídea y en la mayoría de los casos es de origen reumático. Por ello, prácticamente siempre se relaciona con lesiones de válvulas izquierdas, particularmente con estenosis mitral, que suele dominar la presentación clínica. Es raro que se produzca por otras causas, como valvulopatías congénitas o inducidas por fármacos, enfermedad de Whipple, endocarditis o tumores grandes en la aurícula derecha.

\subsection{Evaluación}

La ecocardiografía es la técnica que aporta la información más útil. La estenosis tricuspídea suele estar enmascarada y requiere una eva- luación meticulosa. Es importante evaluar la anatomía valvular y el aparato subvalvular mediante ecocardiografía para determinar la posibilidad de reparación de la válvula. Aunque no existe una clasificación aceptada universalmente para definir la gravedad de la estenosis tricuspídea, un gradiente medio $\geq 5 \mathrm{mmHg}$ con una frecuencia cardiaca normal se considera indicativo de estenosis tricuspídea clínicamente significativa ${ }^{3}$. El cateterismo cardiaco ha dejado de utilizarse para evaluar la gravedad de la estenosis tricuspídea.

\subsection{Indicaciones de la intervención}

La ausencia de tejido flexible de las valvas es la limitación más importante para la reparación valvular. Aunque sigue siendo una cuestión controvertida, se suele preferir las prótesis biológicas para el 
reemplazo valvular en lugar de prótesis mecánicas, debido al alto riesgo de trombosis de estas y la duración satisfactoria a largo plazo de las primeras en posición tricuspídea ${ }^{162}$.

En un pequeño número de casos, se ha practicado la dilatación percutánea con balón de la válvula tricuspídea, ya sea sola o combinada con CMP, pero frecuentemente esta opción induce insuficiencia significativa. No se dispone de datos sobre sus resultados a largo plazo ${ }^{163}$.

La intervención de la válvula tricúspide se suele llevar a cabo al mismo tiempo que la intervención de otras válvulas en pacientes que siguen sintomáticos a pesar del tratamiento médico. La elección entre la reparación o el reemplazo valvular depende de la anatomía de la válvula y la experiencia del cirujano. Puede considerarse la comisurotomía con balón en los pocos casos de válvulas anatómicamente adecuadas con estenosis tricuspídea aislada o cuando la estenosis mitral también se puede tratar mediante intervención (véase en el apartado 7.2 la tabla de indicaciones para CMP y cirugía mitral en la estenosis mitral clínicamente significativa).

\subsection{Tratamiento médico}

En presencia de insuficiencia cardiaca, los diuréticos son útiles, pero tienen poca eficacia a largo plazo.

\section{Puntos clave}

- La estenosis tricuspídea es una enfermedad rara, mientras que la insuficiencia tricuspídea es más común, especialmente en su forma secundaria.

- Para determinar el tratamiento adecuado, hay que diferenciar claramente la insuficiencia tricuspídea secundaria de la primaria.

- Al igual que en la insuficiencia mitral, la insuficiencia tricuspídea primaria requiere la intervención en una fase temprana para evitar el daño secundario del VD, el cual se asocia con mal pronóstico.

- En la mayoría de los casos, la insuficiencia tricuspídea secundaria debe tratarse al mismo tiempo que la cirugía de válvulas izquierdas.

- Cuando se considere la cirugía aislada de la insuficiencia tricuspídea secundaria después de cirugía valvular izquierda, hay que evaluar detenidamente la enfermedad subyacente, las condiciones hemodinámicas pulmonares y la función del VD.

\section{Lagunas en la evidencia}

- Es preciso mejorar los criterios para decidir el momento más adecuado para la cirugía en la insuficiencia tricuspídea primaria.

- Es preciso mejorar los criterios para la indicación de cirugía concomitante de válvula tricúspide en el momento de la cirugía valvular izquierda de pacientes sin valvulopatía tricuspídea grave.

- Sigue siendo necesario determinar la utilidad potencial del tratamiento percutáneo de la válvula tricúspide en pacientes con alto riesgo.

\section{VALVULOPATÍAS COMBINADAS Y MÚLTIPLES}

Se puede encontrar en la misma válvula estenosis e insuficiencia significativas. La valvulopatía múltiple puede darse en distintas enfermedades, especialmente en las cardiopatías reumáticas y congénitas, pero también en la valvulopatía degenerativa. Debido a la falta de datos sobre las valvulopatías combinadas o múltiples, no se pueden establecer recomendaciones basadas en la evidencia ${ }^{164}$. Los principios generales para el tratamiento de valvulopatías combinadas o múltiples son los siguientes:

- Cuando la estenosis o la insuficiencia sean la enfermedad predominante, el tratamiento debe seguir las recomendaciones sobre la valvulopatía predominante. Cuando la gravedad de la estenosis y la insuficiencia estén equilibradas, las indicaciones para la intervención deben basarse en los síntomas y las consecuencias objetivas, en lugar de en los índices de gravedad de una u otra. En este contexto, la valoración del gradiente de presión, que refleja la carga hemodinámica que la lesión valvular está soportando, es más importante que el área valvular y las mediciones de la insuficiencia que se realizan para determinar la gravedad de la enfermedad.

- Además de evaluar por separado cada lesión valvular, es necesario tener en cuenta la interacción entre distintas lesiones valvulares. Como ejemplo de ello, la insuficiencia mitral concomitante puede llevar a que se subestime la gravedad de la estenosis aórtica, ya que la disminución del volumen del latido debida a la insuficiencia mitral disminuye el flujo a través de la válvula aórtica y, por lo tanto, reduce también el gradiente aórtico. Esto subraya la necesidad de combinar distintas mediciones, que incluyan la evaluación de las áreas valvulares y, siempre que sea posible, con los métodos menos dependientes de las condiciones de carga, como la planimetría.

- Las indicaciones de la intervención se basan en la evaluación general de las consecuencias de las distintas lesiones valvulares (p. ej., los síntomas o la presencia de dilatación o disfunción del VI). Puede considerarse la intervención de lesiones múltiples que no son graves pero están asociadas con los síntomas o pueden llevar a deterioro del VI.

- La decisión de intervenir varias válvulas debe tener en cuenta el riesgo quirúrgico adicional de los procedimientos combinados.

- En la elección de la técnica quirúrgica, se debe valorar la presencia de otras valvulopatías; la reparación valvular sigue siendo la opción preferible. El tratamiento de combinaciones específicas de valvulopatías se trata en los apartados correspondientes de este documento.

\section{Puntos clave}

- En las valvulopatías combinadas, la enfermedad se considera grave incluso cuando la estenosis y la insuficiencia solo presentan una gravedad moderada; en estos casos, los gradientes de presión son muy importantes para la evaluación.

- El tratamiento de la valvulopatía múltiple está dictado por la valvulopatía predominante.

\section{Lagunas en la evidencia}

- Son necesarios más datos sobre la historia natural y el impacto de las intervenciones en los resultados para definir mejor las indicaciones de intervención.

\section{VÁLVULAS PROTÉSICAS}

El implante de cualquier prótesis valvular marca el inicio de un nuevo proceso en la evolución de la enfermedad. En la práctica, la elección se dirime entre una válvula biológica o una mecánica. Los estudios aleatorizados que compararon ambos tipos de prótesis mostraron tasas similares de supervivencia, sin diferencias significativas en las tasas de trombosis y tromboembolia, tasas de hemorragia más elevadas con las prótesis mecánicas y tasas de reintervención más elevadas con las bioprótesis ${ }^{165-167}$.

\subsection{Elección de la válvula protésica}

La elección entre una válvula mecánica y una biológica para adultos se determina fundamentalmente considerando los riesgos de hemorragia relacionada con la anticoagulación y tromboembolia de las válvulas mecánicas frente al riesgo de deterioro estructural de las 
Elección de una prótesis aórtica o mitral favoreciendo el uso de prótesis mecánicas. La decisión se basa en la integración de varios de los siguientes factores

\begin{tabular}{|c|c|c|}
\hline Recomendaciones & Clase $^{\mathrm{a}}$ & Nivel ${ }^{\mathrm{b}}$ \\
\hline $\begin{array}{l}\text { Se recomienda el implante de una prótesis mecánica de acuerdo con el deseo del paciente bien informado, siempre que no haya contraindicaciones para la } \\
\text { anticoagulación a largo plazoc }\end{array}$ & I & $\mathrm{C}$ \\
\hline Se recomienda el implante de una prótesis mecánica en pacientes con riesgo de deterioro estructural de la válvula acelerado ${ }^{d}$ & I & $\mathrm{C}$ \\
\hline $\begin{array}{l}\text { Debe considerarse el implante de una válvula mecánica en pacientes con tratamiento anticoagulante debido a la presencia de una prótesis mecánica } \\
\text { en otra posición valvular }\end{array}$ & IIa & $\mathrm{C}$ \\
\hline Debe considerarse el implante de una prótesis mecánica en pacientes menores de 60 años para prótesis aórtica y de 65 años para prótesis mitrale & IIa & $\mathrm{C}$ \\
\hline $\begin{array}{l}\text { Debe considerarse el implante de una prótesis mecánica en pacientes con una esperanza de vida razonable para los que una reoperación valvular en el } \\
\text { futuro sería de alto riesgo }\end{array}$ & IIa & $\mathrm{C}$ \\
\hline $\begin{array}{l}\text { Puede considerarse el implante de una prótesis mecánica en pacientes que reciben tratamiento anticoagulante indefinidamente debido al alto riesgo } \\
\text { de tromboembolias }\end{array}$ & IIb & $\mathrm{C}$ \\
\hline
\end{tabular}

VI: ventrículo izquierdo.

aClase de recomendación.

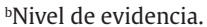

cRiesgo hemorrágico aumentado debido a comorbilidades, falta de adherencia al tratamiento y condiciones geográficas, ocupacionales o estilo de vida.

dEdad joven ( $<40$ años), hiperparatiroidismo.

ePara los pacientes de 60-65 años que requieren una prótesis aórtica y pacientes de 65-70 años en caso de prótesis mitral, ambas válvulas son aceptables y la elección requiere que se analicen detenidamente otros factores distintos de la edad.

fLa esperanza de vida debe estimarse a más de 10 años según la edad, el sexo, las comorbilidades y la esperanza de vida específica del país.

gLos factores de riesgo de tromboembolias son fibrilación auricular, tromboembolia previa, estado de hipercoagulación y disfunción sistólica grave del VI.

Elección de prótesis aórtica o mitral favoreciendo el uso de bioprótesis. La decisión se basa en la integración de varios de los siguientes factores

\begin{tabular}{|c|c|c|}
\hline Recomendaciones & Clase $^{\mathrm{a}}$ & Nivel $^{\mathrm{b}}$ \\
\hline Se recomienda una bioprótesis de acuerdo con el deseo del paciente bien informado & I & $\mathrm{C}$ \\
\hline $\begin{array}{l}\text { Se recomienda una bioprótesis cuando una anticoagulación de buena calidad sea improbable (por problemas de adherencia, falta de disponibilidad) o } \\
\text { esté contraindicada debido a un riesgo alto (hemorragia mayor previa, comorbilidades, negación del paciente, problemas de adherencia, estilo de vida, } \\
\text { ocupación) }\end{array}$ & I & C \\
\hline $\begin{array}{l}\text { Se recomienda una bioprótesis en casos de reoperación por trombosis de prótesis valvular mecánica a pesar de un buen control de la anticoagulación } \\
\text { a largo plazo }\end{array}$ & I & C \\
\hline Debe considerarse el implante de una bioprótesis en pacientes con baja probabilidad o bajo riesgo quirúrgico de una futura reoperación valvular & Ila & C \\
\hline Debe considerarse el implante de una bioprótesis para mujeres jóvenes que prevean gestar & IIa & C \\
\hline $\begin{array}{l}\text { Debe considerarse el implante de una bioprótesis para los pacientes mayores de } 65 \text { años si es en posición aórtica o mayores de } 70 \text { si es en posición mitral } \\
\text { o para pacientes con una esperanza de vidac más corta que la durabilidad estimada de la bioprótesis }{ }^{d}\end{array}$ & IIa & $C$ \\
\hline
\end{tabular}

aClase de recomendación.

bNivel de evidencia.

'La esperanza de vida debe estimarse según la edad, el sexo, las comorbilidades y la esperanza de vida específica del país.

dPara pacientes de 60-65 años que requieran una prótesis aórtica y pacientes de 65-70 años en caso de prótesis mitral, ambas válvulas son aceptables y la elección requiere que se analicen detenidamente otros factores distintos de la edad.

bioprótesis, además de tener en cuenta el estilo de vida y las preferencias del paciente. Más que establecer límites arbitrarios de edad, la elección de la prótesis se debe discutir en detalle con el paciente bien informado, los cardiólogos y los cirujanos, teniendo en cuenta los factores que se enumeran a continuación (véanse las tablas de recomendaciones en el apartado 11.1). Debe considerarse el implante de una bioprótesis para los pacientes cuya esperanza de vida sea más corta que la durabilidad previsible de la bioprótesis, especialmente si pudiesen ser necesarios otros procedimientos quirúrgicos debido a la presencia de comorbilidades, y para los pacientes con alto riesgo hemorrágico. En el caso de mujeres que deseen gestar, el alto riesgo de complicaciones tromboembólicas con las prótesis mecánicas durante la gestación y el bajo riesgo de la reoperación electiva son incentivos para considerar el implante de una bioprótesis, pese a la pronta aparición de deterioro estructural de la válvula en este grupo de edad.

\subsection{Tratamiento después de la intervención valvular}

La tromboembolia y las hemorragias debidas a la anticoagulación representan la mayoría de las complicaciones que padecen los recep- tores de válvulas protésicas. La profilaxis y el tratamiento de la endocarditis se detallan en la guía específica de la ESC ${ }^{28}$.

\subsubsection{Evaluación basal y modalidades de seguimiento}

Después de la cirugía valvular, todos los pacientes requieren seguimiento cardiológico durante el resto de la vida para detectar el deterioro precoz de la función protésica o ventricular o la progresión de la enfermedad en otra válvula cardiaca. El seguimiento clínico debe tener lugar cada año o tan pronto como sea posible si aparecen nuevos síntomas cardiacos. Debe realizarse un estudio por ETT en caso de nuevos síntomas tras el reemplazo valvular o si se sospechan posibles complicaciones. Tras el implante transcatéter o quirúrgico de una bioprótesis, debe realizarse un estudio ecocardiográfico que incluya la medición de gradientes transprotésicos en los primeros 30 días para obtener imágenes basales (preferiblemente a los 30 días para la cirugía), otro estudio 1 año después del implante y, a partir de entonces, un seguimiento anual ${ }^{168}$. Debe considerarse la ETE si las imágenes de ETT son de baja calidad y en todos los casos de sospecha de disfunción protésica o endocarditis ${ }^{169,170}$. La fluoroscopia para válvulas mecánicas 
y la TCMC proporcionan información útil si se sospecha que la función valvular puede estar afectada por un trombo o un paño valvular ${ }^{170}$.

\subsubsection{Tratamiento antitrombótico}

\subsubsection{Tratamiento general}

El tratamiento antitrombótico debe incluir tanto el control efectivo de los factores de riesgo de tromboembolia como la prescripción de fármacos antitrombóticos ${ }^{171}$. Las indicaciones para el tratamiento antitrombótico tras la reparación o el reemplazo valvular se resumen en la tabla de recomendaciones.

Para los pacientes con bioprótesis aórtica quirúrgica, se favorece la administración de dosis bajas de ácido acetilsalicílico (AAS) como alternativa al tratamiento anticoagulante posoperatorio, aunque esta opción se basa en pruebas científicas insuficientes ${ }^{42,172,173}$.

Cuando esté indicada la anticoagulación posoperatoria, la anticoagulación oral debe iniciarse en los primeros días tras la intervención. La heparina no fraccionada (HNF) intravenosa, monitorizada a un tiempo de tromboplastina parcial activado (TTPa) de 1,5-2,0 veces el valor de control, permite una anticoagulación rápida que debe activarse antes de la elevación del INR ${ }^{42}$. La heparina de bajo peso molecular (HBPM) parece que puede ofrecer una anticoagulación efectiva y estable, y se ha empleado en series observacionales, sobre todo la enoxaparina ${ }^{174,175}$. Este uso de la heparina no se describe en las indicaciones aprobadas.

El primer mes del posoperatorio es un periodo de alto riesgo de tromboembolia. La adición de AAS al tratamiento anticoagulante disminuye este riesgo, pero aumenta el de hemorragia y no se puede recomendar su uso sitemático ${ }^{176}$.

Debe favorecerse el uso de AVK cuando un paciente con bioprótesis requiera anticoagulación indefinidamente. Pese a la ausencia de datos de estudios clínicos, los NACO pueden emplearse en pacientes con FA asociada con una bioprótesis, después del tercer mes del posoperatorio ${ }^{43}$. No hay datos que respalden el uso del tratamiento antiagregante después de 3 meses para pacientes con bioprótesis quirúrgicas sin otra indicación que no sea la propia bioprótesis.

La combinación de dosis bajas de AAS y una tienopiridina se usa normalmente después del TAVI, seguida de AAS o una tienopiridina sola para los pacientes sin otra indicación para la anticoagulación oral. Datos recientes indican que el tratamiento con un antiagregante puede tener un mejor perfil de seguridad que el tratamiento antiagregante plaquetario doble (TAPD) después del TAVI ${ }^{177}$. Según datos de estudios observacionales, el tratamiento anticoagulante reduce la incidencia de trombosis subclínica, comparado con el TAPD ${ }^{178}$. Es necesario esperar a los resultados de estudios a gran escala actualmente en curso para disponer de más evidencia en este campo.

\subsubsection{Objetivo de cociente internacional normalizado (INR)}

El objetivo de INR debe adaptarse a los factores de riesgo de los pacientes y la trombogenicidad de las prótesis (tabla 10) ${ }^{171}$. Algunos estudios aleatorizados recientes respaldan el uso de objetivos de INR más bajos en el caso de las prótesis aórticas ${ }^{186-188}$. Sin embargo, debido a su escasa potencia estadística, algunos problemas metodológicos y la restricción a ciertas prótesis o el control del INR por el propio paciente, este Grupo de Trabajo no ha cambiado las recomendaciones sobre el objetivo de INR.

Se recomienda el uso de un valor medio de INR en lugar de un intervalo de valores, para evitar que se consideren objetivos de INR válidos unos valores extremos dentro del intervalo objetivo. La alta variabilidad del INR es un fuerte predictor independiente de una reducción de la supervivencia tras el reemplazo valvular. Se han publicado nuevos datos que indican que el autocontrol del INR reduce su variabilidad y la incidencia de eventos clínicos, incluidos los pacientes con prótesis valvulares cardiacas ${ }^{181}$; sin embargo, serían
Tabla 10

Objetivo de INR para las prótesis mecánicas

\begin{tabular}{lcc}
\hline \multirow{2}{*}{ Trombogenicidad de la prótesis } & Factores de riesgo relacionados con el paciente \\
\cline { 2 - 3 } & Ninguno & $\geq 1$ factor de riesgo \\
\hline Baja $^{\mathrm{b}}$ & 2,5 & 3,0 \\
\hline Media $^{\mathrm{a}}$ & 3,0 & 3,5 \\
\hline Alta $^{\mathrm{d}}$ & 3,5 & 4,0 \\
\hline
\end{tabular}

FEVI: fracción de eyección del ventrículo izquierdo; INR: cociente internacional normalizado.

aReemplazo de válvula mitral o tricuspídea, tromboembolia previa, fibrilación auricular, estenosis mitral de cualquier grado y $\mathrm{FEVI}<35 \%$.

${ }^{\mathrm{b} C}$ arbomedics, Medtronic Hall, ATS, Medtronic Open-Pivot, St. Jude Medical, On-X, Sorin Bicarbon.

'Otras válvulas bivalvas con datos insuficientes.

¿Lillehei-Kaster, Omniscience, Starr-Edwards (ball-cage), Bjork-Shiley y otras válvulas con disco basculante.

necesarios un entrenamiento adecuado del paciente y un control periódico de calidad. No obstante, debe considerarse la monitorización de la anticoagulación en consulta para los pacientes con un INR inestable o con complicaciones relacionadas con la anticoagulación. La determinación sistemática del genotipo de los pacientes que reciben tratamiento con AVK no se recomienda si no se esperan beneficios clínicos convincentes, además de tener en cuenta otras consideraciones sobre la relación entre coste y efectividad ${ }^{189}$.

\subsubsection{Tratamiento para la sobredosis de antagonistas de la vitamina $K$ y sangrado}

El riesgo de hemorragia mayor aumenta considerablemente cuando el INR excede 4,5 y aumenta exponencialmente a partir de un INR de 6,0. Por lo tanto, un INR $\geq 6,0$ requiere revertir rápidamente la anticoagulación debido al riesgo de hemorragia que implica.

En ausencia de hemorragia, el tratamiento depende del objetivo de INR, el INR que se determine en el momento y la vida media del AVK utilizado. Es posible interrumpir la anticoagulación oral y esperar a que el INR baje gradualmente o administrar vitamina K oral con incrementos de 1 o $2 \mathrm{mg}^{190}$. La reversión inmediata de la anticoagulación mediante la administración intravenosa de concentrado de complejo de protrombina y vitamina $\mathrm{K}$ solo es necesaria en casos de hemorragia grave, definida como una hemorragia no tratable mediante control local, que pone en riesgo la vida o la función de órganos importantes (p. ej., la hemorragia intracraneal), causa inestabilidad hemodinámica o requiere un procedimiento quirúrgico urgente o transfusión ${ }^{190}$. No hay datos de que el riesgo de tromboembolia debido a la reversión transitoria de la anticoagulación sea superior a las consecuencias de una hemorragia grave en pacientes con prótesis mecánicas. La decisión sobre el momento óptimo para reinstaurar el tratamiento anticoagulante depende de la localización de la complicación hemorrágica, su evolución y las intervenciones realizadas para detener el sangrado, además del tratamiento de la causa subyacente ${ }^{191}$.

\subsubsection{Combinación de fármacos anticoagulantes y antiagregantes}

La adición de AAS en el contexto de los nuevos objetivos de INR no se ha estudiado en pacientes sin enfermedad vascular ${ }^{42}$. La incertidumbre sobre la relación entre el riesgo y el beneficio de la combinación de un AVK con AAS se refleja en la discrepancia entre distintas recomendaciones ${ }^{192,193}$. Cuando se añaden a la anticoagulación, los fármacos antiagregantes reducen el riesgo tromboembólico, pero aumentan el riesgo de hemorragia mayor ${ }^{194}$. Por lo tanto, no deben prescribirse a todos los pacientes con válvulas protésicas, sino que deben restringirse para indicaciones específicas según el análisis del 
Indicaciones para el tratamiento antitrombótico de pacientes con prótesis o reparación valvular

\begin{tabular}{|c|c|c|}
\hline Recomendaciones & Clase $^{\mathrm{a}}$ & Nivel $^{\mathrm{b}}$ \\
\hline \multicolumn{3}{|l|}{ Prótesis mecánicas } \\
\hline Se recomienda el tratamiento anticoagulante oral crónico con un AVK para todos los pacientes ${ }^{179,180}$ & I & B \\
\hline Se recomienda el tratamiento puente con dosis terapéuticas de HNF o HBPM cuando haya que interrumpir el tratamiento con AVK & I & $\mathrm{C}$ \\
\hline $\begin{array}{l}\text { Debe considerarse la adición de dosis bajas de ácido acetilsalicílico ( } 75-100 \text { mg/día) al tratamiento con AVK después de un evento tromboembólico que } \\
\text { ocurre a pesar de un INR adecuado }\end{array}$ & Ila & C \\
\hline $\begin{array}{l}\text { Puede considerarse la adición de dosis bajas de ácido acetilsalicílico ( } 75-100 \text { mg/día) al tratamiento con AVK en caso de enfermedad ateroesclerótica } \\
\text { concomitante }\end{array}$ & IIb & $\mathrm{C}$ \\
\hline Se recomienda el control del INR por el propio paciente siempre que esté adecuadamente entrenado y se realicen controles de calidad & I & B \\
\hline $\begin{array}{l}\text { Para los pacientes tratados con implante de stents coronarios, debe considerarse el tratamiento triple con ácido acetilsalicílico (75-100 mg/día), } \\
\text { clopidogrel ( } 75 \mathrm{mg} / \text { día) y un AVK durante } 1 \mathrm{mes} \text {, independientemente del tipo de stent implantado y de la presentación clínica (SCA o EAC estable) }\end{array}$ & IIa & B \\
\hline $\begin{array}{l}\text { Debe considerarse el tratamiento triple con ácido acetilsalicílico ( } 75-100 \mathrm{mg} / \text { día), clopidogrel ( } 75 \mathrm{mg} / \text { día) y un AVK durante más de } 1 \text { mes y hasta } \\
6 \text { meses para los pacientes con alto riesgo isquémico debido a SCA u otras características anatómicas o del procedimiento que supere el riesgo } \\
\text { hemorrágico }^{182}\end{array}$ & IIa & B \\
\hline $\begin{array}{l}\text { Debe considerarse el tratamiento doble con un AVK y clopidogrel ( } 75 \mathrm{mg} / \text { día }) \text { como alternativa al tratamiento triple durante } 1 \text { mes para los pacientes } \\
\text { cuyo riesgo hemorrágico sea superior al isquémico }{ }^{183,184}\end{array}$ & Ila & A \\
\hline Para pacientes tratados con ICP, debe considerarse la suspensión del tratamiento antiagregante a los 12 meses ${ }^{185}$ & IIa & B \\
\hline $\begin{array}{l}\text { Para los pacientes que requieren ácido acetilsalicílico o clopidogrel además de un AVK, se debe regular cuidadosamente la intensidad de la dosis de AVK } \\
\text { con un objetivo de INR en la parte inferior del intervalo recomendado y con un tiempo en rango terapéutico }>65-70 \% 182,184\end{array}$ & Ila & B \\
\hline El uso de NACO está contraindicado ${ }^{45}$ & III & B \\
\hline
\end{tabular}

\section{Bioprótesis}

Se recomienda el tratamiento anticoagulante oral crónico para los pacientes con bioprótesis quirúrgicas o percutáneas que tengan otras indicaciones para la anticoagulaciónc

Debe considerarse la anticoagulación oral con un AVK durante los primeros 3 meses tras el implante quirúrgico de una bioprótesis mitral o tricuspídea

Debe considerarse la anticoagulación oral con un AVK durante los primeros 3 meses tras la reparación quirúrgica de válvula mitral o tricuspídea

Debe considerarse la administración de dosis bajas de ácido acetilsalicílico (75-100 mg/día) durante los primeros 3 meses tras el implante quirúrgico de una bioprótesis aórtica o la cirugía de conservación valvular

Debe considerarse el tratamiento antiagregante doble durante los primeros 3-6 meses tras el TAVI, seguido de tratamiento antiagregante simple crónico, para pacientes que no requieren anticoagulación oral por otras razones

Puede considerarse el tratamiento antiagregante simple tras el TAVI en caso de riesgo hemorrágico alto

Puede considerarse el tratamiento anticoagulante oral durante los primeros 3 meses tras el implante quirúrgico de una bioprótesis aórtica

\begin{tabular}{cc}
\hline I & C \\
\hline Ila & C \\
\hline IIa & C \\
\hline IIa & C \\
\hline Ila & C \\
\hline IIb & C \\
\hline IIb & C \\
\hline
\end{tabular}

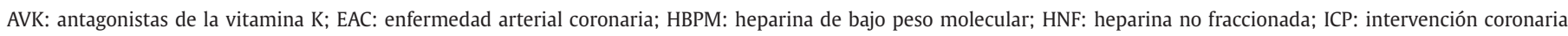

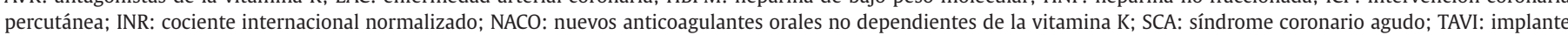
percutáneo de válvula aórtica; VI: ventrículo izquierdo.

aClase de recomendación.

${ }^{\mathrm{b}}$ Nivel de evidencia.

'Fibrilación auricular, tromboembolia venosa, estado de hipercoagulación o, con un nivel de evidencia menor, disfunción grave del VI (fracción de eyección < 35\%).

beneficio esperado y el aumento de riesgo de hemorragia mayor. Si se emplea esta combinación, debe prescribirse la dosis más baja recomendada (p. ej., AAS 75-100 mg/día).

Las indicaciones para la adición de un fármaco antiagregante a la anticoagulación oral se detallan en el apartado 11.2.2.1 (véase la tabla de recomendaciones para las indicaciones del tratamiento antitrombótico para pacientes con prótesis o reparación valvular) y la figura 7. Debe evitarse el uso de prasugrel o ticagrelor como parte del tratamiento triple ${ }^{37}$. Durante el tratamiento antitrombótico triple, se aconseja la monitorización estrecha del INR, que debe mantenerse en la parte baja del intervalo terapéutico.

\subsubsection{Interrupción del tratamiento anticoagulante para procedimientos invasivos planificados}

Durante la cirugía no cardiaca, la anticoagulación requiere una atención meticulosa basada en la evaluación del riesgo ${ }^{196}$. No se recomienda la interrupción de la anticoagulación oral en la mayoría de los procedimientos quirúrgicos menores (incluida la extracción dental y la cirugía de catataras) y en los procedimientos en que la hemorragia se puede controlar fácilmente ${ }^{197}$. La cirugía mayor requiere un INR $<1,5$. Los pacientes con prótesis mecánicas deben interrumpir la anticoagulación oral antes de la cirugía y recibir heparina como trata- miento puente ${ }^{196}$. La HNF sigue siendo la única heparina aprobada para pacientes con prótesis mecánicas; la administración intravenosa es preferible a la subcutánea. Aunque está fuera de su indicación, la HBPM subcutánea es una alternativa a la HNF como tratamiento puente. Cuando se emplea HBPM, debe administrarse 2 veces al día con dosis terapéuticas adaptadas al peso corporal y la función renal y, siempre que sea posible, con monitorización de la actividad anti-Xa con un objetivo de $0,5-1,0 \mathrm{U} / \mathrm{ml}$. No debe emplearse fondaparinux como tratamiento puente para pacientes con prótesis mecánicas. Las modalidades prácticas del tratamiento anticoagulante puente se detallan en la figura 8.

Cuando sea necesario, y tras un análisis minucioso de la relación entre riesgo y beneficio, debe interrumpirse el tratamiento combinado con AAS 1 semana antes de los procedimientos no cardiacos.

La anticoagulación oral se puede continuar con dosis modificadas para la mayoría de los pacientes sometidos a cateterismo cardiaco, especialmente si se emplea el acceso radial. Para los pacientes que requieren cateterismo transeptal para una intervención valvular, punción directa del VI o drenaje pericárdico, se debe interrumpir la anticoagulación oral y administrar tratamiento puente de anticoagulación ${ }^{171}$

Para los pacientes que no presentan un INR terapéutico en la consulta de monitorización, está indicada la administración de HNF o 


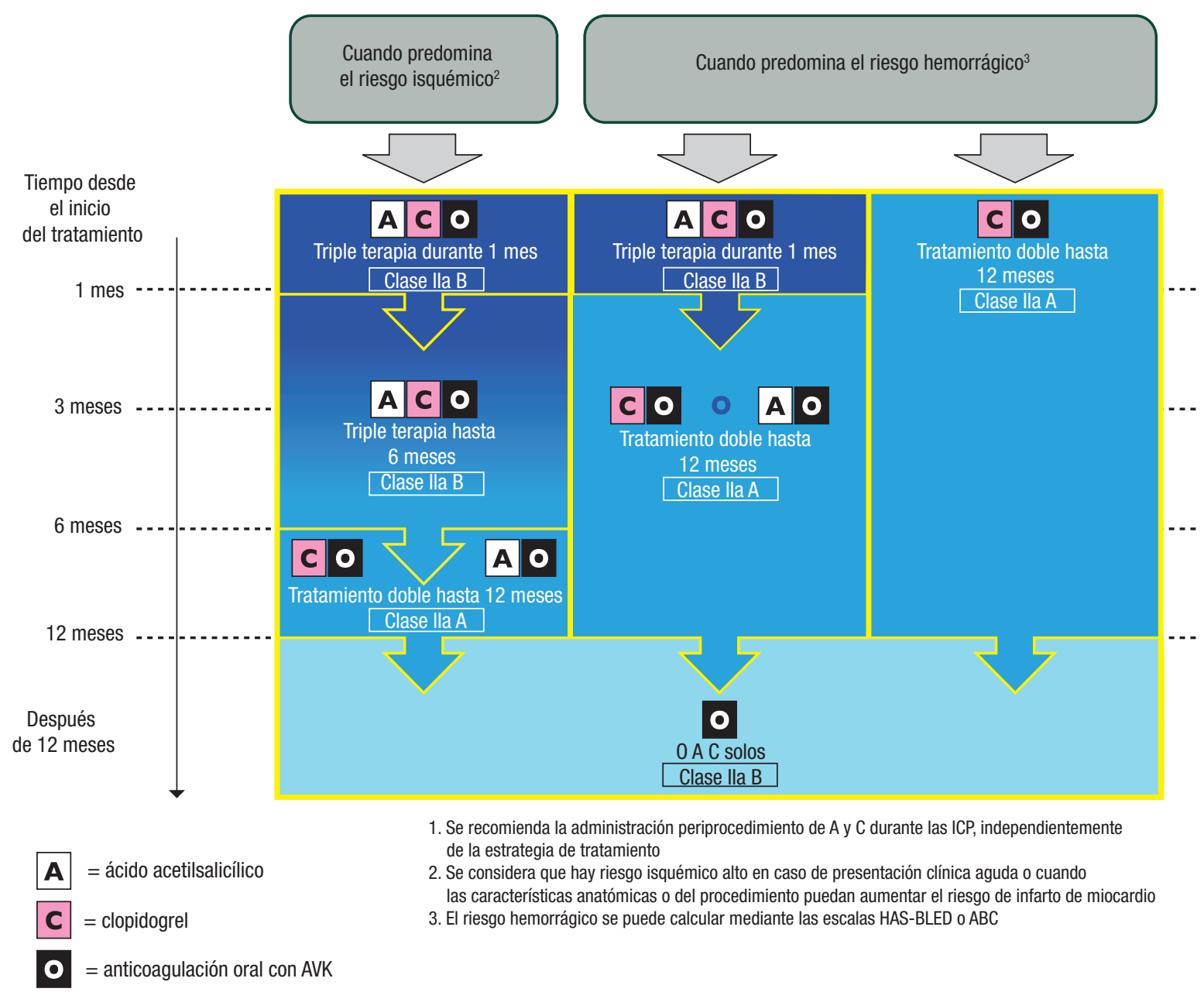

Figura 7. Tratamiento antitrombótico para pacientes con prótesis valvulares que van a someterse a ICP (adaptada de 2017 ESC Focused Update on Dual Antiplatelet Therapy) ${ }^{195}$. A: ácido acetilsalicílico; ABC: edad, biomarcadores, historia clínica; AVK: antagonistas de la vitamina K; C: clopidogrel; ICP: intervención coronaria percutánea; O: anticoagulación oral con un AVK; SCA: síndrome coronario agudo.

Para más información sobre la estimación del riesgo hemorrágico (escalas HAS-BLED y ABC), véase Valgimigli et al. ${ }^{195}$.

preferiblemente HBPM en consulta ambulatoria como tratamiento puente hasta que se alcance un valor de INR terapéutico.

\subsubsection{Tratamiento de la trombosis valvular}

Hay que sospechar pronto la trombosis valvular obstructiva ante todo paciente con válvula protésica de cualquier tipo que se presente con síntomas recientes de disnea o un evento embólico. El diagnóstico debe confirmarse mediante ETT, ETE o fluoroscopia, o TC si está fácilmente disponible ${ }^{169,170}$.

El tratamiento de la trombosis valvular de prótesis mecánicas es de alto riesgo, sea cual sea la opción que se siga. La cirugía es de alto riesgo porque a menudo se realiza de urgencia y es una reintervención. Por otra parte, comparada con la cirugía, la fibrinolisis implica mayor riesgo de hemorragia, embolia sistémica y trombosis recurrente $^{198}$.

El reemplazo valvular urgente para la trombosis obstructiva de válvula protésica está recomendado para pacientes críticos sin contraindicaciones para la cirugía (véanse la tabla de recomendaciones en el apartado 11.2.3 para el tratamiento de la disfunción valvular protésica y la figura 9).

El tratamiento de la trombosis no obstructiva de válvula protésica depende fundamentalmente de si ha habido un evento tromboembólico y el tamaño del trombo (figura 10). Debe considerarse la cirugía cuando en la prótesis valvular haya un trombo no obstructivo grande (>10 mm) complicado con embolia o que persiste a pesar del tratamiento anticoagulante óptimo ${ }^{199}$. Aunque se asocia con riesgo de hemorragia y tromboembolia, puede considerarse la fibrinolisis cuando la cirugía sea de alto riesgo.

La trombosis valvular ocurre más frecuentemente en prótesis mecánicas, aunque también se han descrito casos de trombosis de bioprótesis después de la cirugía o del implante transcatéter ${ }^{200,201}$. La trombosis subclínica de bioprótesis puede ser más frecuente cuando se evalúa mediante $\mathrm{TC}^{202}$ y en el TAVI esta entidad puede asociarse a un aumento moderado de los gradientes transprotésicos, aunque se desconocen sus consecuencias clínicas ${ }^{203}$.

La anticoagulación con un AVK o HNF es la primera línea de tratamiento de la trombosis valvular de bioprótesis. 
Tratamiento de la disfunción de válvulas protésicas

\begin{tabular}{|c|c|c|}
\hline Recomendaciones & Clase $^{\mathrm{a}}$ & Nivel $^{\mathrm{b}}$ \\
\hline \multicolumn{3}{|l|}{ Trombosis de prótesis mecánica } \\
\hline Se recomienda el reemplazo valvular urgente o emergente para la trombosis obstructiva en pacientes críticos sin comorbilidad grave & I & $\mathrm{C}$ \\
\hline $\begin{array}{l}\text { Debe considerarse la fibrinolisis (con bolo de } 10 \mathrm{mg} \text { de activador tisular del plasminógeno recombinante }+90 \text { mg de HNF en } 90 \text { min o infusión de } \\
1.500 .000 \mathrm{U} \text { de estreptoquinasa sin HNF en } 60 \mathrm{~min} \text { ) cuando la cirugía no esté disponible o sea de alto riesgo o para la trombosis de prótesis de lado } \\
\text { derecho }\end{array}$ & Ila & C \\
\hline Debe considerarse la cirugía en presencia de trombos no obstructivos grandes ( $>10 \mathrm{~mm}$ ) en prótesis sin complicaciones embólicas & Ila & C \\
\hline \multicolumn{3}{|l|}{ Trombosis de bioprótesis } \\
\hline Se recomienda la anticoagulación con un AVK o HNF para la trombosis de válvula bioprotésica antes de considerar la reintervención & I & C \\
\hline \multicolumn{3}{|l|}{ Hemolisis y fuga paravalvular } \\
\hline $\begin{array}{l}\text { Se recomienda la reoperación si la fuga paravalvular está relacionada con endocarditis o causa hemolisis que requiere transfusiones sanguíneas repetidas } \\
\text { o produce síntomas graves }\end{array}$ & I & C \\
\hline $\begin{array}{l}\text { Puede considerarse el cierre percutáneo de las fugas paravalvulares que producen insuficiencia clínicamente significativa en pacientes con riesgo } \\
\text { quirúrgico alto (decisión del equipo cardiológico) }\end{array}$ & IIb & C \\
\hline \multicolumn{3}{|l|}{ Disfunción de la bioprótesis } \\
\hline $\begin{array}{l}\text { Se recomienda la reintervención para los pacientes sintomáticos que presentan un aumento significativo del gradiente transprotésico (tras la exclusión } \\
\text { de trombosis valvular) o insuficiencia grave }\end{array}$ & I & C \\
\hline Debe considerarse la reintervención para los pacientes asintomáticos con disfunción significativa de la prótesis si la reoperación es de bajo riesgo & Ila & $\mathrm{C}$ \\
\hline $\begin{array}{l}\text { El equipo cardiológico debe considerar el implante percutáneo de «válvula en válvula» en posición aórtica dependiendo del riesgo de la reoperación y el } \\
\text { tipo y el tamaño de la prótesis }\end{array}$ & IIa & C \\
\hline
\end{tabular}

AVK: antagonista de la vitamina K; HNF: heparina no fraccionada.

aClase de recomendación.

bNivel de evidencia.

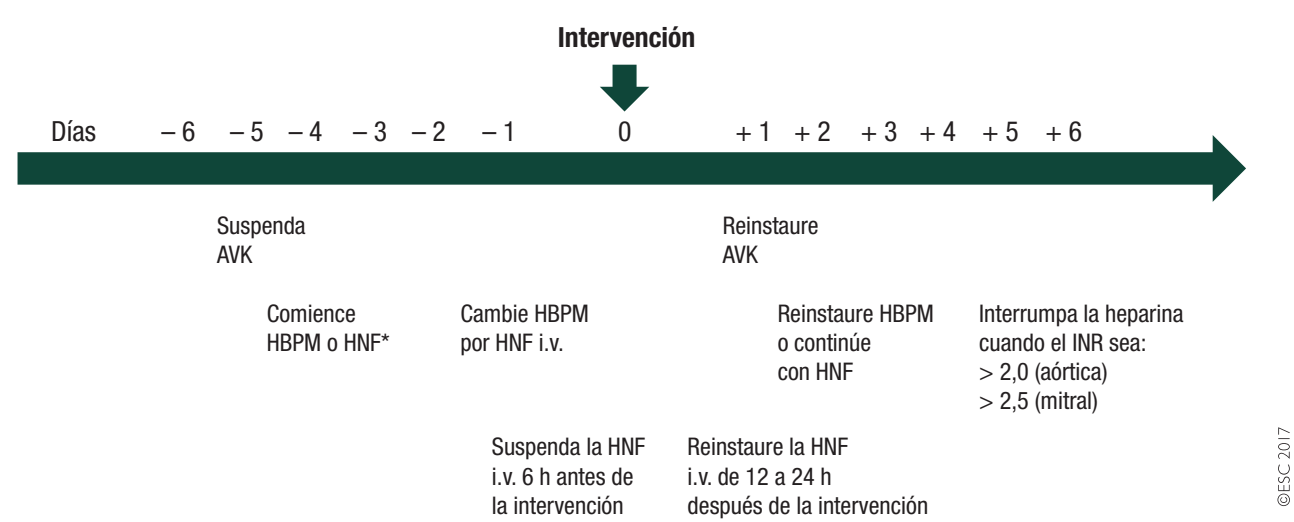

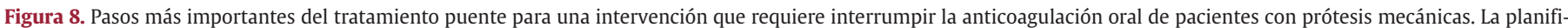

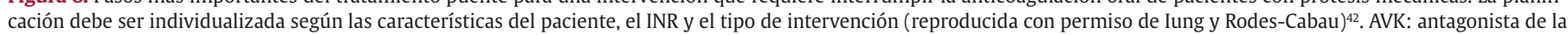
vitamina K; HBPM: heparina de bajo peso molecular; HNF: heparina no fraccionada; INR: cociente internacional normalizado; i.v.: intravenoso.

*Puede ser aconsejable administrar HNF intravenosa a los pacientes con alto riesgo trombótico.

\subsubsection{Tratamiento de la tromboembolia}

La tromboembolia después de la cirugía valvular tiene un origen multifactorial ${ }^{171}$. Por ello, es muy importante examinar detenidamente cada evento tromboembólico (incluidas las técnicas de imagen cardiacas y no cardiacas; figura 10), en lugar de simplemente aumentar el objetivo de INR o añadir un fármaco antiagregante. La prevención de posteriores eventos tromboembólicos requiere tratar los factores de riesgo, optimizar el control de la anticoagulación y añadir dosis bajas de AAS ( $\leq 100 \mathrm{mg} /$ día), después de un minucioso análisis de la relación entre el riesgo y el beneficio.

\subsubsection{Tratamiento de la hemolisis y la fuga paravalvular}

Los análisis sanguíneos para la hemolisis deben formar parte del seguimiento sistemático después del reemplazo valvular. La concentración de lactato deshidrogenasa, aunque no es específica, se rela- ciona con la gravedad de la hemolisis. El diagnóstico de anemia hemolítica precisa de la ETE para detectar una fuga paravalvular si la ETT no aporta datos. La reoperación está recomendada si la fuga paravalvular está relacionada con endocarditis o causa una hemolisis que requiere transfusiones sanguíneas repetidas o produce síntomas graves (véase la tabla de recomendaciones del apartado 11.2.3 sobre el tratamiento de la disfunción protésica). El tratamiento médico, que incluye suplementos de hierro, bloqueadores beta y eritropoyetina, está indicado para pacientes con anemia hemolítica grave que tengan contraindicada la cirugía. El cierre percutáneo de una fuga paravalvular es factible, pero la experiencia es escasa y por el momento no hay pruebas concluyentes que demuestren su eficacia ${ }^{204}$.

\subsubsection{Tratamiento de la disfunción de válvulas bioprotésicas}

Tras el implante percutáneo o quirúrgico de una bioprótesis debe realizarse un estudio ecocardiográfico que incluya la medición de gra- 


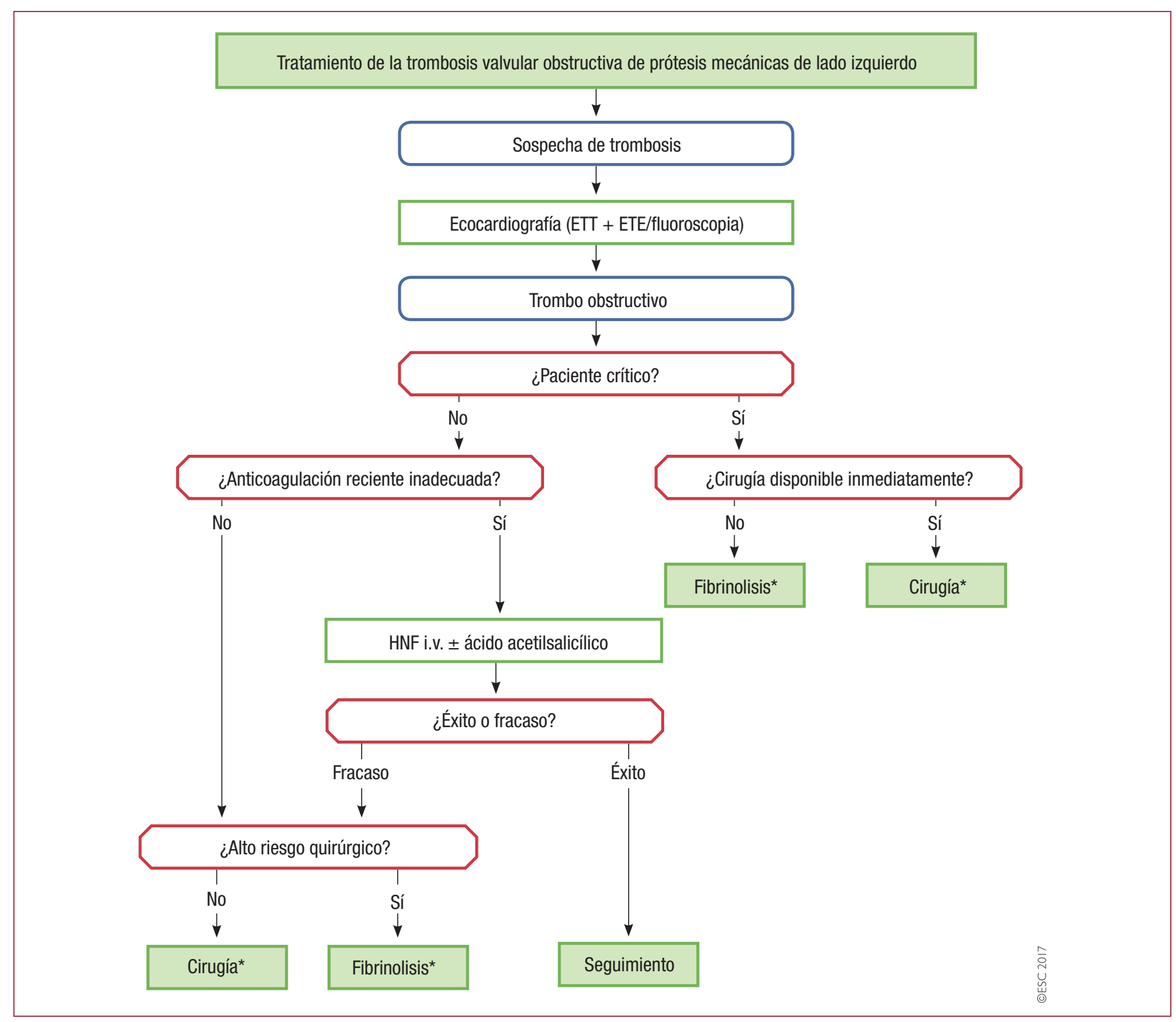

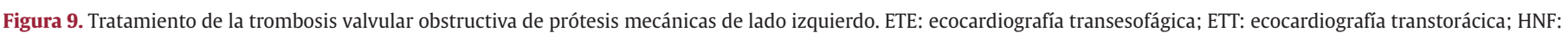
heparina no fraccionada; i.v.: intravenoso.

*Se debe individualizar los riesgos y los beneficios de ambos tratamientos. La presencia de una prótesis de primera generación es un incentivo para la cirugía.

dientes transprotésicos en los primeros 30 días para obtener imágenes basales (preferiblemente a los 30 días para la cirugía), otro estudio 1 año tras el implante y, a partir de entonces, un seguimiento anual ${ }^{168}$. La definición de deterioro estructural valvular y disfunción de válvulas bioprotésicas se ha estandarizado recientemente en un artículo de consenso ${ }^{168}$.

Las indicaciones para la reintervención se detallan en la tabla de recomendaciones sobre la disfunción de válvulas protésicas (apartado 11.2.3).

Deben evitarse las intervenciones percutáneas con balón para el tratamiento de estenosis en bioprótesis del lado izquierdo.

El implante transcatéter con la técnica de "válvula en válvula» es hoy en día una opción para el tratamiento de bioprótesis deterioradas en pacientes con riesgo quirúrgico elevado. Esta técnica se ha experimentado sobre todo con bioprótesis en posición aórtica, menos en la posición mitral y aún menos en la válvula tricús- pide ${ }^{205,206}$. Los procedimientos de "válvula en válvula» o "válvula en anillo" pueden ser una alternativa razonable si el paciente tiene un riesgo quirúrgico alto, pero es necesario que el equipo cardiológico multidisciplinario valore cada caso y opte por la mejor estrategia de forma individualizada.

\subsubsection{Insuficiencia cardiaca}

La insuficiencia cardiaca después de una cirugía valvular debe llevar a la búsqueda de disfunción valvular o disparidad entre el paciente y la prótesis, deterioro de la reparación, disfunción del VI o progresión de otra valvulopatía. También deben considerarse otras causas no relacionadas con las válvulas, como la enfermedad coronaria, la hipertensión o las arritmias mantenidas. El tratamiento de los pacientes con insuficiencia cardiaca debe seguir las recomendaciones de la guía específica sobre esta enfermedad ${ }^{113}$. 


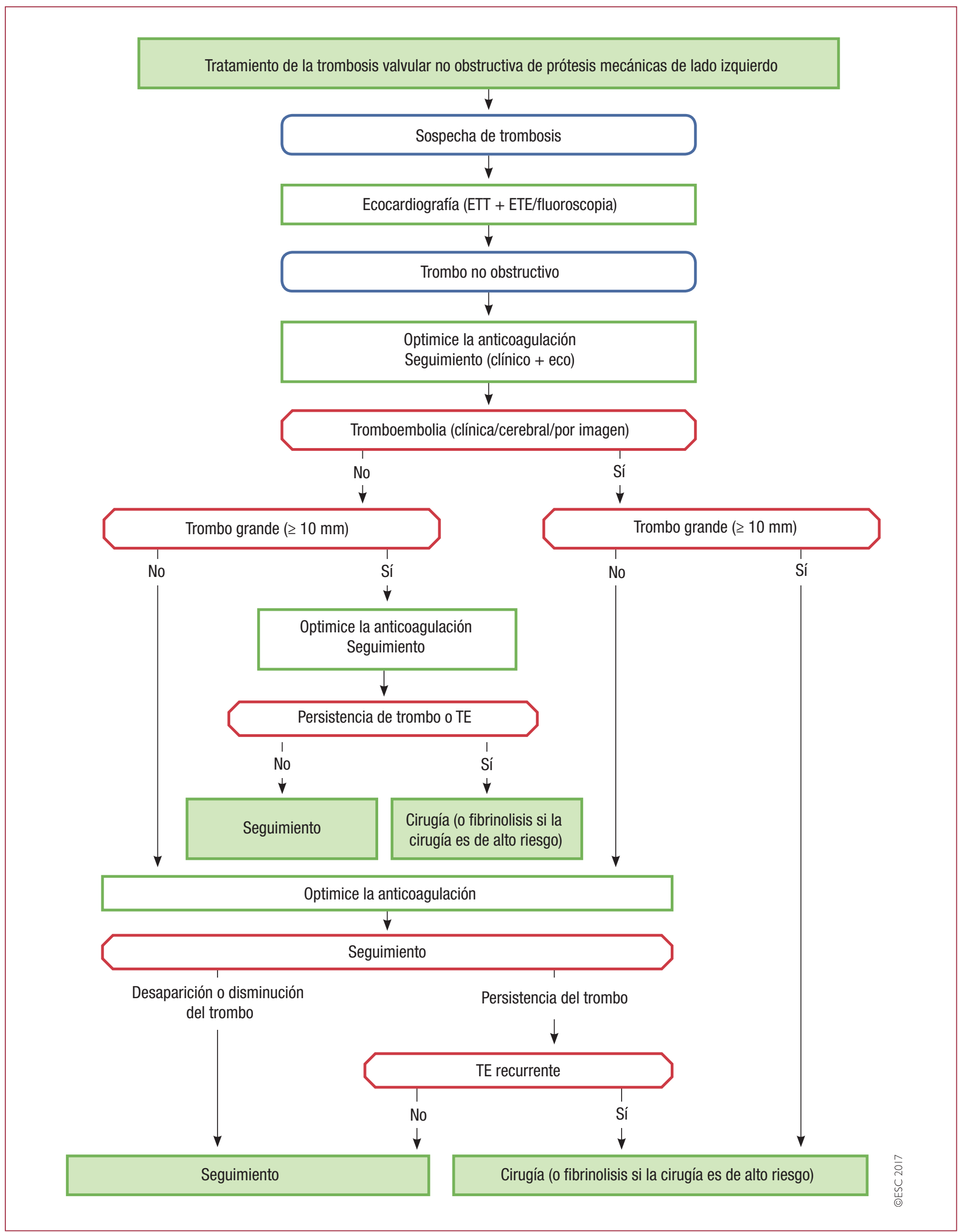

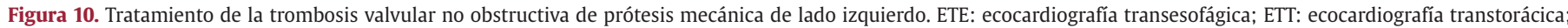
TE: tromboembolia. 


\section{Puntos clave}

- En la elección entre una prótesis mecánica y una bioprótesis, no hay que conceder demasiada importancia a la edad y se debe tener en cuenta los deseos del paciente bien informado.

- Los pacientes receptores de una prótesis mecánica requieren tratamiento con AVK de por vida, con un objetivo de INR adaptado a la prótesis y las características del paciente.

- Solo deben añadirse dosis bajas de AAS al tratamiento con AVK de pacientes con una prótesis valvular mecánica seleccionados que sufran ateroesclerosis o embolias recurrentes.

- El riesgo de tromboembolia y hemorragia es más alto durante el periodo posoperatorio y requiere la monitorización estrecha del tratamiento anticoagulante.

- El tratamiento anticoagulante durante la cirugía no cardiaca debe adaptarse al tipo de cirugía. Los procedimientos quirúrgicos menores generalmente no requieren la interrupción de la anticoagulación.

\section{Lagunas en la evidencia}

- La seguridad y la eficacia de los objetivos de INR muy bajos (media $<2,5$ ) en pacientes con prótesis mecánicas en posición aórtica requieren más estudio.

- La seguridad y la eficacia de los NACO en pacientes con prótesis mecánicas requieren más estudio.

- La seguridad y la eficacia del tratamiento con dosis bajas de AAS junto con los objetivos de INR contemporáneos en pacientes con prótesis mecánicas, y dependiendo de la presencia o ausencia de ateroesclerosis, requieren más estudio.

- Es preciso definir mejor el tratamiento antitrombótico óptimo en las fases tempranas después del implante quirúrgico o percutáneo de bioprótesis aórticas.

- Son necesarios resultados a largo plazo de los procedimientos de «válvula en válvula» y «válvula en anillo».

\section{TRATAMIENTO DURANTE LA CIRUGÍA NO CARDIACA}

La morbimortalidad cardiovascular es mayor en los pacientes con valvulopatías que reciben tratamiento quirúrgico no cardiaco. La estenosis aórtica sintomática grave o la estenosis mitral pueden requerir el reemplazo valvular o una intervención valvular percutánea antes de la cirugía no cardiaca. En la guía específica se encuentra una descripción detallada de las recomendaciones ${ }^{196}$.

\subsection{Evaluación preoperatoria}

Debe realizarse un estudio ecocardiográfico de todo paciente con valvulopatías. La determinación de la capacidad funcional es un paso esencial en la evaluación preoperatoria del riesgo que se puede medir en una prueba de esfuerzo o según la capacidad para realizar actividades cotidianas. La decisión sobre el tratamiento se debe tomar después de la discusión en un equipo multidisciplinario que incluya a cardiólogos, cirujanos y anestesistas.

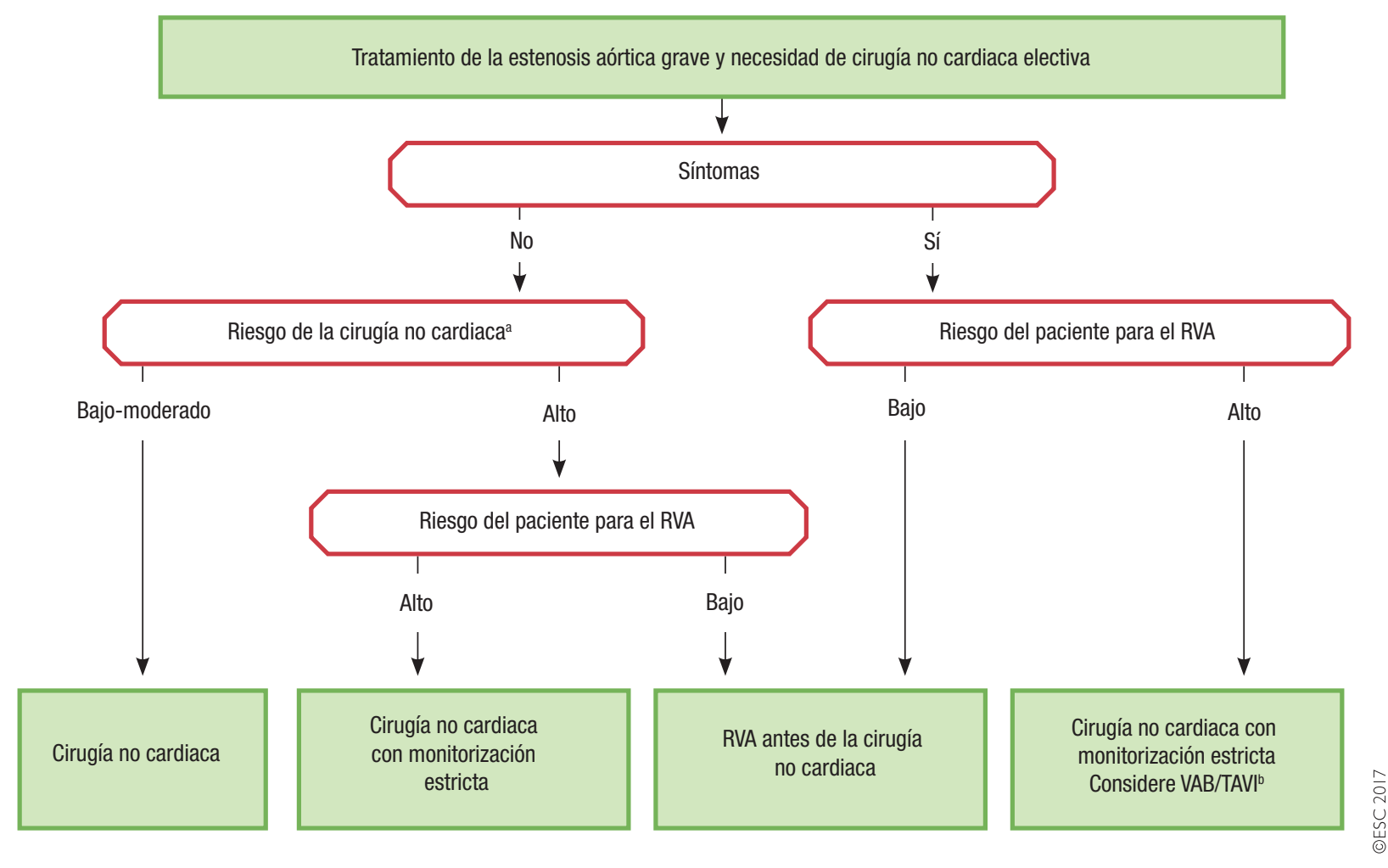

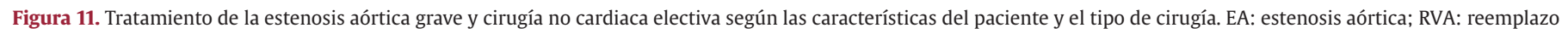
de válvula aórtica; TAVI: implante percutáneo de válvula aórtica; VAB: valvuloplastia aórtica con balón.

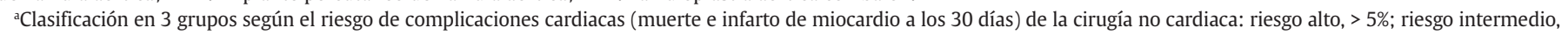
$1-5 \%$; riesgo bajo, $<1 \%{ }^{196}$.

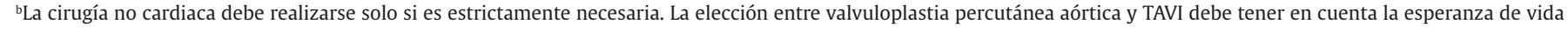
del paciente. 


\subsection{Lesiones valvulares específicas}

\subsubsection{Estenosis aórtica}

En pacientes con estenosis aórtica grave, la cirugía no cardiaca urgente debe realizarse con estricta monitorización hemodinámica.

El tratamiento en la cirugía no cardiaca electiva depende de la presencia de síntomas y el tipo de cirugía ${ }^{196,207,208}$. Para los pacientes sintomáticos, debe considerarse el reemplazo de válvula aórtica antes de la cirugía no cardiaca. Para los pacientes con riesgo quirúrgico alto, el TAVI es la opción terapéutica. En pacientes asintomáticos, la cirugía no cardiaca electiva puede llevarse a cabo con seguridad, pese al riesgo de empeoramiento de la insuficiencia cardiaca ${ }^{207,208}$. Si la cirugía no cardiaca implica grandes cambios de volumen, debe considerarse primero el reemplazo de la válvula aórtica (figura 11).

\subsubsection{Estenosis mitral}

La cirugía no cardiaca se puede realizar con seguridad en pacientes con estenosis mitral no significativa (área valvular $>1,5 \mathrm{~cm}^{2}$ ) y pacientes asintomáticos con estenosis mitral significativa y PAPs $<50 \mathrm{mmHg}$.

Para los pacientes sintomáticos o con PAPs $>50 \mathrm{mmHg}$, debe intentarse la corrección de la estenosis mitral, mediante CMP siempre que sea posible, antes de la cirugía no cardiaca si esta es de alto riesgo.

\subsubsection{Insuficiencia aórtica y mitral}

La cirugía no cardiaca puede realizarse con seguridad en pacientes asintomáticos con insuficiencia mitral grave o insuficiencia aórtica y función del VI conservada. La presencia de síntomas o disfunción del VI debe llevar a que se considere la cirugía valvular, aunque rara vez es necesaria antes de la cirugía no cardiaca. Si la disfunción del VI es grave (FEVI < 30\%), la cirugía debe realizarse solo si es estrictamente necesaria y tras la optimización del tratamiento médico para la insuficiencia cardiaca.

\subsection{Monitorización perioperatoria}

Es necesario controlar la frecuencia cardiaca (especialmente en la estenosis mitral) y un control meticuloso de los fluidos (especialmente en la estenosis aórtica). Puede considerarse la monitorización mediante ETE.

\section{Puntos clave}

- Para los pacientes sintomáticos con estenosis aórtica grave, debe considerarse el reemplazo de la válvula aórtica o el TAVI antes de la cirugía no cardiaca.

- En pacientes con estenosis mitral grave y síntomas o PAPs $>50 \mathrm{mmHg}$, debe intentarse una CMP antes de la cirugía no cardiaca.

\section{TRATAMIENTO DURANTE LA GESTACIÓN}

Las recomendaciones sobre el tratamiento de la enfermedad cardiovascular durante la gestación están descritas en otra guía ${ }^{209}$.
Las decisiones sobre el tratamiento durante la gestación deben tomarse después de la discusión en un equipo multidisciplinario que incluya a cardiólogos, obstetras y anestesistas ${ }^{209}$. Se debe evaluar la valvulopatía antes del embarazo y tratarla si fuera necesario. Se debe desaconsejar el embarazo a las pacientes con estenosis mitral grave, estenosis aórtica sintomática grave y con un diámetro aórtico $>4,5 \mathrm{~mm}$ en el síndrome de Marfan o > 27,5 mm/ $\mathrm{m}^{2}$ en el síndrome de Turner.

Se recomienda el parto por cesárea para las pacientes con estenosis mitral o aórtica grave, un diámetro de la aorta ascendente $>$ 4,5 mm o hipertensión pulmonar grave, así como en casos de parto prematuro durante el tratamiento anticoagulante oral.

\subsection{Valvulopatía nativa}

Las gestantes toleran mal la estenosis mitral moderada o grave con un área valvular $<1,5 \mathrm{~cm}^{2}$. Debe considerarse la CMP para las pacientes con síntomas graves (NYHA III-IV) o con PAPs > $50 \mathrm{mmHg}$ pese a recibir el tratamiento médico óptimo. La CMP debe realizarse después de la semana 20 de gestación en un centro con experiencia ${ }^{209}$.

Las complicaciones de la estenosis aórtica grave ocurren mayoritariamente a pacientes sintomáticas antes de la gestación y pacientes con función del VI reducida. Se recomienda una evaluación mediante prueba de ejercicio antes del embarazo.

La insuficiencia mitral o aórtica crónicas se toleran bien, aunque sean graves, siempre que la función sistólica del VI esté conservada.

La cirugía con derivación cardiopulmonar se asocia con una tasa de mortalidad fetal del $15-30 \%{ }^{210}$ y debe restringirse a entidades raras que pongan en riesgo la vida de la madre.

\subsection{Prótesis valvulares}

La mortalidad materna estimada varía entre el 1 y el $4 \%$ y las complicaciones graves ocurren en hasta el $40 \%$ de las mujeres receptoras de válvulas mecánicas ${ }^{211}$.

La anticoagulación en rango terapéutico es de extrema importancia para evitar complicaciones. Para las pacientes que requieran $\leq 5 \mathrm{mg}$ de warfarina, es preferible la anticoagulación oral durante la gestación y cambiar a HNF antes del parto. Para las pacientes que requieran dosis más altas, se prefiere cambiar a HBPM durante el primer trimestre con control estricto de la actividad anti-Xa (rango terapéutico, 0,8-1,2 UI/ml) y el uso de anticoagulantes orales después ${ }^{209}$.

\section{Puntos clave}

- Debe desaconsejarse la gestación a las mujeres con estenosis mitral grave o estenosis aórtica sintomática grave.

- La gestación de mujeres con una válvula mecánica, especialmente en posición mitral, se asocia con un alto riesgo de complicaciones para la madre y el feto. En estas pacientes, la anticoagulación en rango terapéutico durante la gestación es de máxima importancia.

\section{Lagunas en la evidencia}

- Es preciso definir mejor el régimen antitrombótico óptimo para las gestantes con válvulas cardiacas mecánicas. 


\section{MENSAJES CLAVE DE LA GUÍA SOBRE QUÉ SE DEBE HACER Y QUÉ NO SE DEBE HACER}

Tratamiento de la EAC en pacientes con valvulopatías; adaptado de Windecker et al. ${ }^{16}$

Se recomienda la coronariografía antes de la cirugía valvular para pacientes con valvulopatía grave y uno de los siguientes:

- Historia de enfermedad cardiovascular

- Sospecha de isquemia miocárdica

- Disfunción sistólica del VI

- Varones de más de 40 años y mujeres posmenopáusicas

- Uno o más factores de riesgo cardiovascular

Se recomienda la coronariografía para la evaluación de la insuficiencia mitral secundaria de moderada a grave

Se recomienda la CABG para pacientes con una indicación primaria de cirugía valvular aórtica o mitral y estenosis aórtica $\geq 70 \%$ del diámetro

\section{Tratamiento de la fibrilación auricular en pacientes con valvulopatía}

No se recomienda el uso de NACO para pacientes con fibrilación auricular y estenosis mitral de moderada a grave

Los NACO están contraindicados para los pacientes con prótesis valvular mecánica

Indicaciones para la cirugía

\section{A. Insuficiencia aórtica grave}

La cirugía está indicada para los pacientes sintomáticos ${ }^{57,58,66,67}$

La cirugía está indicada para pacientes asintomáticos con FEVI en reposo $\leq 50 \% 57,58$

La cirugía está indicada para pacientes que van a someterse a CABG o cirugía de la aorta ascendente o de otra válvula

Se recomienda que el equipo cardiológico valore los casos de pacientes seleccionados en los que la reparación de válvula aórtica puede ser una alternativa viable al reemplazo valvular

B. Enfermedad de la raíz aórtica (independientemente de la gravedad de la insuficiencia aórtica)

Se recomienda la reparación valvular aórtica, mediante la técnica de anuloplastia aórtica con reimplante o remodelado, para pacientes jóvenes con dilatación de la raíz aórtica y válvula tricúspide, siempre que cirujanos experimentados realicen el procedimiento

La cirugía está indicada para pacientes con síndrome de Marfan que tienen enfermedad de la raíz aórtica con un diámetro máximo de la aorta ascendente $\geq 50 \mathrm{~mm}$

\section{Indicaciones para la intervención en la estenosis aórtica y recomendaciones sobre la elección del tipo de intervención}

La intervención está indicada para pacientes sintomáticos con estenosis aórtica grave de gradiente alto (gradiente medio $\geq 40$ mm o velocidad pico $\geq 4,0 \mathrm{~m} / \mathrm{s})^{91-93}$

La intervención está indicada para pacientes sintomáticos con estenosis aórtica grave con flujo bajo y gradiente bajo (< 40 mmHg) con fracción de eyección reducida y evidencia de reserva de flujo (reserva contráctil) tras excluir la estenosis aórtica seudograve

No se debe intervenir a los pacientes con comorbilidad grave cuando sea improbable que la intervención mejore la calidad de vida o la supervivencia

Las intervenciones de válvula aórtica deben realizarse solo en hospitales con servicios de cardiología y cirugía cardiaca en el centro que colaboren de manera estructurada e incluyan un equipo multidisciplinario de cardiología (centros especializados en valvulopatías)

La elección de la intervención debe basarse en una cuidadosa evaluación individual de la viabilidad técnica y la valoración de los riesgos y beneficios de cada modalidad (los aspectos que hay que considerar se encuentran en la tabla 7). Además, hay que tener en cuenta la experiencia del centro y los datos de los resultados de una intervención dada

Se recomienda el RQVA para pacientes con riesgo quirúrgico bajo (STS o EuroSCORE II $<4 \%$ o EuroSCORE I logístico < 10\% y sin otros factores de riesgo que no se incluyan en estas escalas, como la fragilidad, la aorta de porcelana y las secuelas de la radiación torácica $)^{93}$

Se recomienda el TAVI para pacientes que no son candidatos a RQVA según la valoración del equipo cardiológico ${ }^{91,94}$

Para los pacientes con riesgo quirúrgico mayor (STS o EuroSCORE II $\geq 4 \%$ o EuroSCORE I logístico $\geq 10 \%$ u otros factores de riesgo que no se incluyan en estas escalas, como la fragilidad, la aorta de porcelana y las secuelas de la radiación torácica), la decisión entre RQVA y TAVI debe tomarla el equipo cardiológico multidisciplinario teniendo en cuenta las características individuales del paciente (véase la tabla 7), y se favorece el TAVI para los pacientes ancianos en los que sea posible el acceso femoral ${ }^{11,94-102}$

El RQVA está indicado para pacientes asintomáticos con estenosis aórtica grave y disfunción sistólica del VI (FEVI < 50\%) que no se deba a otra causa

El RQVA está indicado para pacientes asintomáticos con estenosis aórtica grave y resultados anormales en la prueba de esfuerzo que muestran síntomas durante el ejercicio claramente relacionados con la estenosis aórtica 


\section{Indicaciones para la intervención en la insuficiencia mitral primaria grave}

La reparación de válvula mitral debe ser la técnica preferida cuando se espere que los resultados sean duraderos

La cirugía está indicada para pacientes sintomáticos con FEVI > 30\%121,131,132

La cirugía está indicada para pacientes asintomáticos con disfunción del VI (DTSVI $\geq 45 \mathrm{~mm}$ o FEVI $\leq 60 \%)^{122,131}$

Indicaciones para la intervención de válvula mitral en la insuficiencia mitral secundaria crónica

La cirugía está indicada para pacientes con insuficiencia mitral secundaria grave y FEVI > 30\% que van a someterse a CABG

Indicaciones para la CMP y la cirugía de válvula mitral en la estenosis mitral clínicamente significativa (moderada o grave; área valvular $\leq 1,5 \mathrm{~cm}^{2}$ )

La CMP está indicada para pacientes sintomáticos sin características desfavorables para este procedimiento ${ }^{144,146,148}$

La CMP está indicada para todo paciente sintomático con contraindicaciones o alto riesgo quirúrgico

La cirugía de válvula mitral está indicada para pacientes sintomáticos que no son candidatos a CMP

\begin{tabular}{l|l} 
I & C \\
\hline I & B \\
\hline I & B \\
\hline
\end{tabular}

Indicaciones para la cirugía de válvula tricúspide

La cirugía está indicada para pacientes sintomáticos con estenosis tricuspídea grave

La cirugía está indicada para pacientes con estenosis tricuspídea grave que van a someterse a una intervención de válvula izquierda

La cirugía está indicada para pacientes con insuficiencia tricuspídea primaria grave que van a someterse a una intervención de válvula izquierda

La cirugía está indicada para pacientes sintomáticos con insuficiencia tricuspídea primaria grave aislada sin disfunción grave del VD

La cirugía está indicada para pacientes con insuficiencia tricuspídea secundaria grave que van a someterse a cirugía de válvula izquierda

\begin{tabular}{lll}
\hline I & B \\
\hline I & C \\
\hline I & C \\
\hline
\end{tabular}

Elección de una prótesis aórtica o mitral: a favor del uso de prótesis mecánicas. La decisión se basa en la integración de varios de los siguientes factores

Se recomienda el implante de una prótesis mecánica de acuerdo con el deseo del paciente bien informado, siempre que no haya contraindicaciones para la anticoagulación a largo plazo

Se recomienda el implante de una prótesis mecánica en pacientes con riesgo de deterioro estructural de la válvula acelerado

\begin{tabular}{ll} 
I & C \\
I & C \\
\hline I & C \\
\hline I & C \\
I & C \\
\hline
\end{tabular}

Elección de prótesis aórtica o mitral: a favor del uso de bioprótesis. La decisión se basa en la integración de varios de los siguientes factores

Se recomienda una bioprótesis de acuerdo con el deseo del paciente bien informado

Se recomienda una bioprótesis cuando una anticoagulación de buena calidad sea improbable (por problemas de adherencia, falta de disponibilidad) o esté contraindicada debido a un riesgo hemorrágico alto (hemorragia mayor previa, comorbilidades, negación del paciente, problemas de adherencia, estilo de vida, ocupación)

Se recomienda una bioprótesis en casos de reoperación por trombosis de prótesis valvular mecánica a pesar de un buen control de la anticoagulación a largo plazo

\section{Indicaciones para el tratamiento antitrombótico de pacientes con prótesis o bioprótesis}

Prótesis mecánicas

Se recomienda el tratamiento anticoagulante oral crónico con un AVK para todos los pacientes ${ }^{179,180}$

Se recomienda el tratamiento puente con dosis terapéuticas de HNF o HBPM cuando haya que interrumpir el tratamiento con AVK

Se recomienda el control del INR por el propio paciente siempre que esté adecuadamente entrenado y se realicen controles de calidad ${ }^{181}$

El uso de NACO está contraindicado ${ }^{45}$

Bioprótesis

Se recomienda el tratamiento anticoagulante oral crónico para pacientes con bioprótesis quirúrgicas o percutáneas que tengan otras indicaciones para la anticoagulación

Tratamiento de la disfunción de válvulas protésicas

Se recomienda el reemplazo valvular urgente o emergente para la trombosis obstructiva en pacientes críticos sin comorbilidad grave

Se recomienda la anticoagulación con un AVK o HNF para la trombosis de válvula bioprotésica antes de considerar la reintervención

Se recomienda la reoperación si la fuga paravalvular está relacionada con endocarditis o causa hemolisis que requiere transfusiones sanguíneas repetidas o produce síntomas graves

Se recomienda la reoperación de los pacientes sintomáticos que presenten un aumento significativo del gradiente transprotésico (tras la exclusión de trombosis valvular) o insuficiencia grave

\begin{tabular}{|c|c|}
\hline I & B \\
\hline I & C \\
\hline I & B \\
\hline III & B \\
\hline
\end{tabular}




\section{5. ¿QUÉ HAY NUEVO EN LA EDICIÓN DE 2017?}

\begin{tabular}{|c|c|}
\hline \multicolumn{2}{|c|}{ Cambios en las recomendaciones } \\
\hline 2012 & 2017 \\
\hline \multicolumn{2}{|l|}{ Indicaciones para la intervención en la estenosis aórtica sintomática } \\
\hline $\begin{array}{l}\text { IIb C } \\
\text { Puede considerarse la intervención en pacientes sintomáticos con estenosis aórtica } \\
\text { de flujo bajo y gradiente bajo junto con fracción de eyección reducida sin reserva de } \\
\text { flujo (reserva contráctil) }\end{array}$ & $\begin{array}{l}\text { Ila C } \\
\text { Debe considerarse la intervención en pacientes sintomáticos con estenosis aórtica de } \\
\text { flujo bajo y gradiente bajo junto con fracción de eyección reducida sin reserva de flujo } \\
\text { (reserva contráctil), especialmente si la determinación de calcio por TC confirma una } \\
\text { estenosis aórtica grave }\end{array}$ \\
\hline
\end{tabular}

\section{Elección de la intervención en la estenosis aórtica sintomática}

Recomendaciones sobre el uso de TAVI

(tablas de "Contraindicaciones del TAVI» y la tabla de "Recomendaciones sobre el uso de TAVI»)

Sustituidas por recomendaciones sobre la elección de la intervención

Véanse la sección «b» en la tabla «Indicaciones para la intervención en la estenosis aórtica y recomendaciones sobre la elección de la intervención» (apartado 5.2) y la tabla 7 «Aspectos que debe considerar el equipo cardiológico multidisciplinario para decidir entre RQVA o TAVI para pacientes con riesgo quirúrgico elevado»

\section{Indicaciones para la cirugía en la estenosis aórtica asintomática}

\begin{tabular}{|c|c|}
\hline $\begin{array}{l}\text { IIb C } \\
\text { Concentraciones de BNP significativamente elevadas }\end{array}$ & $\begin{array}{l}\text { Ila C } \\
\text { Concentraciones de BNP significativamente elevadas (más de } 3 \text { veces el valor normal } \\
\text { corregido por edad y sexo), confirmadas en mediciones repetidas, que no se explican } \\
\text { por otra causa }\end{array}$ \\
\hline $\begin{array}{l}\text { IIb C } \\
\text { Aumento }>20 \text { mmHg del gradiente medio de presión durante el ejercicio }\end{array}$ & Eliminada \\
\hline $\begin{array}{l}\text { IIb C } \\
\text { Hipertrofia del VI excesiva en ausencia de hipertensión }\end{array}$ & Eliminada \\
\hline \multicolumn{2}{|l|}{ Indicaciones para la intervención en la insuficiencia mitral primaria asintomática grave } \\
\hline $\begin{array}{l}\text { IIb C } \\
\text { Puede considerarse la cirugía para pacientes asintomáticos con función del VI } \\
\text { conservada, alta probabilidad de reparación duradera, riesgo quirúrgico bajo y: } \\
\text { - Dilatación de la aurícula izquierda (índice de volumen latido } \geq 60 \mathrm{ml} / \mathrm{m}^{2} \text { del ASC) } \\
\text { y ritmo sinusal }\end{array}$ & $\begin{array}{l}\text { Ila C (modificada) } \\
\text { Debe considerarse la cirugía para pacientes asintomáticos con FEVI conservada } \\
\text { (> 60\%) y DTSVI de } 40-44 \mathrm{~mm} \text { cuando sea probable una reparación duradera, el } \\
\text { riesgo quirúrgico sea bajo, la reparación tenga lugar en un centro especializado } \\
\text { en valvulopatías y haya dilatación significativa de la AI (índice de volumen latido } \\
\geq 60 \mathrm{ml} / \mathrm{m}^{2} \text { del ASC) en ritmo sinusal }\end{array}$ \\
\hline Hipertensión pulmomar durante el ejercicio (PAPs $\geq 60 \mathrm{mmHg}$ durante el ejercicio) & Eliminada \\
\hline \multicolumn{2}{|l|}{ Indicaciones para la intervención de válvula mitral en la insuficiencia mitral secundaria } \\
\hline $\begin{array}{l}\text { Ila C } \\
\text { Debe considerarse la cirugía para pacientes con insuficiencia mitral secundaria } \\
\text { moderada que van a someterse a CABG }\end{array}$ & Eliminada \\
\hline \multirow[t]{4}{*}{$\begin{array}{l}\text { IIb C } \\
\text { Cuando la revascularización no esté indicada, puede considerarse la cirugía } \\
\text { para pacientes con insuficiencia mitral secundaria grave y FEVI > } 30 \% \text { que sigan } \\
\text { sintomáticos a pesar del tratamiento médico óptimo (incluida la TRC si está indicada) }\end{array}$} & $\begin{array}{l}\text { IIb C (modificada) } \\
\text { Cuando la revascularización no esté indicada, puede considerarse la cirugía } \\
\text { para pacientes con insuficiencia mitral secundaria grave y FEVI }>30 \% \text { que sigan } \\
\text { sintomáticos a pesar del tratamiento médico óptimo (incluida la TRC si está indicada) } \\
\text { y tengan bajo riesgo quirúrgico }\end{array}$ \\
\hline & $\begin{array}{l}\text { Cuando la revascularización no esté indicada y el riesgo quirúrgico no sea bajo, puede } \\
\text { considerarse el procedimiento percutáneo de «borde con borde» para pacientes con } \\
\text { insuficiencia mitral secundaria grave y FEVI > 30\% que sigan sintomáticos a pesar } \\
\text { del tratamiento médico óptimo (incluida la TRC si está indicada), que tengan una } \\
\text { morfología valvular adecuada según los resultados ecocardiográficos, evitando los } \\
\text { procedimientos inútiles }\end{array}$ \\
\hline & $\begin{array}{l}\text { Para los pacientes con insuficiencia mitral secundaria grave y FEVI < } 30 \% \text { que sigan } \\
\text { sintomáticos a pesar del tratamiento médico óptimo (incluida la TRC si está indicada) } \\
\text { y no tengan opción de revascularización, el equipo cardiológico puede considerar la } \\
\text { indicación de un procedimiento de «borde con borde» o de cirugía valvular después } \\
\text { de evaluar la necesidad de un dispositivo de asistencia ventricular o trasplante } \\
\text { cardiaco de acuerdo con las características individuales del paciente }\end{array}$ \\
\hline & $\begin{array}{l}\text { Comentario adicional: } \\
\text { Los umbrales más bajos que definen la insuficiencia mitral (IM) grave comparada con } \\
\text { la IM primaria se basan en su asociación con el pronóstico. Sin embargo, no está claro } \\
\text { si el pronóstico se ve afectado de manera independiente por la IM, comparada con la } \\
\text { disfunción del VI. Para el tratamiento aislado de válvula mitral en la IM secundaria, } \\
\text { los umbrales de gravedad de la IM para la intervención todavía tienen que validarse } \\
\text { en estudios clínicos. Hasta la fecha, no se ha confirmado el beneficio clínico asociado } \\
\text { con la reducción de la IM secundaria }\end{array}$ \\
\hline \multicolumn{2}{|c|}{ Indicaciones para el tratamiento antitrombótico de pacientes con válvulas protésicas o reparación valvular } \\
\hline $\begin{array}{l}\text { Ila C } \\
\text { Debe considerarse la adición de dosis bajas de ácido acetilsalicílico (75-100 mg/día) } \\
\text { a un AVK en caso de enfermedad ateroesclerótica concomitante }\end{array}$ & $\begin{array}{l}\text { IIb C } \\
\text { Debe considerarse la adición de dosis bajas de ácido acetilsalicílico (75-100 mg/día) } \\
\text { a un AVK en caso de enfermedad ateroesclerótica concomitante }\end{array}$ \\
\hline
\end{tabular}




\section{¿QUÉ HAY NUEVO EN LA EDICIÓN DE 2017? Continuación}

Nuevas recomendaciones de 2017

\section{Tratamiento de la EAC en pacientes con valvulopatías}

Nuevas recomendaciones IIa C:

- Debe considerarse la angio-TC como alternativa a la coronariografía antes de la cirugía valvular para los pacientes con valvulopatía grave y baja probabilidad de EAC o en los que la coronariografía convencional no sea técnicamente factible o se asocie con alto riesgo

- Debe considerarse la ICP para pacientes con una indicación primaria de TAVI y estenosis coronaria > 70\% del diámetro en segmentos proximales

- Debe considerarse la ICP para pacientes con una indicación primaria de intervención percutánea de válvula mitral y estenosis coronaria > 70\% del diámetro en segmentos proximales

\section{Tratamiento de la fibrilación auricular en pacientes con valvulopatías}

Nuevas recomendaciones adicionales:

Véase la nueva tabla «Tratamiento de la fibrilación auricular en pacientes con valvulopatías» en el apartado 3.7.2

\section{Indicaciones para la cirugía en la insuficiencia aórtica grave y la enfermedad de la raíz aórtica}

\section{- Nuevas recomendaciones I C:}

Se recomienda la discusión del equipo cardiológico sobre pacientes seleccionados en los que la reparación de válvula aórtica pueda ser una alternativa viable al reemplazo valvular

- Se recomienda la reparación de válvula aórtica mediante la técnica de reimplante o remodelado con anuloplastia aórtica para los pacientes jóvenes con dilatación de la raíz aórtica y válvula aórtica tricúspide siempre que la intervención la realicen cirujanos con experiencia

\section{- Nueva recomendación Ila C:}

Debe considerarse la cirugía para pacientes con enfermedad de la raíz aórtica con un diámetro máximo de la aorta ascendente $\geq 45$ mm en pacientes con mutación en TGFBR1 o TGFBR2 (incluido el síndrome de Loeys-Dietz)

Puede considerarse un umbral de $40 \mathrm{~mm}$ en mujeres con un ASC pequeña, en pacientes con mutación en TGFBR2 o con características graves no relacionadas con enfermedad aórtica ${ }^{60}$

\section{Diagnóstico de la estenosis aórtica grave}

Véanse las nuevas recomendaciones sobre el diagnóstico de la estenosis aórtica grave en la figura 2 y la tabla 6

\section{Indicaciones para la cirugía en la insuficiencia mitral grave primaria asintomática}

- Nueva recomendación Ila C

Hipertensión pulmonar grave (PAPs > $60 \mathrm{mmHg}$ confirmada de manera invasiva) que no se explica por otra causa

\section{Indicaciones para la cirugía en la estenosis aórtica asintomática}

Nuevo comentario adicional:

- Si la hipertensión pulmonar (PAPs > $50 \mathrm{mmHg}$ en reposo) es la única indicación para la cirugía, el valor debe confirmarse mediante mediciones invasivas

\section{Tratamiento después de una intervención valvular}

\section{Nueva recomendación:}

- Tras el implante percutáneo o quirúrgico de una bioprótesis, debe realizarse un estudio ecocardiográfico que incluya la medición de gradientes transprotésicos en los primeros 30 días para obtener imágenes basales (preferiblemente a los 30 días para la cirugía), otro estudio después de 1 año del implante y, a partir de entonces, un seguimiento anual

\section{Indicaciones para el tratamiento antitrombótico de pacientes con válvulas cardiacas protésicas o reparación valvular}

Nuevas recomendaciones:

I B

- Se recomienda el control del INR por el propio paciente siempre que esté adecuadamente entrenado y se realicen controles de calidad

Ila B

- Para pacientes tratados con implante de stents coronarios, debe considerarse el tratamiento triple con ácido acetilsalicílico (75-100 mg/día), clopidogrel (75 mg/día) y un

AVK durante 1 mes, independientemente del tipo de stent implantado y la presentación clínica (SCA o EAC estable)

- Debe considerarse el tratamiento triple con ácido acetilsalicílico (75-100 mg/día), clopidogrel (75 mg/día) y un AVK durante más de 1 mes y hasta 6 meses para los pacientes con alto riesgo isquémico debido a SCA u otras características anatómicas o del procedimiento que supere el riesgo hemorrágico

IIa A

- Debe considerarse el tratamiento doble con un AVK y clopidogrel (75 mg/día) como alternativa al tratamiento triple durante 1 mes para pacientes cuyo riesgo hemorrágico sea superior al isquémico

IIa B

- Para pacientes tratados con ICP, debe considerarse la suspensión del tratamiento antiagregante a los 12 meses

- Para pacientes que requieren ácido acetilsalicílico o clopidogrel además de un AVK, debe regularse cuidadosamente la intensidad de la dosis de AVK con un objetivo de INR en la parte inferior del intervalo recomendado y con un tiempo en rango terapéutico $>65-70 \%$

IIa C

- Debe considerarse el tratamiento antiagregante doble durante los primeros 3-6 meses tras un TAVI, seguido de tratamiento antiagregante simple crónico para pacientes que no requieran anticoagulación oral por otras razones

\section{IIb C}

- Puede considerarse el tratamiento antiagregante simple tras un TAVI en caso de riesgo hemorrágico alto 


\section{¿QUÉ HAY NUEVO EN LA EDICIÓN DE 2017? Continuación}

\begin{tabular}{l} 
Nuevas recomendaciones de 2017 \\
\hline Tratamiento de la disfunción de válvulas protésicas \\
Nuevas recomendaciones: \\
IC \\
• Se recomienda la anticoagulación con un AVK o HNF para la trombosis de válvula bioprotésica antes de considerar la reintervención \\
IC \\
• Se recomienda la reoperación si la fuga paravalvular está relacionada con endocarditis o causa hemolisis que requiere transfusiones sanguíneas repetidas o produce \\
síntomas graves \\
IIb C \\
• Puede considerarse el cierre transcatéter para las fugas paravalvulares que producen insuficiencia clínicamente significativa en pacientes con riesgo quirúrgico alto (decisión \\
del equipo cardiológico) \\
Ila C \\
• El equipo cardiológico debe considerar el implante percutáneo de «válvula en válvula» en posición aórtica dependiendo del riesgo de la reoperación y el tipo y el tamaño \\
de la prótesis \\
\hline Conceptos nuevos o revisados en 2017 \\
\hline
\end{tabular}

Concepto nuevo

- El texto condensado de la guía está unido al manual suplementario de la ESC, donde se puede consultar información general complementaria

- Puntos clave y lagunas en la evidencia al final de cada sección

¡Centros especializados en valvulopatías y nuevo concepto de Equipo Cardiológico (heart team)!

- Véanse la nueva tabla 5 «Requisitos recomendados para un centro especializado en valvulopatías» y la sección 3.6

\begin{tabular}{|c|c|c|}
\hline Clase I & Clase IIa & Clase IIb \\
\hline
\end{tabular}

\section{APÉNDICE}

Comité de la ESC para las Guías de Práctica Clínica: Stephan Windecker (coordinador) (Suiza), Victor Aboyans (Francia), Stefan Agewall (Noruega), Emanuele Barbato (Italia), Héctor Bueno (España), Antonio Coca (España), Jean-Philippe Collet (Francia), Ioan Mircea Coman (Rumanía), Veronica Dean (Francia), Victoria Delgado (Países Bajos), Donna Fitzsimons (Reino Unido), Oliver Gaemperli (Suiza), Gerhard Hindricks (Alemania), Bernard Iung (Francia), Peter Jüni (Canadá), Hugo A. Katus (Alemania), Juhani Knuuti (Finlandia), Patrizio Lancellotti (Bélgica), Christophe Leclercq (Francia), Theresa McDonagh (Reino Unido), Massimo Franciasco Piepoli (Italia), Piotr Ponikowski (Polonia), Dimitrios J. Richter (Grecia), Marco Roffi (Suiza), Evgeny Shlyakhto (Rusia), Iain A. Simpson (Reino Unido) y José Luis Zamorano (España).

Sociedades nacionales de la ESC que han colaborado activamente en el proceso de revisión de la Guía ESC 2017 sobre el tratamiento de las valvulopatías:

Alemania: German Cardiac Society, Hüseyin Ince; Antigua República Yugoslava de Macedonia: Macedonian FYR Society of Cardiology, Elizabeta Srbinovska-Kostovska; Armenia: Armenian Cardiologists Association, Hovhannes K. Kzhdryan; Austria: Austrian Society of Cardiology, Julia Mascherbauer; Azerbaiyán: Azerbaijan Society of Cardiology, Fuad Samadov; Bélgica: Belgian Society of Cardiology, Guy Van Camp; Bielorrusia: Belorussian Scientific Society of Cardiologists, Vadim Shumavets; BosniaHerzegovina: Association of Cardiologists of Bosnia and Herzegovina, Daniela Loncar; Chipre: Cyprus Society of Cardiology, Georgios M. Georgiou; Croacia: Croatian Cardiac Society, Daniel Lovric; Dinamarca: Danish Society of Cardiology, Nikolaj Ihlemann; Egipto: Egyptian Society of Cardiology, Magdy Abdelhamid; Eslovaquia: Slovak Society of Cardiology, Iveta Simkova; Eslovenia: Slovenian Society of Cardiology, Matjaz Bunc; España: Spanish Society of Cardiology, José Antonio Vázquez de Prada; Estonia: Estonian Society of Cardiology, Teele Pern; Federación Rusa: Russian Society of Cardiology, Vladimir Uspenskiy; Finlandia: Finnish Cardiac Society, Anu Turpeinen; Francia: French Society of Cardiology, Ariel Cohen; Georgia: Georgian
Society of Cardiology, Zviad Bakhutashvili; Grecia: Hellenic Society of Cardiology, Manolis Vavuranakis; Hungría: Hungarian Society of Cardiology, András Temesvári; Islandia: Icelandic Society of Cardiology, Thorarinn Gudnason; Irlanda: Irish Cardiac Society, Darren Mylotte; Israel: Israel Heart Society, Rafael Kuperstein; Italia: Italian Federation of Cardiology, Ciro Indolfi; Kazajistán: Association of Cardiologists of Kazakhstan, Yury Pya; Kirguizistán: Kyrgyz Society of Cardiology, Alina Kerimkulova; Kosovo: Kosovo Society of Cardiology, Gani Bajraktari; Letonia: Latvian Society of Cardiology, Ainars Rudzitis; Lituania: Lithuanian Society of Cardiology, Vaida Mizariene; Luxemburgo: Luxembourg Society of Cardiology, Frédéric Lebrun; Malta: Maltese Cardiac Society, Daniela Cassar Demarco; Marruecos: Moroccan Society of Cardiology, Latifa Oukerraj; Noruega: Norwegian Society of Cardiology, Terje Kristian Steigen; Países Bajos: Netherlands Society of Cardiology, Berto J. Bouma; Polonia: Polish Cardiac Society, Monika Komar; Portugal: Portuguese Society of Cardiology, Luisa Maria De Moura Branco; Reino Unido: British Cardiovascular Society, Stephen J. D. Brecker; República Checa: Czech Society of Cardiology, Katerina Linhartova; Rumanía: Romanian Society of Cardiology, Bogdan A. Popescu; San Marino: San Marino Society of Cardiology, Marina Foscoli; Serbia: Cardiology Society of Serbia, Ljiljana Jovovic; Suecia: Swedish Society of Cardiology, Martin Stagmo; Suiza: Swiss Society of Cardiology, Beat Andreas Kaufmann; Túnez: Tunisian Society of Cardiology and Cardio-Vascular Surgery, Abdallah Mahdhaoui; Turquía: Turkish Society of Cardiology, Engin Bozkurt; Ucrania: Ukrainian Association of Cardiology, Elena Nesukay.

Nuestro agradecimiento al Prof. A. Pieter Kappetein por su asesoramiento y contribución a esta guía de práctica clínica.

\section{BIBLIOGRAFÍA}

1. Popescu BA, Andrade MJ, Badano LP, Fox KF, Flachskampf FA, Lancellotti P, Varga A, Sicari R, Evangelista A, Nihoyannopoulos P, Zamorano JL, Derumeaux G, Kasprzak JD, Roelandt JR. European Association of Echocardiography recommendations for training, competence, and quality improvement in echocardiography. Eur J Echocardiogr. 2009;10:893-905.

2. Lancellotti P, Tribouilloy C, Hagendorff A, Popescu BA, Edvardsen T, Pierard LA, Badano L, Zamorano JL, Scientific Document Committee of the European Association of Cardiovascular Imaging. Recommendations for the echocardiographic assessment of native valvular regurgitation: an executive 
summary from the European Association of Cardiovascular Imaging. Eur Heart J Cardiovasc Imaging. 2013;14:611-644.

3. Baumgartner H, Hung J, Bermejo J, Chambers JB, Evangelista A, Griffin BP, Iung B, Otto CM, Pellikka PA, Quinones M, EAE/ASE. Echocardiographic assessment of valve stenosis: EAE/ASE recommendations for clinical practice. Eur J Echocardiogr. 2009;10:1-25.

4. Baumgartner H, Hung J, Bermejo J, Chambers JB, Edvardsen T, Goldstein S, Lancellotti P, LeFevre M, Miller F, Otto CM. Focus update on the echocardiographic assessment of aortic valve stenosis: EAE/ASE recommendations for clinical practice. Eur Heart J Cardiovasc Imaging. 2017;18:254-275.

5. Rudski LG, Lai WW, Afilalo J, Hua L, Handschumacher MD, Chandrasekaran K, Solomon SD, Louie EK, Schiller NB. Guidelines for the echocardiographic assessment of the right heart in adults: a report from the American Society of Echocardiography endorsed by the European Association of Echocardiography, a registered branch of the European Society of Cardiology, and the Canadian Society of Echocardiography. J Am Soc Echocardiogr. 2010;23:685-713.

6. Lancellotti P, Tribouilloy C, Hagendorff A, Moura L, Popescu BA, Agricola E, Monin JL, Pierard LA, Badano L, Zamorano JL, European Association of Echocardiography. European Association of Echocardiography recommendations for the assessment of valvular regurgitation. Part 1: aortic and pulmonary regurgitation (native valve disease). Eur J Echocardiogr. 2010;11:223-244.

7. Lancellotti P, Moura L, Pierard LA, Agricola E, Popescu BA, Tribouilloy C, Hagendorff A, Monin JL, Badano L, Zamorano JL, European Association of Echocardiography. European Association of Echocardiography recommendations for the assessment of valvular regurgitation. Part 2: mitral and tricuspid regurgitation (native valve disease). Eur J Echocardiogr. 2010;11:307-332.

8. Henri C, Pierard LA, Lancellotti P, Mongeon FP, Pibarot P, Basmadjian AJ. Exercise testing and stress imaging in valvular heart disease. Can J Cardiol. 2014;30: 1012-1026.

9. Picano E, Pibarot P, Lancellotti P, Monin JL, Bonow RO. The emerging role of exercise testing and stress echocardiography in valvular heart disease. J Am Coll Cardiol. 2009;54:2251-2260.

10. Monin JL, Quere JP, Monchi M, Petit H, Baleynaud S, Chauvel C, Pop C, Ohlmann P, Lelguen C, Dehant P, Tribouilloy C, Gueret P. Low-gradient aortic stenosis: operative risk stratification and predictors for long-term outcome: a multicenter study using dobutamine stress hemodynamics. Circulation. 2003;108:319-324.

11. Clavel MA, Magne J, Pibarot P. Low-gradient aortic stenosis. Eur Heart J. 2016;37:2645-57.

12. American College of Cardiology Foundation Task Force on Expert Consensus Documents, Hundley WG, Bluemke DA, Finn JP, Flamm SD, Fogel MA, Friedrich MG, Ho VB, Jerosch-Herold M, Kramer CM, Manning WJ, Patel M, Pohost GM, Stillman AE, White RD, Woodard PK. ACCF/ACR/AHA/NASCI/SCMR 2010 expert consensus document on cardiovascular magnetic resonance: a report of the American College of Cardiology Foundation Task Force on Expert Consensus Documents. J Am Coll Cardiol. 2010;55:2614-2662.

13. Cueff C, Serfaty JM, Cimadevilla C, Laissy JP, Himbert D, Tubach F, Duval X, Iung B, Enriquez-Sarano M, Vahanian A, Messika-Zeitoun D. Measurement of aortic valve calcification using multislice computed tomography: correlation with haemodynamic severity of aortic stenosis and clinical implication for patients with low ejection fraction. Heart. 2011;97:721-726.

14. Clavel MA, Messika-Zeitoun D, Pibarot P, Aggarwal SR, Malouf J, Araoz PA, Michelena HI, Cueff C, Larose E, Capoulade R, Vahanian A, Enriquez-Sarano M. The complex nature of discordant severe calcified aortic valve disease grading: new insights from combined Doppler echocardiographic and computed tomographic study. J Am Coll Cardiol. 2013;62:2329-2338.

15. Bergler-Klein J, Gyongyosi M, Maurer G. The role of biomarkers in valvular heart disease: focus on natriuretic peptides. Can J Cardiol. 2014;30:1027-1034.

16. Windecker S, Kolh P, Alfonso F, Collet JP, Cremer J, Falk V, Filippatos G, Hamm C, Head SJ, Juni P, Kappetein AP, Kastrati A, Knuuti J, Landmesser U, Laufer G, Neumann FJ, Richter DJ, Schauerte P, Sousa Uva M, Stefanini GG, Taggart DP, Torracca L, Valgimigli M, Wijns W, Witkowski A. 2014 ESC/EACTS Guidelines on myocardial revascularization: the Task Force on Myocardial Revascularization of the European Society of Cardiology (ESC) and the European Association for Cardio-Thoracic Surgery (EACTS). Developed with the special contribution of the European Association of Percutaneous Cardiovascular Interventions (EAPCI). Eur Heart J. 2014;35:2541-2619.

17. Osnabrugge RL, Speir AM, Head SJ, Fonner CE, Fonner E, Kappetein AP, Rich JB. Performance of EuroSCORE II in a large US database: implications for transcatheter aortic valve implantation. Eur J Cardiothorac Surg. 2014;46:400-408.

18. Barili F, Pacini D, Capo A, Rasovic O, Grossi C, Alamanni F, Di Bartolomeo R, Parolari A. Does EuroSCORE II perform better than its original versions? A multicentre validation study. Eur Heart J. 2013;34:22-29.

19. Iung B, Laouenan C, Himbert D, Eltchaninoff H, Chevreul K, Donzeau-Gouge P, Fajadet J, Leprince P, Leguerrier A, Lievre M, Prat A, Teiger E, Laskar M, Vahanian A, Gilard M, FRANCE 2 Investigators. Predictive factors of early mortality after transcatheter aortic valve implantation: individual risk assessment using a simple score. Heart. 2014;100:1016-1023.

20. Edwards FH, Cohen DJ, O'Brien SM, Peterson ED, Mack MJ, Shahian DM, Grover FL, Tuzcu EM, Thourani VH, Carroll J, Brennan JM, Brindis RG, Rumsfeld J, Holmes DR Jr. Steering Committee of the Society of Thoracic Surgeons/American College of Cardiology Transcatheter Valve Therapy Registry. Development and validation of a risk prediction model for in-hospital mortality after transcatheter aortic valve replacement. JAMA Cardiol. 2016;1:46-52.

21. Arnold SV, Reynolds MR, Lei Y, Magnuson EA, Kirtane AJ, Kodali SK, Zajarias A, Thourani VH, Green P, Rodes-Cabau J, Beohar N, Mack MJ, Leon MB, Cohen DJ, PARTNER Investigators. Predictors of poor outcomes after transcatheter aortic valve replacement: results from the PARTNER (Placement of Aortic Transcatheter Valve) trial. Circulation. 2014;129:2682-2690.

22. Puri R, Iung B, Cohen DJ, Rodes-Cabau J. TAVI or no TAVI: identifying patients unlikely to benefit from transcatheter aortic valve implantation. Eur Heart J. 2016;37:2217-2225.

23. Gagne JJ, Glynn RJ, Avorn J, Levin R, Schneeweiss S. A combined comorbidity score predicted mortality in elderly patients better than existing scores. J Clin Epidemiol. 2011:64:749-759.

24. Gunter RL, Kilgo P, Guyton RA, Chen EP, Puskas JD, Cooper WA, Halkos ME, Lattouf OM, Babaliaros V, Myung R, Leshnower B, Thourani VH. Impact of preoperative chronic lung disease on survival after surgical aortic valve replacement. Ann Thorac Surg. 2013;96:1322-1328.

25. Allende R, Webb JG, Munoz-Garcia AJ, de Jaegere P, Tamburino C, Dager AE, Cheema A, Serra V, Amat-Santos I, Velianou JL, Barbanti M, Dvir D, AlonsoBriales JH, Nuis RJ, Faqiri E, Imme S, Benitez LM, Cucalon AM, Al Lawati H, Garcia del Blanco B, Lopez J, Natarajan MK, DeLarochelliere R, Urena M, Ribeiro HB, Dumont E, Nombela-Franco L, Rodes-Cabau J. Advanced chronic kidney disease in patients undergoing transcatheter aortic valve implantation: insights on clinical outcomes and prognostic markers from a large cohort of patients. Eur Heart J. 2014;35:2685-2696.

26. Stortecky S, Schoenenberger AW, Moser A, Kalesan B, Juni P, Carrel T, Bischoff S, Schoenenberger CM, Stuck AE, Windecker S, Wenaweser P. Evaluation of multidimensional geriatric assessment as a predictor of mortality and cardiovascular events after transcatheter aortic valve implantation. JACC Cardiovasc Interv. 2012;5:489-496.

27. Puls M, Sobisiak B, Bleckmann A, Jacobshagen C, Danner BC, Hunlich M, Beissbarth T, Schondube F, Hasenfuss G, Seipelt R, Schillinger W. Impact of frailty on short- and long-term morbidity and mortality after transcatheter aortic valve implantation: risk assessment by Katz Index of activities of daily living. EuroIntervention. 2014;10:609-619.

28. Habib G, Lancellotti P, Antunes MJ, Bongiorni MG, Casalta JP, Del Zotti F, Dulgheru R, El Khoury G, Erba PA, Iung B, Miro JM, Mulder BJ, Plonska- Gosciniak E, Price S, Roos-Hesselink J, Snygg-Martin U, Thuny F, Tornos Mas P, Vilacosta I, Zamorano JL, Document R, Erol C, Nihoyannopoulos P, Aboyans V, Agewall S, Athanassopoulos G, Aytekin S, Benzer W, Bueno H, Broekhuizen L, Carerj S, Cosyns B, De Backer J, De Bonis M, Dimopoulos K, Donal E, Drexel H, Flachskampf FA, Hall R, Halvorsen S, Hoen B, Kirchhof P, Lainscak M, Leite-Moreira AF, Lip GY, Mestres CA, Piepoli MF, Punjabi PP, Rapezzi C, Rosenhek R, Siebens K, Tamargo J, Walker DM. 2015 ESC Guidelines for the management of infective endocarditis: the Task Force for the Management of Infective Endocarditis of the European Society of Cardiology (ESC). Endorsed by: European Association for Cardio-Thoracic Surgery (EACTS), the European Association of Nuclear Medicine (EANM). Eur Heart J. 2015;36: 3075-3128.

29. Marijon E, Mirabel M, Celermajer DS, Jouven X. Rheumatic heart disease. Lancet. 2012;379:953-964

30. Gerber MA, Baltimore RS, Eaton CB, Gewitz M, Rowley AH, Shulman ST, Taubert KA. Prevention of rheumatic fever and diagnosis and treatment of acute Streptococcal pharyngitis: a scientific statement from the American Heart Association Rheumatic Fever, Endocarditis, and Kawasaki Disease Committee of the Council on Cardiovascular Disease in the Young, the Interdisciplinary Council on Functional Genomics and Translational Biology, and the Interdisciplinary Council on Quality of Care and Outcomes Research: endorsed by the American Academy of Pediatrics. Circulation. 2009;119:1541-1551.

31. Remenyi B, Carapetis J, Wyber R, Taubert K, Mayosi BM, World Heart Federation. Position statement of the World Heart Federation on the prevention and control of rheumatic heart disease. Nat Rev Cardiol. 2013:10:284-292.

32. Chambers J, Prendergast B, Iung B, Rosenhek R, Zamorano JL, Pierard LA, Modine T, Falk V, Kappetein AP, Pibarot P, Sundt T, Bamgartner H, Bax JJ, Lancellotti P. Standards defining a "heart valve centre": ESC Working Group on Valvular Heart Disease and European Association for Cardiothoracic Surgery viewpoint. Eur Heart J. 2017;38:2177-2182.

33. Chambers JB, Ray S, Prendergast B, Taggart D, Westaby S, Grothier L, Arden C, Wilson J, Campbell B, Sandoe J, Gohlke-Barwolf C, Mestres CA, Rosenhek R, Otto C. Specialist valve clinics: recommendations from the British Heart Valve Society working group on improving quality in the delivery of care for patients with heart valve disease. Heart. 2013:99:1714-1716.

34. Badheka AO, Patel NJ, Panaich SS, Patel SV, Jhamnani S, Singh V, Pant S, Patel N, Patel N, Arora S, Thakkar B, Manvar S, Dhoble A, Patel A, Savani C, Patel J, Chothani A, Savani GT, Deshmukh A, Grines CL, Curtis J, Mangi AA, Cleman M, Forrest JK. Effect of hospital volume on outcomes of transcatheter aortic valve implantation. Am J Cardiol. 2015;116:587-594.

35. Kilic A, Shah AS, Conte JV, Baumgartner WA, Yuh DD. Operative outcomes in mitral valve surgery: combined effect of surgeon and hospital volume in a population-based analysis. J Thorac Cardiovasc Surg. 2013;146:638-646.

36. Pagano D, Kappetein AP, Sousa-Uva M, Beyersdorf F, Klautz R, Mohr F, Falk V, European Association for Cardio-Thoracic Surgery (EACTS) and the EACTS Quality Improvement Programme. EACTS clinical statement: guidance for the provision of adult cardiac surgery. Eur J Cardiothorac Surg. 2016;50:1006-1009.

37. Kirchhof P, Benussi S, Kotecha D, Ahlsson A, Atar D, Casadei B, Castella M, Diener HC, Heidbuchel H, Hendriks J, Hindricks G, Manolis AS, Oldgren J, Popescu BA Schotten U, Van Putte B, Vardas P. 2016 ESC Guidelines for the management of atrial fibrillation developed in collaboration with EACTS: the Task Force for the management of atrial fibrillation of the European Society of Cardiology (ESC). Developed with the special contribution of the European Heart Rhythm Association (EHRA) of the ESC: endorsed by the European Stroke Organisation (ESO). Eur Heart J. 2016;37:2893-2962. 
38. Breithardt G, Baumgartner H, Berkowitz SD, Hellkamp AS, Piccini JP, Stevens SR Lokhnygina Y, Patel MR, Halperin JL, Singer DE, Hankey GJ, Hacke W, Becker RC, Nessel CC, Mahaffey KW, Fox KA, Califf RM, ROCKET AF Steering Committee and Investigators. Clinical characteristics and outcomes with rivaroxaban vs. warfarin in patients with non-valvular atrial fibrillation but underlying native mitral and aortic valve disease participating in the ROCKET AF trial. Eur Heart J. 2014;35:3377-3385.

39. Avezum A, Lopes RD, Schulte PJ, Lanas F, Gersh BJ, Hanna M, Pais P, Erol C, Diaz R, Bahit MC, Bartunek J, De Caterina R, Goto S, Ruzyllo W, Zhu J, Granger CB, Alexander JH. Apixaban in comparison with warfarin in patients with atrial fibrillation and valvular heart disease: findings from the Apixaban for Reduction in Stroke and Other Thromboembolic Events in Atrial Fibrillation (ARISTOTLE) Trial. Circulation. 2015;132:624-632.

40. Ezekowitz MD, Nagarakanti R, Noack H, Brueckmann M, Litherland C, Jacobs M, Clemens A, Reilly PA, Connolly SJ, Yusuf S, Wallentin L. Comparison of dabigatran and warfarin in patients with atrial fibrillation and valvular heart disease: the RE-LY Trial (Randomized Evaluation of Long-Term Anticoagulant Therapy). Circulation. 2016;134:589-598.

41. De Caterina R, Renda G, Carnicelli AP, Nordio F, Trevisan M, Mercuri MF, Ruff CT, Antman EM, Braunwald E, Giugliano RP. Valvular heart disease patients on edoxaban or warfarin in the ENGAGE AF-TIMI 48 Trial. J Am Coll Cardiol. 2017;69:1372-1382.

42. Iung B, Rodes-Cabau J. The optimal management of anti-thrombotic therapy after valve replacement: certainties and uncertainties. Eur Heart J. 2014;35 2942-2949.

43. Heidbuchel H, Verhamme P, Alings M, Antz M, Diener HC, Hacke W, Oldgren J, Sinnaeve P, Camm AJ, Kirchhof P. Updated European Heart Rhythm Association Practical Guide on the use of non-vitamin K antagonist anticoagulants in patients with non-valvular atrial fibrillation. Europace. 2015;17:1467-1507.

44. Gillinov AM, Gelijns AC, Parides MK, DeRose JJ Jr, Moskowitz AJ, Voisine P, Ailawadi G, Bouchard D, Smith PK, Mack MJ, Acker MA, Mullen JC, Rose EA, Chang HL, Puskas JD, Couderc JP, Gardner TJ, Varghese R, Horvath KA, Bolling SF, Michler RE, Geller NL, Ascheim DD, Miller MA, Bagiella E, Moquete EG, Williams P, Taddei-Peters WC, O'Gara PT, Blackstone EH, Argenziano M, CTSN Investigators. Surgical ablation of atrial fibrillation during mitral-valve surgery. $N \mathrm{Engl} \mathrm{J} \mathrm{Med.}$ 2015;372:1399-1409.

45. Eikelboom JW, Connolly SJ, Brueckmann M, Granger CB, Kappetein AP, Mack MJ Blatchford J, Devenny K, Friedman J, Guiver K, Harper R, Khder Y, Lobmeyer MT, Maas H, Voigt JU, Simoons ML, Van de Werf F, RE-ALIGN Investigators. Dabigatran versus warfarin in patients with mechanical heart valves. $N$ Engl J Med. 2013;369:1206-1214.

46. Tsai YC, Phan K, Munkholm-Larsen S, Tian DH, La Meir M, Yan TD. Surgical left atrial appendage occlusion during cardiac surgery for patients with atrial fibrillation: a meta-analysis. Eur J Cardiothorac Surg. 2015;47:847-854.

47. Iung B, Baron G, Butchart EG, Delahaye F, Gohlke-Barwolf C, Levang OW, Tornos P, Vanoverschelde JL, Vermeer F, Boersma E, Ravaud P, Vahanian A. A prospective survey of patients with valvular heart disease in Europe: the Euro Heart Survey on Valvular Heart Disease. Eur Heart J. 2003;24:1231-1243.

48. le Polain de Waroux JB, Pouleur AC, Goffinet C, Vancraeynest D, Van Dyck M Robert A, Gerber BL, Pasquet A, El Khoury G, Vanoverschelde JL. Functional anatomy of aortic regurgitation: accuracy, prediction of surgical repairability, and outcome implications of transesophageal echocardiography. Circulation. 2007; 116:I264-269.

49. Lansac E, Di Centa I, Raoux F, Al Attar N, Acar C, Joudinaud T, Raffoul R. A lesional classification to standardize surgical management of aortic insufficiency towards valve repair. Eur J Cardiothorac Surg. 2008;33:872-878.

50. Sambola A, Tornos P, Ferreira-Gonzalez I, Evangelista A. Prognostic value of preoperative indexed end-systolic left ventricle diameter in the outcome after surgery in patients with chronic aortic regurgitation. Am Heart J. 2008;155:1114-1120.

51. Marciniak A, Sutherland GR, Marciniak M, Claus P, Bijnens B, Jahangiri M. Myocardial deformation abnormalities in patients with aortic regurgitation: a strain rate imaging study. Eur J Echocardiogr. 2009;10:112-119.

52. Goldstein SA, Evangelista A, Abbara S, Arai A, Asch FM, Badano LP, Bolen MA Connolly HM, Cuellar-Calabria H, Czerny M, Devereux RB, Erbel RA, Fattori R, Isselbacher EM, Lindsay JM, McCulloch M, Michelena HI, Nienaber CA, Oh JK, Pepi M, Taylor AJ, Weinsaft JW, Zamorano JL, Dietz H, Eagle K, Elefteriades J, Jondeau G, Rousseau H, Schepens M. Multimodality imaging of diseases of the thoracic aorta in adults: from the American Society of Echocardiography and the European Association of Cardiovascular Imaging: endorsed by the Society of Cardiovascular Computed Tomography and Society for Cardiovascular Magnetic Resonance. J Am Soc Echocardiogr. 2015;28:119-182.

53. Lang RM, Badano LP, Mor-Avi V, Afilalo J, Armstrong A, Ernande L, Flachskampf FA, Foster E, Goldstein SA, Kuznetsova T, Lancellotti P, Muraru D, Picard MH Rietzschel ER, Rudski L, Spencer KT, Tsang W, Voigt JU. Recommendations for cardiac chamber quantification by echocardiography in adults: an update from the American Society of Echocardiography and the European Association of Cardiovascular Imaging. J Am Soc Echocardiogr. 2015;28:1-39.e14.

54. Freeman LA, Young PM, Foley TA, Williamson EE, Bruce CJ, Greason KL. CT and MRI assessment of the aortic root and ascending aorta. AJR Am J Roentgenol. 2013;200:W581-W592.

55. Amsallem M, Ou P, Milleron O, Henry-Feugeas MC, Detaint D, Arnoult F, Vahanian A, Jondeau G. Comparative assessment of ascending aortic aneurysms in Marfan patients using ECG-gated computerized tomographic angiography versus transthoracic echocardiography. Int J Cardiol. 2015;184:22-27.

56. Erbel R, Aboyans V, Boileau C, Bossone E, Bartolomeo RD, Eggebrecht H, Evangelista A, Falk V, Frank H, Gaemperli O, Grabenwoger M, Haverich A, Iung B,
Manolis AJ, Meijboom F, Nienaber CA, Roffi M, Rousseau H, Sechtem U, Sirnes PA, Allmen RS, Vrints CJ, ESC Committee for Practice Guidelines. 2014 ESC Guidelines on the diagnosis and treatment of aortic diseases: Document covering acute and chronic aortic diseases of the thoracic and abdominal aorta of the adult. The Task Force for the Diagnosis and Treatment of Aortic Diseases of the European Society of Cardiology (ESC). Eur Heart J. 2014;35:2873-2926.

57. Chaliki HP, Mohty D, Avierinos JF, Scott CG, Schaff HV, Tajik AJ, Enriquez-Sarano M. Outcomes after aortic valve replacement in patients with severe aortic regurgitation and markedly reduced left ventricular function. Circulation. 2002;106:2687-2693.

58. Tornos P, Sambola A, Permanyer-Miralda G, Evangelista A, Gomez Z, Soler-Soler J. Long-term outcome of surgically treated aortic regurgitation: influence of guideline adherence toward early surgery. J Am Coll Cardiol. 2006;47:1012-1017.

59. Jondeau G, Detaint D, Tubach F, Arnoult F, Milleron O, Raoux F, Delorme G, Mimoun L, Krapf L, Hamroun D, Beroud C, Roy C, Vahanian A, Boileau C. Aortic event rate in the Marfan population: a cohort study. Circulation. 2012;125: 226-232.

60. Jondeau G, Ropers I, Regalado E, Braverman A, Evangelista A, Teixedo G, De Backer J, Muino-Mosquera L, Naudion S, Zordan C, Morisaki T, Morisaki H, Von Kodolitsch Y, Dupuis-Girod S, Morris SA, Jeremy R, Odent S, Ades LC, Bakshi M, Holman K, LeMaire S, Milleron O, Langeois M, Spentchian M, Aubart M, Boileau C, Pyeritz R, Milewicz DM, Montalcino Aortic Consortium. International Registry of Patients Carrying TGFBR1 or TGFBR2 Mutations: results of the MAC (Montalcino Aortic Consortium). Circ Cardiovasc Genet. 2016;9:548-558.

61. Borger MA, Preston M, Ivanov J, Fedak PW, Davierwala P, Armstrong S, David TE. Should the ascending aorta be replaced more frequently in patients with bicuspid aortic valve disease? J Thorac Cardiovasc Surg. 2004;128:677-683.

62. Aicher D, Fries R, Rodionycheva S, Schmidt K, Langer F, Schafers HJ. Aortic valve repair leads to a low incidence of valve-related complications. Eur J Cardiothorac Surg. 2010;37:127-132.

63. Vohra HA, Whistance RN, De Kerchove L, Punjabi P, El Khoury G. Valve-preserving surgery on the bicuspid aortic valve. Eur J Cardiothorac Surg. 2013:43:888-898.

64. Arabkhani B, Mookhoek A, Di Centa I, Lansac E, Bekkers JA, De Lind Van Wijngaarden R, Bogers AJ, Takkenberg JJ. Reported outcome after valve-sparing aortic root replacement for aortic root aneurysm: a systematic review and metaanalysis. Ann Thorac Surg. 2015;100:1126-1131.

65. Lansac E, Di Centa I, Sleilaty G, Lejeune S, Khelil N, Berrebi A, Diakov C, Mankoubi L, Malergue MC, Noghin M, Zannis K, Salvi S, Dervanian P, Debauchez M. Longterm results of external aortic ring annuloplasty for aortic valve repair. Eur J Cardiothorac Surg. 2016;50:350-360.

66. Dujardin KS, Enriquez-Sarano M, Schaff HV, Bailey KR, Seward JB, Tajik AJ. Mortality and morbidity of aortic regurgitation in clinical practice. A long-term follow-up study. Circulation. 1999;99:1851-1857.

67. Klodas E, Enriquez-Sarano M, Tajik AJ, Mullany CJ, Bailey KR, Seward JB. Optimizing timing of surgical correction in patients with severe aortic regurgitation: role of symptoms. J Am Coll Cardiol. 1997;30:746-752.

68. Zendaoui A, Lachance D, Roussel E, Couet J, Arsenault M. Usefulness of carvedilol in the treatment of chronic aortic valve regurgitation. Circ Heart Fail. 2011;4: 207-213.

69. Elder DH, Wei L, Szwejkowski BR, Libianto R, Nadir A, Pauriah M, Rekhraj S, Lim TK, George J, Doney A, Pringle SD, Choy AM, Struthers AD, Lang CC. The impact of renin-angiotensin-aldosterone system blockade on heart failure outcomes and mortality in patients identified to have aortic regurgitation: a large population cohort study. J Am Coll Cardiol. 2011;58:2084-2091.

70. Lacro RV, Dietz HC, Sleeper LA, Yetman AT, Bradley TJ, Colan SD, Pearson GD, Selamet Tierney ES, Levine JC, Atz AM, Benson DW, Braverman AC, Chen S, De Backer J, Gelb BD, Grossfeld PD, Klein GL, Lai WW, Liou A, Loeys BL, Markham LW, Olson AK, Paridon SM, Pemberton VL, Pierpont ME, Pyeritz RE, Radojewski E, Roman MJ, Sharkey AM, Stylianou MP, Wechsler SB, Young LT, Mahony L, Pediatric Heart Network Investigators. Atenolol versus losartan in children and young adults with Marfan's syndrome. N Engl J Med. 2014;371:2061-2071.

71. Milleron O, Arnoult F, Ropers J, Aegerter P, Detaint D, Delorme G, Attias D, Tubach F, Dupuis-Girod S, Plauchu H, Barthelet M, Sassolas F, Pangaud N, Naudion S, Thomas-Chabaneix J, Dulac Y, Edouard T, Wolf JE, Faivre L, Odent S, Basquin A, Habib G, Collignon P, Boileau C, Jondeau G. Marfan Sartan: a randomized, doubleblind, placebo-controlled trial. Eur Heart J. 2015;36:2160-2166.

72. Forteza A, Evangelista A, Sanchez V, Teixido-Tura G, Sanz P, Gutierrez L, Gracia T, Centeno J, Rodriguez-Palomares J, Rufilanchas JJ, Cortina J, Ferreira- Gonzalez I, Garcia-Dorado D. Efficacy of losartan vs. atenolol for the prevention of aortic dilation in Marfan syndrome: a randomized clinical trial. Eur Heart J. 2016;37: 978-985.

73. Meijboom LJ, Vos FE, Timmermans J, Boers GH, Zwinderman AH, Mulder BJ. Pregnancy and aortic root growth in the Marfan syndrome: a prospective study. Eur Heart J. 2005;26:914-920.

74. McKellar SH, MacDonald RJ, Michelena HI, Connolly HM, Sundt TM 3rd. Frequency of cardiovascular events in women with a congenitally bicuspid aortic valve in a single community and effect of pregnancy on events. Am J Cardiol. 2011;107: 96-99.

75. Braverman AC, Harris KM, Kovacs RJ, Maron BJ, American Heart Association Electrocardiography and Arrhythmias Committee of Council on Clinical Cardiology, Council on Cardiovascular Disease in Young, Council on Cardiovascular and Stroke Nursing, Council on Functional Genomics and Translational Biology, American College of Cardiology. Eligibility and disqualification recommendations for competitive athletes with cardiovascular abnormalities: Task Force 7: aortic diseases, including Marfan syndrome: a scientific statement from the American Heart Association and American College of Cardiology. Circulation. 2015;132:e303-e309. 
76. Pizarro R, Bazzino OO, Oberti PF, Falconi ML, Arias AM, Krauss JG, Cagide AM. Prospective validation of the prognostic usefulness of B-type natriuretic peptide in asymptomatic patients with chronic severe aortic regurgitation. J Am Coll Cardiol. 2011;58:1705-1714.

77. Weisenberg D, Omelchenko A, Shapira Y, Vaturi M, Monakier D, Bental T, Sagie A Mid-term echocardiographic progression of patients with moderate aortic regurgitation: implications for aortic valve surgery. J Heart Valve Dis. 2013;22: 192-194.

78. Levy F, Laurent M, Monin JL, Maillet JM, Pasquet A, Le Tourneau T, Petit-Eisenmann H, Gori M, Jobic Y, Bauer F, Chauvel C, Leguerrier A, Tribouilloy C. Aortic valve replacement for low-flow/low-gradient aortic stenosis operative risk stratification and long-term outcome: a European multicenter study. J Am Coll Cardiol. 2008;51:1466-1472.

79. Hachicha Z, Dumesnil JG, Bogaty P, Pibarot P. Paradoxical low-flow, low-gradient severe aortic stenosis despite preserved ejection fraction is associated with higher afterload and reduced survival. Circulation. 2007;115:2856-2864.

80. Clavel MA, Dumesnil JG, Capoulade R, Mathieu P, Senechal M, Pibarot P. Outcome of patients with aortic stenosis, small valve area, and low-flow, lowgradient despite preserved left ventricular ejection fraction. J Am Coll Cardiol. 2012;60:1259-1267.

81. Clavel MA, Pibarot P, Messika-Zeitoun D, Capoulade R, Malouf J, Aggarval S, Araoz PA, Michelena HI, Cueff C, Larose E, Miller JD, Vahanian A, Enriquez-Sarano M. Impact of aortic valve calcification, as measured by MDCT, on survival in patients with aortic stenosis: results of an international registry study. J Am Coll Cardiol. 2014;64:1202-1213.

82. Mehrotra P, Jansen K, Flynn AW, Tan TC, Elmariah S, Picard MH, Hung J. Differential left ventricular remodelling and longitudinal function distinguishes low flow from normal-flow preserved ejection fraction low-gradient severe aortic stenosis. Eur Heart J. 2013;34:1906-1914.

83. Tribouilloy C, Rusinaru D, Marechaux S, Castel AL, Debry N, Maizel J, Mentaverri R, Kamel S, Slama M, Levy F. Low-gradient, low-flow severe aortic stenosis with preserved left ventricular ejection fraction: characteristics, outcome, and implications for surgery. J Am Coll Cardiol. 2015;65:55-66.

84. Jander N, Minners J, Holme I, Gerdts E, Boman K, Brudi P, Chambers JB, Egstrup K, Kesaniemi YA, Malbecq W, Nienaber CA, Ray S, Rossebo A, Pedersen TR, Skjaerpe T, Willenheimer R, Wachtell K, Neumann FJ, Gohlke-Barwolf C. Outcome of patients with low-gradient "severe" aortic stenosis and preserved ejection fraction. Circulation. 2011;123:887-895.

85. Rafique AM, Biner S, Ray I, Forrester JS, Tolstrup K, Siegel RJ. Meta-analysis of prognostic value of stress testing in patients with asymptomatic severe aortic stenosis. Am J Cardiol. 2009;104:972-977.

86. Marechaux S, Hachicha Z, Bellouin A, Dumesnil JG, Meimoun P, Pasquet A, Bergeron S, Arsenault M, Le Tourneau T, Ennezat PV, Pibarot P. Usefulness of exercise-stress echocardiography for risk stratification of true asymptomatic patients with aortic valve stenosis. Eur Heart J. 2010;31:1390-1397.

87. Zamorano JL, Badano LP, Bruce C, Chan KL, Goncalves A, Hahn RT, Keane MG, La Canna G, Monaghan MJ, Nihoyannopoulos P, Silvestry FE, Vanoverschelde JL, Gillam LD. EAE/ASE recommendations for the use of echocardiography in new transcatheter interventions for valvular heart disease. Eur Heart J. 2011;32: 2189-2214.

88. Azevedo CF, Nigri M, Higuchi ML, Pomerantzeff PM, Spina GS, Sampaio RO, Tarasoutchi F, Grinberg M, Rochitte CE. Prognostic significance of myocardial fibrosis quantification by histopathology and magnetic resonance imaging in patients with severe aortic valve disease. J Am Coll Cardiol. 2010;56:278-287.

89. Bergler-Klein J, Klaar U, Heger M, Rosenhek R, Mundigler G, Gabriel H, Binder T, Pacher R, Maurer G, Baumgartner H. Natriuretic peptides predict symptomfree survival and postoperative outcome in severe aortic stenosis. Circulation. 2004;109:2302-2308

90. Clavel MA, Malouf J, Michelena HI, Suri RM, Jaffe AS, Mahoney DW, EnriquezSarano M. B-type natriuretic peptide clinical activation in aortic stenosis: impact on long-term survival. J Am Coll Cardiol. 2014;63:2016-2025.

91. Leon MB, Smith CR, Mack M, Miller DC, Moses JW, Svensson LG, Tuzcu EM, Webb JG, Fontana GP, Makkar RR, Brown DL, Block PC, Guyton RA, Pichard AD, Bavaria JE, Herrmann HC, Douglas PS, Petersen JL, Akin JJ, Anderson WN, Wang D, Pocock S, PARTNER Trial Investigators. Transcatheter aortic-valve implantation for aortic stenosis in patients who cannot undergo surgery. N Engl J Med. 2010;363: 1597-1607.

92. Rosenhek R, Binder T, Porenta G, Lang I, Christ G, Schemper M, Maurer G, Baumgartner H. Predictors of outcome in severe, asymptomatic aortic stenosis. $N$ Engl J Med. 2000;343:611-617.

93. Thourani VH, Suri RM, Gunter RL, Sheng S, O’Brien SM, Ailawadi G, Szeto WY, Dewey TM, Guyton RA, Bavaria JE, Babaliaros V, Gammie JS, Svensson L, Williams M, Badhwar V, Mack MJ. Contemporary real-world outcomes of surgical aortic valve replacement in 141,905 low-risk, intermediate-risk, and high-risk patients. Ann Thorac Surg. 2015;99:55-61.

94. Deeb GM, Reardon MJ, Chetcuti S, Patel HJ, Grossman PM, Yakubov SJ, Kleiman NS, Coselli JS, Gleason TG, Lee JS, Hermiller JB Jr, Heiser J, Merhi W, Zorn GL 3rd, Tadros P, Robinson N, Petrossian G, Hughes GC, Harrison JK, Maini B, Mumtaz M, Conte J, Resar J, Aharonian V, Pfeffer T, Oh JK, Qiao H, Adams DH, Popma JJ, CoreValve US Clinical Investigators. 3-year outcomes in high-risk patients who underwent surgical or transcatheter aortic valve replacement. J Am Coll Cardiol. 2016;67:2565-2574.

95. Smith CR, Leon MB, Mack MJ, Miller DC, Moses JW, Svensson LG, Tuzcu EM, Webb JG, Fontana GP, Makkar RR, Williams M, Dewey T, Kapadia S, Babaliaros V, Thourani VH, Corso P, Pichard AD, Bavaria JE, Herrmann HC, Akin JJ, Anderson WN, Wang D, Pocock SJ, PARTNER Trial Investigators. Transcatheter versus surgical aortic-valve replacement in high-risk patients. $N$ Engl J Med. 2011;364:2187-2198

96. Mack MJ, Leon MB, Smith CR, Miller DC, Moses JW, Tuzcu EM, Webb JG, Douglas PS, Anderson WN, Blackstone EH, Kodali SK, Makkar RR, Fontana GP, Kapadia S, Bavaria J, Hahn RT, Thourani VH, Babaliaros V, Pichard A, Herrmann HC, Brown DL, Williams M, Akin J, Davidson MJ, Svensson LG, PARTNER 1 Trial Investigators. 5 -year outcomes of transcatheter aortic valve replacement or surgical aortic valve replacement for high surgical risk patients with aortic stenosis (PARTNER 1): a randomised controlled trial. Lancet. 2015;385:2477-2484.

97. Adams DH, Popma JJ, Reardon MJ, Yakubov SJ, Coselli JS, Deeb GM, Gleason TG Buchbinder M, Hermiller J Jr, Kleiman NS, Chetcuti S, Heiser J, Merhi W, Zorn G Tadros P, Robinson N, Petrossian G, Hughes GC, Harrison JK, Conte J, Maini B, Mumtaz M, Chenoweth S, Oh JK, U.S. CoreValve Clinical Investigators. Transcatheter aortic-valve replacement with a self-expanding prosthesis. $N \mathrm{Engl}$ J Med. 2014;370:1790-1798.

98. Thyregod HG, Steinbruchel DA, Ihlemann N, Nissen H, Kjeldsen BJ, Petursson P, Chang Y, Franzen OW, Engstrom T, Clemmensen P, Hansen PB, Andersen LW, Olsen PS, Sondergaard L. Transcatheter versus surgical aortic valve replacement in patients with severe aortic valve stenosis: 1-year results from the all-comers NOTION randomized clinical trial. J Am Coll Cardiol. 2015;65:2184-2194.

99. Leon MB, Smith CR, Mack MJ, Makkar RR, Svensson LG, Kodali SK, Thourani VH Tuzcu EM, Miller DC, Herrmann HC, Doshi D, Cohen DJ, Pichard AD, Kapadia S, Dewey T, Babaliaros V, Szeto WY, Williams MR, Kereiakes D, Zajarias A, Greason KL, Whisenant BK, Hodson RW, Moses JW, Trento A, Brown DL, Fearon WF, Pibarot P, Hahn RT, Jaber WA, Anderson WN, Alu MC, Webb JG, PARTNER 2 Investigators. Transcatheter or surgical aortic-valve replacement in intermediaterisk patients. $N$ Engl J Med. 2016;374:1609-1620.

100. Thourani VH, Kodali S, Makkar RR, Herrmann HC, Williams M, Babaliaros V, Smalling R, Lim S, Malaisrie SC, Kapadia S, Szeto WY, Greason KL, Kereiakes D, Ailawadi G, Whisenant BK, Devireddy C, Leipsic J, Hahn RT, Pibarot P, Weissman NJ, Jaber WA, Cohen DJ, Suri R, Tuzcu EM, Svensson LG, Webb JG, Moses JW, Mack MJ, Miller DC, Smith CR, Alu MC, Parvataneni R, D’Agostino RB Jr, Leon MB. Transcatheter aortic valve replacement versus surgical valve replacement in intermediate-risk patients: a propensity score analysis. Lancet. 2016;387: 2218-2225.

101. Siontis GC, Praz F, Pilgrim T, Mavridis D, Verma S, Salanti G, Sondergaard L, Juni P, Windecker S. Transcatheter aortic valve implantation vs. surgical aortic valve replacement for treatment of severe aortic stenosis: a meta-analysis of randomized trials. Eur Heart J. 2016;37:3503-3512.

102. Reardon MJ, Van Mieghem NM, Popma JJ, Kleiman NS, Sondergaard L, Mumtaz M Adams DH, Deeb GM, Maini B, Gada H, Chetcuti S, Gleason T, Heiser J, Lange R, Merhi W, Oh JK, Olsen PS, Piazza N, Williams M, Windecker S, Yakubov SJ, Grube E, Makkar R, Lee JS, Conte J, Vang E, Nguyen H, Chang Y, Mugglin AS, Serruys PW, Kappetein AP, SURTAVI Investigators. Surgical or transcatheter aortic-valve replacement in intermediate-risk patients. N Engl J Med. 2017;376:1321-1331.

103. Rogers T, Koifman E, Patel N, Gai J, Torguson R, Corso P, Waksman R. Society of Thoracic Surgeons score variance results in risk reclassification of patients undergoing transcatheter aortic valve replacement. JAMA Cardiol. 2017;2: $455-456$.

104. Tribouilloy C, Levy F, Rusinaru D, Gueret P, Petit-Eisenmann H, Baleynaud S, Jobic Y, Adams C, Lelong B, Pasquet A, Chauvel C, Metz D, Quere JP, Monin JL. Outcome after aortic valve replacement for low-flow/low-gradient aortic stenosis without contractile reserve on dobutamine stress echocardiography. J Am Coll Cardiol. 2009;53:1865-1873.

105. Fougeres E, Tribouilloy C, Monchi M, Petit-Eisenmann H, Baleynaud S, Pasquet A, Chauvel C, Metz D, Adams C, Rusinaru D, Gueret P, Monin JL. Outcomes of pseudo-severe aortic stenosis under conservative treatment. Eur Heart $J$. 2012;33:2426-2433.

106. Genereux P, Stone GW, O'Gara PT, Marquis-Gravel G, Redfors B, Giustino G, Pibarot P, Bax JJ, Bonow RO, Leon MB. Natural history, diagnostic approaches, and therapeutic strategies for patients with asymptomatic severe aortic stenosis. J Am Coll Cardiol. 2016;67:2263-2288.

107. Das $\mathrm{P}$, Rimington $\mathrm{H}$, Chambers J. Exercise testing to stratify risk in aortic stenosis. Eur Heart J. 2005;26:1309-1313.

108. Rosenhek R, Zilberszac R, Schemper M, Czerny M, Mundigler G, Graf S, BerglerKlein J, Grimm M, Gabriel H, Maurer G. Natural history of very severe aortic stenosis. Circulation. 2010;121:151-156.

109. Cioffi G, Faggiano P, Vizzardi E, Tarantini L, Cramariuc D, Gerdts E, de Simone G. Prognostic effect of inappropriately high left ventricular mass in asymptomatic severe aortic stenosis. Heart. 2011;97:301-307.

110. Dahl JS, Videbaek L, Poulsen MK, Rudbaek TR, Pellikka PA, Moller JE. Global strain in severe aortic valve stenosis: relation to clinical outcome after aortic valve replacement. Circ Cardiovasc Imaging. 2012;5:613-620.

111. Zlotnick DM, Ouellette ML, Malenka DJ, DeSimone JP, Leavitt BJ, Helm RE Olmstead EM, Costa SP, DiScipio AW, Likosky DS, Schmoker JD, Quinn RD, Sisto D, Klemperer JD, Sardella GL, Baribeau YR, Frumiento C, Brown JR, O’Rourke DJ, Northern New England Cardiovascular Disease Study Group. Effect of preoperative pulmonary hypertension on outcomes in patients with severe aortic stenosis following surgical aortic valve replacement. Am J Cardiol. 2013;112:1635-1640.

112. Rossebo AB, Pedersen TR, Boman K, Brudi P, Chambers JB, Egstrup K, Gerdts E, Gohlke-Barwolf C, Holme I, Kesaniemi YA, Malbecq W, Nienaber CA, Ray S, Skjaerpe T, Wachtell K, Willenheimer R, SEAS Investigators. Intensive lipid lowering with simvastatin and ezetimibe in aortic stenosis. $N$ Engl J Med. 2008;359:1343-1356.

113. Ponikowski P, Voors AA, Anker SD, Bueno H, Cleland JG, Coats AJ, Falk V, GonzalezJuanatey JR, Harjola VP, Jankowska EA, Jessup M, Linde C, Nihoyannopoulos P, 
Parissis JT, Pieske B, Riley JP, Rosano GM, Ruilope LM, Ruschitzka F, Rutten FH, van der Meer P. 2016 ESC Guidelines for the diagnosis and treatment of acute and chronic heart failure: the Task Force for the diagnosis and treatment of acute and chronic heart failure of the European Society of Cardiology (ESC). Developed with the special contribution of the Heart Failure Association (HFA) of the ESC. Eur Heart J. 2016;37:2129-2200.

114. Smith WT 4th, Ferguson TB Jr, Ryan T, Landolfo CK, Peterson ED. Should coronary artery bypass graft surgery patients with mild or moderate aortic stenosis undergo concomitant aortic valve replacement? A decision analysis approach to the surgical dilemma. J Am Coll Cardiol. 2004;44:1241-1247.

115. Baumgartner H, Bonhoeffer P. De Groot NM, de Haan F, Deanfield JE, Galie N, Gatzoulis MA, Gohlke-Baerwolf C, Kaemmerer H, Kilner P, Meijboom F, Mulder BJ, Oechslin E, Oliver JM, Serraf A, Szatmari A, Thaulow E, Vouhe PR, Walma E, Task Force on the Management of Grown-up Congenital Heart Disease of the European Society of Cardiology (ESC), Association for European Paediatric Cardiology (AEPC), ESC Committee for Practice Guidelines (CPG). ESC Guidelines for the management of grown-up congenital heart disease (new version 2010). Eur Heart J. 2010;31:2915-2957.

116. De Bonis M, Al-Attar N, Antunes M, Borger M, Casselman F, Falk V, Folliguet T, Iung B, Lancellotti P, Lentini S, Maisano F, Messika-Zeitoun D, Muneretto $C$ Pibarot P, Pierard L, Punjabi P, Rosenhek R, Suwalski P, Vahanian A, Wendler O, Prendergast B. Surgical and interventional management of mitral valve regurgitation: a position statement from the European Society of Cardiology Working Groups on Cardiovascular Surgery and Valvular Heart Disease. Eur Heart J. 2016;37:133-139.

117. Monin JL, Dehant P, Roiron C, Monchi M, Tabet JY, Clerc P, Fernandez G, Houel R, Garot J, Chauvel C, Gueret P. Functional assessment of mitral regurgitation by transthoracic echocardiography using standardized imaging planes diagnostic accuracy and outcome implications. J Am Coll Cardiol. 2005;46:302-309.

118. Lancellotti P, Gerard PL, Pierard LA. Long-term outcome of patients with heart failure and dynamic functional mitral regurgitation. Eur Heart J. 2005;26:1528-1532.

119. Magne J, Lancellotti P, Pierard LA. Exercise pulmonary hypertension in asymptomatic degenerative mitral regurgitation. Circulation. 2010;122:33-41.

120. Pizarro R, Bazzino OO, Oberti PF, Falconi M, Achilli F, Arias A, Krauss JG, Cagide AM. Prospective validation of the prognostic usefulness of brain natriuretic peptide in asymptomatic patients with chronic severe mitral regurgitation. J Am Coll Cardiol. 2009;54:1099-1106.

121. Tribouilloy CM, Enriquez-Sarano M, Schaff HV, Orszulak TA, Bailey KR, Tajik AJ Frye RL. Impact of preoperative symptoms on survival after surgical correction of organic mitral regurgitation: rationale for optimizing surgical indications. Circulation. 1999;99:400-405.

122. Enriquez-Sarano M, Tajik AJ, Schaff HV, Orszulak TA, Bailey KR, Frye RL Echocardiographic prediction of survival after surgical correction of organic mitral regurgitation. Circulation. 1994;90:830-837.

123. Badhwar V, Peterson ED, Jacobs JP, He X, Brennan JM, O’Brien SM, Dokholyan RS, George KM, Bolling SF, Shahian DM, Grover FL, Edwards FH, Gammie JS, Longitudinal outcome of isolated mitral repair in older patients: results from 14,604 procedures performed from 1991 to 2007. Ann Thorac Surg. 2012;94:18701877; discussion 1877-1879.

124. Le Tourneau T, Richardson M, Juthier F, Modine T, Fayad G, Polge AS, Ennezat PV Bauters C, Vincentelli A, Deklunder G. Echocardiography predictors and prognostic value of pulmonary artery systolic pressure in chronic organic mitral regurgitation. Heart. 2010;96:1311-1317.

125. Tribouilloy C, Grigioni F, Avierinos JF, Barbieri A, Rusinaru D, Szymanski C, Ferlito M, Tafanelli L, Bursi F, Trojette F, Branzi A, Habib G, Modena MG, Enriquez-Sarano M, MIDA Investigators. Survival implication of left ventricular end-systolic diameter in mitral regurgitation due to flail leaflets a long-term follow-up multicenter study. J Am Coll Cardiol. 2009;54:1961-1968.

126. Rosenhek R, Rader F, Klaar U, Gabriel H, Krejc M, Kalbeck D, Schemper M, Maure $\mathrm{G}$, Baumgartner $\mathrm{H}$. Outcome of watchful waiting in asymptomatic severe mitral regurgitation. Circulation. 2006;113:2238-2244.

127. Gammie JS, O'Brien SM, Griffith BP, Ferguson TB, Peterson ED. Influence of hospital procedural volume on care process and mortality for patients undergoing elective surgery for mitral regurgitation. Circulation. 2007;115:881-887.

128. Bolling SF, Li S, O'Brien SM, Brennan JM, Prager RL, Gammie JS. Predictors of mitral valve repair: clinical and surgeon factors. Ann Thorac Surg. 2010;90:1904-1911.

129. Feldman T, Foster E, Glower DD, Kar S, Rinaldi MJ, Fail PS, Smalling RW, Siegel R, Rose GA, Engeron E, Loghin C, Trento A, Skipper ER, Fudge T, Letsou GV, Massaro JM, Mauri L, EVEREST II Investigators. Percutaneous repair or surgery for mitral regurgitation. N Engl J Med. 2011:364:1395-1406.

130. Feldman T, Kar S, Elmariah S, Smart SC, Trento A, Siegel RJ, Apruzzese P, Fail P, Rinaldi MJ, Smalling RW, Hermiller JB, Heimansohn D, Gray WA, Grayburn PA Mack MJ, Lim DS, Ailawadi G, Herrmann HC, Acker MA, Silvestry FE, Foster E, Wang A, Glower DD, Mauri L, EVEREST II Investigators. Randomized comparison of percutaneous repair and surgery for mitral regurgitation: 5-year results of EVEREST II. J Am Coll Cardiol. 2015;66:2844-2854.

131. Enriquez-Sarano M, Tajik AJ, Schaff HV, Orszulak TA, McGoon MD, Bailey KR, Frye RL. Echocardiographic prediction of left ventricular function after correction of mitral regurgitation: results and clinical implications. J Am Coll Cardiol 1994;24:1536-1543

132. Haan CK, Cabral CI, Conetta DA, Coombs LP, Edwards FH. Selecting patients with mitral regurgitation and left ventricular dysfunction for isolated mitral valve surgery. Ann Thorac Surg. 2004;78:820-825.

133. Samad Z, Kaul P, Shaw LK, Glower DD, Velazquez EJ, Douglas PS, Jollis JG. Impact of early surgery on survival of patients with severe mitral regurgitation. Heart. 2011;97:221-224.
134. Levine RA, Schwammenthal E. Ischemic mitral regurgitation on the threshold of a solution: from paradoxes to unifying concepts. Circulation. 2005;112:745-758.

135. Grigioni F, Enriquez-Sarano M, Zehr KJ, Bailey KR, Tajik AJ. Ischemic mitral regurgitation: long-term outcome and prognostic implications with quantitative Doppler assessment. Circulation. 2001;103:1759-1764.

136. Acker MA, Parides MK, Perrault LP, Moskowitz AJ, Gelijns AC, Voisine P, Smith PK, Hung JW, Blackstone EH, Puskas JD, Argenziano M, Gammie JS, Mack M, Ascheim DD, Bagiella E, Moquete EG, Ferguson TB, Horvath KA, Geller NL, Miller MA, Woo YJ, D’Alessandro DA, Ailawadi G, Dagenais F, Gardner TJ, O'Gara PT, Michler RE, Kron IL. Mitral-valve repair versus replacement for severe ischemic mitral regurgitation. N Engl J Med. 2014;370:23-32.

137. Mihaljevic T, Lam BK, Rajeswaran J, Takagaki M, Lauer MS, Gillinov AM, Blackstone EH, Lytle BW. Impact of mitral valve annuloplasty combined with revascularization in patients with functional ischemic mitral regurgitation. J Am Coll Cardiol. 2007:49:2191-2201

138. Wu AH, Aaronson KD, Bolling SF, Pagani FD, Welch K, Koelling TM. Impact of mitral valve annuloplasty on mortality risk in patients with mitral regurgitation and left ventricular systolic dysfunction. J Am Coll Cardiol. 2005;45: 381-387.

139. Mauri L, Foster E, Glower DD, Apruzzese P, Massaro JM, Herrmann HC, Hermiller J, Gray W, Wang A, Pedersen WR, Bajwa T, Lasala J, Low R, Grayburn P, Feldman T, EVEREST II Investigators, 4-year results of a randomized controlled trial of percutaneous repair versus surgery for mitral regurgitation. J Am Coll Cardiol. 2013;62:317-328

140. Maisano F, Franzen O, Baldus S, Schafer U, Hausleiter J, Butter C, Ussia GP, Sievert H, Richardt G, Widder JD, Moccetti T, Schillinger W. Percutaneous mitral valve interventions in the real world: early and 1-year results from the ACCESS-EU, a prospective, multicenter, nonrandomized postapproval study of the MitraClip therapy in Europe. J Am Coll Cardiol. 2013;62:1052-1061.

141. Michler RE, Smith PK, Parides MK, Ailawadi G, Thourani V, Moskowitz AJ, Acker MA, Hung JW, Chang HL, Perrault LP, Gillinov AM, Argenziano M, Bagiella E, Overbey JR, Moquete EG, Gupta LN, Miller MA, Taddei-Peters WC, Jeffries N, Weisel RD, Rose EA, Gammie JS, DeRose JJ Jr, Puskas JD, Dagenais F, Burks SG, ElHamamsy I, Milano CA, Atluri P, Voisine P, O'Gara PT, Gelijns AC, CTSN. Two-year outcomes of surgical treatment of moderate ischemic mitral regurgitation. $N$ Engl J Med. 2016;374:1932-1941.

142. Iung B, Vahanian A. Epidemiology of acquired valvular heart disease. Can J Cardiol. 2014;30:962-970.

143. Abramowitz Y, Jilaihawi H, Chakravarty T, Mack MJ, Makkar RR. Mitral annulus calcification. J Am Coll Cardiol. 2015;66:1934-1941.

144. Bouleti C, Iung B, Laouenan C, Himbert D, Brochet E, Messika-Zeitoun D, Detaint D, Garbarz E, Cormier B, Michel PL, Mentre F, Vahanian A. Late results of percutaneous mitral commissurotomy up to 20 years: development and validation of a risk score predicting late functional results from a series of 912 patients. Circulation. 2012;125:2119-2127.

145. Wilkins GT, Weyman AE, Abascal VM, Block PC, Palacios IF. Percutaneous balloon dilatation of the mitral valve: an analysis of echocardiographic variables related to outcome and the mechanism of dilatation. Br Heart J. 1988;60:299-308.

146. Nunes MC, Tan TC, Elmariah S, do Lago R, Margey R, Cruz-Gonzalez I, Zheng H, Handschumacher MD, Inglessis I, Palacios IF, Weyman AE, Hung J. The echo score revisited: Impact of incorporating commissural morphology and leaflet displacement to the prediction of outcome for patients undergoing percutaneous mitral valvuloplasty. Circulation. 2014:129:886-895.

147. Badheka AO, Shah N, Ghatak A, Patel NJ, Chothani A, Mehta K, Singh V, Patel N, Grover P, Deshmukh A, Panaich SS, Savani GT, Bhalara V, Arora S, Rathod A, Desai H, Kar S, Alfonso C, Palacios IF, Grines C, Schreiber T, Rihal CS, Makkar R, Cohen MG, O'Neill W, de Marchena E. Balloon mitral valvuloplasty in the United States: a 13-year perspective. Am J Med. 2014;127:1126 e1121-1112.

148. Tomai F, Gaspardone A, Versaci F, Ghini AS, Altamura L, De Luca L, Gioffre G, Gioffre PA. Twenty year follow-up after successful percutaneous balloon mitral valvuloplasty in a large contemporary series of patients with mitral stenosis. Int J Cardiol. 2014;177:881-885.

149. Bouleti C, Iung B, Himbert D, Messika-Zeitoun D, Brochet E, Garbarz E, Cormier B, Vahanian A. Relationship between valve calcification and long-term results of percutaneous mitral commissurotomy for rheumatic mitral stenosis. Circ Cardiovasc Interv. 2014;7:381-389.

150. Iung B, Cormier B, Ducimetiere P, Porte JM, Nallet O, Michel PL, Acar J, Vahanian A. Immediate results of percutaneous mitral commissurotomy. A predictive model on a series of 1514 patients. Circulation. 1996;94:2124-2130.

151. Bouleti C, Iung B, Himbert D, Brochet E, Messika-Zeitoun D, Detaint D, Garbarz E, Cormier B, Vahanian A. Reinterventions after percutaneous mitral commissurotomy during long-term follow-up, up to 20 years: the role of repeat percutaneous mitral commissurotomy. Eur Heart J. 2013;34:1923-1930.

152. Guerrero M, Dvir D, Himbert D, Urena M, Eleid M, Wang DD, Greenbaum A, Mahadevan VS, Holzhey D, O'Hair D, Dumonteil N, Rodes-Cabau J, Piazza N, Palma JH, DeLago A, Ferrari E, Witkowski A, Wendler O, Kornowski R, MartinezClark P, Ciaburri D, Shemin R, Alnasser S, McAllister D, Bena M, Kerendi F, Pavlides G, Sobrinho JJ, Attizzani GF, George I, Nickenig G, Fassa AA, Cribier A, Bapat V, Feldman T, Rihal C, Vahanian A, Webb J, O'Neill W. Transcatheter mitral valve replacement in native mitral valve disease with severe mitral annular calcification: results from the first multicenter global registry. JACC Cardiovasc Interv. 2016;9:1361-1371.

153. Song H, Kang DH, Kim JH, Park KM, Song JM, Choi KJ, Hong MK, Chung CH, Song JK, Lee JW, Park SW, Park SJ. Percutaneous mitral valvuloplasty versus surgical treatment in mitral stenosis with severe tricuspid regurgitation. Circulation. 2007;116:I-246-I-250 
154. Sousa C, Botelho C, Rodrigues D, Azeredo J, Oliveira R. Infective endocarditis in intravenous drug abusers: an update. Eur J Clin Microbiol Infect Dis. 2012;31: 2905-2910.

155. Park JB, Lee SP, Lee JH, Yoon YE, Park EA, Kim HK, Lee W, Kim YJ, Cho GY, Sohn DW Quantification of right ventricular volume and function using singlebeat threedimensional echocardiography: a validation study with cardiac magnetic resonance. J Am Soc Echocardiogr. 2016;29:392-401.

156. Dreyfus GD, Corbi PJ, Chan KM, Bahrami T. Secondary tricuspid regurgitation or dilatation: which should be the criteria for surgical repair? Ann Thorac Surg. 2005;79:127-132.

157. Van de Veire NR, Braun J, Delgado V, Versteegh MI, Dion RA, Klautz RJ, Bax JJ. Tricuspid annuloplasty prevents right ventricular dilatation and progression of tricuspid regurgitation in patients with tricuspid annular dilatation undergoing mitral valve repair. J Thorac Cardiovasc Surg. 2011;141:1431-1439.

158. Nath J, Foster E, Heidenreich PA. Impact of tricuspid regurgitation on longterm survival. J Am Coll Cardiol. 2004;43:405-409.

159. Kammerlander AA, Marzluf BA, Graf A, Bachmann A, Kocher A, Bonderman D, Mascherbauer J. Right ventricular dysfunction, but not tricuspid regurgitation, is associated with outcome late after left heart valve procedure. J Am Coll Cardiol. 2014;64:2633-2642.

160. Chikwe J, Itagaki S, Anyanwu A, Adams DH. Impact of concomitant tricuspid annuloplasty on tricuspid regurgitation, right ventricular function, and pulmonary artery hypertension after repair of mitral valve prolapse. J Am Coll Cardiol. 2015;65:1931-1938.

161. Chang BC, Lim SH, Yi G, Hong YS, Lee S, Yoo KJ, Kang MS, Cho BK. Long-term clinical results of tricuspid valve replacement. Ann Thorac Surg. 2006;81:13171323; discussion 1323-1314.

162. Filsoufi F, Anyanwu AC, Salzberg SP, Frankel T, Cohn LH, Adams DH. Longterm outcomes of tricuspid valve replacement in the current era. Ann Thorac Surg. 2005;80:845-850.

163. Yeter E, Ozlem K, Kilic H, Ramazan A, Acikel S. Tricuspid balloon valvuloplasty to treat tricuspid stenosis. J Heart Valve Dis. 2010;19:159-160.

164. Unger P, Rosenhek R, Dedobbeleer C, Berrebi A, Lancellotti P. Management of multiple valve disease. Heart. 2011;97:272-277.

165. Hammermeister K, Sethi GK, Henderson WG, Grover FL, Oprian C, Rahimtoola SH. Outcomes 15 years after valve replacement with a mechanical versus a bioprosthetic valve: final report of the Veterans Affairs randomized trial. J Am Coll Cardiol. 2000;36:1152-1158.

166. Oxenham H, Bloomfield P, Wheatley DJ, Lee RJ, Cunningham J, Prescott RJ, Miller HC. Twenty year comparison of a Bjork-Shiley mechanical heart valve with porcine bioprostheses. Heart. 2003;89:715-721.

167. Stassano P, Di Tommaso L, Monaco M, Iorio F, Pepino P, Spampinato N, Vosa C. Aortic valve replacement: a prospective randomized evaluation of mechanical versus biological valves in patients ages 55 to 70 years. J Am Coll Cardiol. 2009;54:1862-1868.

168. Capodanno D, Petronio AS, Prendergast B, Eltchaninoff H, Vahanian A, Modine T, Lancellotti P, Sondergaard L, Ludman PF, Tamburimno C, Piazza N, Hancock J, Mehilli J, Byrne RA, Baumbach A, Kappetein AP, Windecker S, Bax J, Haude M. Standardised definitions of structural deterioration and valve failure in assessing long-term durability of transcatheter and surgical aortic bioprosthetic valves - a consensus statement from the European Association of Percutaneous Cardiovascular Interventions (EAPCI) endorsed by the European Society of Cardiology (ESC) and the European Association for Cardio-Thoracic Surgery (EACTS). Eur Heart J. 2017; DOI: https://doi.org/10.1093/eurheartj/ehx303.

169. Zoghbi WA, Chambers JB, Dumesnil JG, Foster E, Gottdiener JS, Grayburn PA, Khandheria BK, Levine RA, Marx GR, Miller FA Jr, Nakatani S, Quinones MA Rakowski H, Rodriguez LL, Swaminathan M, Waggoner AD, Weissman NJ, Zabalgoitia M, American Society of Echocardiography's Guidelines and Standards Committee, Task Force on Prosthetic Valves, American College of Cardiology Cardiovascular Imaging Committee, Cardiac Imaging Committee of the American Heart Association, European Association of Echocardiography, European Society of Cardiology, Japanese Society of Echocardiography, Canadian Society of Echocardiography, American College of Cardiology Foundation, American Heart Association, European Association of Echocardiography, European Society of Cardiology, Japanese Society of Echocardiography, Canadian Society of Echocardiography. Recommendations for evaluation of prosthetic valves with echocardiography and Doppler ultrasound: a report from the American Society of Echocardiography's Guidelines and Standards Committee and the Task Force on Prosthetic Valves, developed in conjunction with the American College of Cardiology Cardiovascular Imaging Committee, Cardiac Imaging Committee of the American Heart Association, the European Association of Echocardiography, a registered branch of the European Society of Cardiology, the Japanese Society of Echocardiography and the Canadian Society of Echocardiography, endorsed by the American College of Cardiology Foundation, American Heart Association, European Association of Echocardiography, a registered branch of the European Society of Cardiology, the Japanese Society of Echocardiography, and Canadian Society of Echocardiography. J Am Soc Echocardiogr. 2009;22:975-1014; quiz 1082-1014.

170. Lancellotti P, Pibarot P, Chambers J, Edvardsen T, Delgado V, Dulgheru R, Pepi M, Cosyns B, Dweck MR, Garbi M, Magne J, Nieman K, Rosenhek R, Bernard A, Lowenstein J, Vieira ML, Rabischoffsky A, Vyhmeister RH, Zhou X, Zhang Y, Zamorano JL, Habib G. Recommendations for the imaging assessment of prosthetic heart valves: a report from the European Association of Cardiovascular Imaging endorsed by the Chinese Society of Echocardiography, the InterAmerican Society of Echocardiography, and the Brazilian Department of Cardiovascular Imaging. Eur Heart J Cardiovasc Imaging. 2016;17:589-590.
171. Butchart EG, Gohlke-Barwolf C, Antunes MJ, Tornos P, De Caterina R, Cormier B, Prendergast B, lung B, Bjornstad H, Leport C, Hall RJ, Vahanian A, Working Groups on Valvular Heart Disease, Thrombosis, and Cardiac Rehabilitation and Exercise Physiology, European Society of Cardiology. Recommendations for the management of patients after heart valve surgery. Eur Heart J. 2005;26:2463-2471.

172. Brennan JM, Edwards FH, Zhao Y, O’Brien S, Booth ME, Dokholyan RS, Douglas PS, Peterson ED, DEcIDE AVR Research Team. Early anticoagulation of bioprosthetic aortic valves in older patients: results from the Society of Thoracic Surgeons Adult Cardiac Surgery National Database. J Am Coll Cardiol. 2012;60:971-977.

173. Merie C, Kober L, Skov Olsen P, Andersson C, Gislason G, Skov Jensen J, TorpPedersen C. Association of warfarin therapy duration after bioprosthetic aortic valve replacement with risk of mortality, thromboembolic complications, and bleeding. JAMA. 2012;308:2118-2125.

174. Rivas-Gandara N, Ferreira-Gonzalez I, Tornos P, Torrents A, Permanyer-Miralda G Nicolau I, Arellano-Rodrigo E, Vallejo N, Igual A, Soler-Soler J. Enoxaparin as bridging anticoagulant treatment in cardiac surgery. Heart. 2008;94:205-210.

175. Meurin P, Tabet JY, Weber H, Renaud N, Ben Driss A. Low-molecular-weight heparin as a bridging anticoagulant early after mechanical heart valve replacement. Circulation. 2006;113:564-569.

176. Laffort P, Roudaut R, Roques X, Lafitte S, Deville C, Bonnet J, Baudet E. Early and long-term (one-year) effects of the association of aspirin and oral anticoagulant on thrombi and morbidity after replacement of the mitral valve with the St. Jude medical prosthesis: a clinical and transesophageal echocardiographic study. J Am Coll Cardiol. 2000;35:739-746.

177. Vavuranakis M, Siasos G, Zografos T, Oikonomou E, Vrachatis D, Kalogeras K Papaioannou T, Kolokathis MA, Moldovan C, Tousoulis D. Dual or single antiplatelet therapy after transcatheter aortic valve implantation? A systematic review and meta-analysis. Curr Pharm Des. 2016;22:4596-4603.

178. Chakravarty T, Sondergaard L, Friedman J, De Backer O, Berman D, Kofoed KF, Jilaihawi H, Shiota T, Abramowitz Y, Jorgensen TH, Rami T, Israr S, Fontana G, de Knegt M, Fuchs A, Lyden P, Trento A, Bhatt DL, Leon MB, Makkar RR, RESOLVE, SAVORY Investigators. Subclinical leaflet thrombosis in surgical and transcatheter bioprosthetic aortic valves: an observational study. Lancet. 2017;389:2383-2392.

179. Cannegieter SC, Rosendaal FR, Briet E. Thromboembolic and bleeding complications in patients with mechanical heart valve prostheses. Circulation. 1994;89:635-641.

180. Mok CK, Boey J, Wang R, Chan TK, Cheung KL, Lee PK, Chow J, Ng RP, Tse TF. Warfarin versus dipyridamole-aspirin and pentoxifylline-aspirin for the prevention of prosthetic heart valve thromboembolism: a prospective randomized clinical trial. Circulation. 1985;72:1059-1063.

181. Heneghan C, Ward A, Perera R, Bankhead C, Fuller A, Stevens R, Bradford K, Tyndel S, Alonso-Coello P, Ansell J, Beyth R, Bernardo A, Christensen TD, Cromheecke ME, Edson RG, Fitzmaurice D, Gadisseur AP, Garcia-Alamino JM, Gardiner C, Hasenkam JM, Jacobson A, Kaatz S, Kamali F, Khan TI, Knight E, Kortke H, Levi M, Matchar D, Menendez-Jandula B, Rakovac I, Schaefer C, Siebenhofer A, Souto JC, Sunderji R, Gin K, Shalansky K, Voller H, Wagner O, Zittermann A. Selfmonitoring of oral anticoagulation: systematic review and meta-analysis of individual patient data. Lancet. 2012;379:322-334.

182. Fiedler KA, Maeng M, Mehilli J, Schulz-Schupke S, Byrne RA, Sibbing D, Hoppmann P, Schneider S, Fusaro M, Ott I, Kristensen SD, Ibrahim T, Massberg S, Schunkert H, Laugwitz KL, Kastrati A, Sarafoff N. Duration of triple therapy in patients requiring oral anticoagulation after drug-eluting stent implantation: the ISARTRIPLE Trial. J Am Coll Cardiol. 2015;65:1619-1629.

183. Gibson CM, Mehran R, Bode C, Halperin J, Verheugt FW, Wildgoose P, Birmingham M, Ianus J, Burton P, van Eickels M, Korjian S, Daaboul Y, Lip GY, Cohen M, Husted S, Peterson ED, Fox KA. Prevention of bleeding in patients with atrial fibrillation undergoing PCI. N Engl J Med. 2016;375:2423-2434.

184. Dewilde WJ, Oirbans T, Verheugt FW, Kelder JC, De Smet BJ, Herrman JP, Adriaenssens T, Vrolix M, Heestermans AA, Vis MM, Tijsen JG, van't Hof AW, ten Berg, JM, WOEST study investigators. Use of clopidogrel with or without aspirin in patients taking oral anticoagulant therapy and undergoing percutaneous coronary intervention: an open-label, randomised, controlled trial. Lancet 2013;381:1107-1115.

185. Lamberts M, Gislason GH, Lip GY, Lassen JF, Olesen JB, Mikkelsen AP, Sorensen R, Kober L, Torp-Pedersen C, Hansen ML. Antiplatelet therapy for stable coronary artery disease in atrial fibrillation patients taking an oral anticoagulant: a nationwide cohort study. Circulation. 2014;129:1577-1585.

186. Torella M, Torella D, Chiodini P, Franciulli M, Romano G, De Santo L, De Feo M, Amarelli C, Sasso FC, Salvatore T, Ellison GM, Indolfi C, Cotrufo M, Nappi G. LOWERing the INtensity of oral anticoaGulant Therapy in patients with bileaflet mechanical aortic valve replacement: results from the "LOWERINGIT" Trial. Am Heart J. 2010;160:171-178.

187. Puskas J, Gerdisch M, Nichols D, Quinn R, Anderson C, Rhenman B, Fermin L, McGrath M, Kong B, Hughes C, Sethi G, Wait M, Martin T, Graeve A, PROACT Investigators. Reduced anticoagulation after mechanical aortic valve replacement: interim results from the prospective randomized on-X valve anticoagulation clinical trial randomized Food and Drug Administration investigational device exemption trial. J Thorac Cardiovasc Surg. 2014;147:1202-1210; discussion 1210-1201.

188. Koertke H, Zittermann A, Wagner O, Secer S, Christ of H, Sciangula A, Saggau W, Sack FU, Ennker J, Cremer J, Musumeci F, Gummert JF. Telemedicineguided, very low-dose international normalized ratio self-control in patients with mechanical heart valve implants. Eur Heart J. 2015;36:1297-1305.

189. Bussey HI, Bussey M, Bussey-Smith KL, Frei CR. Evaluation of warfarin management with international normalized ratio self-testing and online remote monitoring and management plus low-dose vitamin $\mathrm{K}$ with genomic considerations: a pilot study. Pharmacotherapy. 2013;33:1136-1146. 
190. Pernod G, Godier A, Gozalo C, Tremey B, Sie P, French National Authority for Health. French clinical practice guidelines on the management of patients on vitamin $\mathrm{K}$ antagonists in at-risk situations (overdose, risk of bleeding, and active bleeding). Thromb Res. 2010;126:e167-174.

191. Halvorsen S, Storey RF, Rocca B, Sibbing D, Ten Berg J, Grove EL, Weiss TW, Collet JP, Andreotti F, Gulba DC, Lip GY, Husted S, Vilahur G, Morais J, Verheugt FW, Lanas A Al-Shahi Salman R, Steg PG, Huber K, ESC Working Group on Thrombosis. Management of antithrombotic therapy after bleeding in patients with coronary artery disease and/or atrial fibrillation: expert consensus paper of the European Society of Cardiology Working Group on Thrombosis. Eur Heart J. 2017;38:1455-1462.

192. Nishimura RA Otto CM, Bonow RO Carabello BA, Erwin JP 3rd, Guyton RA, O'Gara PT, Ruiz CE, Skubas NJ, Sorajja P, Sundt TM 3rd, Thomas JD, ACC/ AHA Task Force Members. 2014 AHA/ACC guideline for the management of patients with valvular heart disease: a report of the American College of Cardiology/American Heart Association Task Force on Practice Guidelines. Circulation. 2014;129:e521-643.

193. Whitlock RP, Sun JC, Fremes SE, Rubens FD, Teoh KH, American College of Chest Physicians. Antithrombotic and thrombolytic therapy for valvular disease: Antithrombotic Therapy and Prevention of Thrombosis, 9th ed: American College of Chest Physicians Evidence-Based Clinical Practice Guidelines. Chest. 2012;141:e576S-600S.

194. Massel DR, Little SH. Antiplatelet and anticoagulation for patients with prosthetic heart valves. Cochrane Database Syst Rev. 2013;4:CD003464.

195. Valgimigli M, Bueno H, Byrne RA, Collet JP, Costa F, Jeppsson A, Juni P, Kastrati A, Kolh P, Mauri L, Montalescot G, Neumann FJ, Petricevic M, Roffi M, Steg PG, Windecker S, Zamorano JL, 2017 ESC focused update on dual antiplatelet therapy in coronary artery disease developed in collaboration with EACTS. The Task Force for dual antiplatelet therapy in coronary artery disease of the European Society of Cardiology (ESC) and of the European Association for Cardio-Thoracic Surgery (EACTS). Eur Heart J. 2017; doi:10.1093/eurheartj/ehx419.

196. Kristensen SD, Knuuti J, Saraste A, Anker S, Botker HE, Hert SD, Ford I, GonzalezJuanatey JR, Gorenek B, Heyndrickx GR, Hoeft A, Huber K, Iung B, Kjeldsen KP, Longrois D, Luscher TF, Pierard L, Pocock S, Price S, Roffi M, Sirnes PA, Sousa-Uva M, Voudris V, Funck-Brentano C. 2014 ESC/ESA Guidelines on non-cardiac surgery: cardiovascular assessment and management: the Joint Task Force on non-cardiac surgery: cardiovascular assessment and management of the European Society of Cardiology (ESC) and the European Society of Anaesthesiology (ESA). Eur Heart J. 2014;35:2383-2431.

197. Francophone Society of Oral Medicine and Oral Surgery, with the collaboration of the French Society of Cardiology. Guidelines for management of patients under antivitamin K treatment in oral surgery (2006). http://www.mbcb-journal. org/ recommendations/254-guidelines-for-management-of-patients-under-antivi tamin-k-treatment-in-oral-surgery-2006.

198. Karthikeyan G, Senguttuvan NB, Joseph J, Devasenapathy N, Bahl VK, Airan B Urgent surgery compared with fibrinolytic therapy for the treatment of leftsided prosthetic heart valve thrombosis: a systematic review and meta-analysis of observational studies. Eur Heart J. 2013;34:1557-1566.

199. Laplace G, Lafitte S, Labeque JN, Perron JM, Baudet E, Deville C, Roques X, Roudaut $\mathrm{R}$. Clinical significance of early thrombosis after prosthetic mitral valve replacement: a postoperative monocentric study of 680 patients. J Am Coll Cardiol. 2004;43:1283-1290.

200. Brown ML, Park SJ, Sundt TM, Schaff HV. Early thrombosis risk in patients with biologic valves in the aortic position. J Thorac Cardiovasc Surg. 2012;144:108-111.
201. Mylotte D, Andalib A, Theriault-Lauzier P, Dorfmeister M, Girgis M, Alharbi W, Chetrit M, Galatas C, Mamane S, Sebag I, Buithieu J, Bilodeau L, de Varennes B, Lachapelle K, Lange R, Martucci G, Virmani R, Piazza N. Transcatheter heart valve failure: a systematic review. Eur Heart J. 2015;36:1306-1327.

202. Makkar RR, Fontana G, Jilaihawi H, Chakravarty T, Kofoed KF, de Backer O, Asch FM, Ruiz CE, Olsen NT, Trento A, Friedman J, Berman D, Cheng W, Kashif M, Jelnin V, Kliger CA, Guo H, Pichard AD, Weissman NJ, Kapadia S, Manasse E, Bhatt DL, Leon MB, Sondergaard L. Possible subclinical leaflet thrombosis in bioprosthetic aortic valves. N Engl J Med. 2015;373:2015-2024.

203. Pache G, Schoechlin S, Blanke P, Dorfs S, Jander N, Arepalli CD, Gick M, Buettner HJ, Leipsic J, Langer M, Neumann FJ, Ruile P. Early hypo-attenuated leaflet thickening in balloon-expandable transcatheter aortic heart valves. Eur Heart J. 2016;37:2263-2271.

204. Sorajja P, Bae R, Lesser JA, Pedersen WA. Percutaneous repair of paravalvular prosthetic regurgitation: patient selection, techniques and outcomes. Heart. 2015;101:665-673.

205. Dvir D, Webb JG, Bleiziffer S, Pasic M, Waksman R, Kodali S, Barbanti M, Latib A, Schaefer U, Rodes-Cabau J, Treede H, Piazza N, Hildick-Smith D, Himbert D, Walther T, Hengstenberg C, Nissen H, Bekeredjian R, Presbitero P, Ferrari E, Segev A, de Weger A, Windecker S, Moat NE, Napodano M, Wilbring M, Cerillo AG, Brecker S, Tchetche D, Lefevre T, De Marco F, Fiorina C, Petronio AS, Teles RC, Testa L, Laborde JC, Leon MB, Kornowski R, Valve-in-Valve International Data Registry Investigators. Transcatheter aortic valve implantation in failed bioprosthetic surgical valves. JAMA. 2014;312:162-170.

206. Ye J, Cheung A, Yamashita M, Wood D, Peng D, Gao M, Thompson CR, Munt B, Moss RR, Blanke P, Leipsic J, Dvir D, Webb JG. Transcatheter aortic and mitral valve-in-valve implantation for failed surgical bioprosthetic valves: an 8- year single-center experience. JACC Cardiovasc Interv. 2015;8:1735-1744.

207. Calleja AM, Dommaraju S, Gaddam R, Cha S, Khandheria BK, Chaliki HP. Cardiac risk in patients aged $>75$ years with asymptomatic, severe aortic stenosis undergoing noncardiac surgery. Am J Cardiol. 2010;105:1159-1163.

208. Tashiro T, Pislaru SV, Blustin JM, Nkomo VT, Abel MD, Scott CG, Pellikka PA. Perioperative risk of major non-cardiac surgery in patients with severe aortic stenosis: a reappraisal in contemporary practice. Eur Heart J. 2014;35: 2372-2381.

209. European Society of Gynecology (ESG), Association for European Paediatric Cardiology (AEPC), German Society for Gender Medicine (DGesGM), RegitzZagrosek V, Blomstrom Lundqvist C, Borghi C, Cifkova R, Ferreira R, Foidart JM, Gibbs JS, Gohlke-Baerwolf C, Gorenek B, lung B, Kirby M, Maas AH, Morais J, Nihoyannopoulos P, Pieper PG, Presbitero P, Roos-Hesselink JW, Schaufelberger M, Seeland U, Torracca L, ESC Committee for Practice Guidelines. ESC Guidelines on the management of cardiovascular diseases during pregnancy: the Task Force on the Management of Cardiovascular Diseases during Pregnancy of the European Society of Cardiology (ESC). Eur Heart J. 2011;32:3147-3197.

210. Elassy SM, Elmidany AA, Elbawab HY. Urgent cardiac surgery during pregnancy: a continuous challenge. Ann Thorac Surg. 2014;97:1624-1629.

211. Van Hagen IM, Roos-Hesselink JW, Ruys TP, Merz WM, Goland S, Gabriel H, Lelonek M, Trojnarska O, Al MahmeedWA, Balint HO, Ashour Z, Baumgartner H, Boersma E, Johnson MR, Hall R, ROPAC Investigators and the EURObservational Research Programme (EORP) Team. Pregnancy in women with a mechanical heart valve: data of the European Society of Cardiology Registry of Pregnancy and Cardiac Disease (ROPAC). Circulation. 2015;132:132-142. 